THE SOCIAL EFFECTS OF ANGER IN INTERNATIONAL NEGOTIATIONS:

THE ROLE OF SELF-REGULATION AND BARGAINING POWER

BY

\title{
STEFFEN BERTRAM
}

\begin{abstract}
A thesis
submitted to the Victoria University of Wellington

in fulfilment of the requirements for the degree of

Doctor of Philosophy
\end{abstract}

Victoria University of Wellington

2018 

To my wife:

it took a strong and special person

to be my wife during this journey. 



\begin{abstract}
This thesis addresses recent calls to investigate the influence of individual differences in a negotiation context. Specifically, I investigate the impact of the personality difference, action orientation versus state orientation, on concessionary behaviour in international negotiations. This personality difference was chosen because it measures a negotiator's capacity to selfregulate (control their behaviour) in a cognitively demanding situation like an international negotiation. I propose that action oriented negotiators will display superior self-regulation ability, compared to state oriented negotiators. Specifically, action oriented negotiators will be able to adapt their response and concede less than state oriented negotiators, when a foreign counterpart displays anger.

In two online studies, I measure how action oriented and state oriented negotiators respond to a display of anger from a foreign counterpart in an international negotiation. The first study of 159 negotiators showed that action oriented individuals conceded fewer points than state oriented individuals, regardless of whether the counterpart displayed anger. The second study of 260 negotiators showed that action oriented individuals can adapt their behaviour according to their level of power in an international negotiation when facing an angry counterpart.

As far as I am aware, this research is one of the first to propose and test the salience of action orientation versus state orientation on displays of anger in international negotiations. My findings highlight the value of incorporating individual differences in negotiation studies and I propose their inclusion into the dominant theoretical framework of how negotiators respond to anger. In addition to extending the model, I discuss how understanding these personality differences can be useful for multinational companies and their international negotiators.
\end{abstract}




\section{Acknowledgements}

Cheryl, you believed in me before this journey even began. For that I will forever be indebted. You have pushed me to academic limits I could not have dreamed of achieving. I am grateful for the teaching opportunities and support you gave me. Revti, your expertise and calm demeanour kept me from insanity many a time throughout this journey. I consider myself extremely honoured to have had such a supervisory team: expert comments, rapid feedback, patience and personal connections. Dr Cheryl Rivers and Dr Revti Raman, thank you.

I would like to extend my thanks to all other academics who have supported me through the last three years, in particular Associate Professor John McDowall for his statistical advice and encouragement. I would also like to thank Dr James Richard for his methodological guidance, being the program director and the many helpful chats. Further I would like to thank Dr Chris Eichbaum for his inspiring and encouraging words. Dr Micael-Lee Johnstone, for being program director, it was a pleasure to start the day with you at 6am these past few months. Associate Professor Wolfgang Steinel for giving me advice, especially during the start of this journey - meeting you in North America and Europe is a particularly fond memory.

I am grateful to Helen Hynes who gave me teaching opportunities in a wide range of courses, you have contributed a lot to my experience. Mary and Hannah, your support and encouragement were appreciated. Katrina, thanks for proofreading and advice on various issues.

I am grateful for all my colleagues who made this journey so much better, our Friday lunches were the weekly highlight. I must specifically thank those whom I have had the privilege to share an office with and make many memories with: Farhana, Naghmeh, Umar, Martyn, Hoang and René. Naghmeh, my journey was never the same after our two years together, thanks for your help and support. Martyn, I always appreciated and will miss our deep philosophical chats that often diverged into politics. René, I doubt our political banter will stop here. Richa, the random coffees left on my desk, your chocolate cache, 24/7 statistical support and the many chats, your friendship made this journey so much better.

My rail family, working with you guys over the last two and half years has regularly been the highlight of my day. Thanks for putting up with my absent mindedness and always 
supporting me. Tangiwai, Jen, Richard, Darren and Ivan, our late-night support groups were always very much appreciated and needed. Levi and Tim, our many morning breakfasts kept my sanity.

My heartfelt gratitude to my brothers and sisters, family, and Jos and Hester. This journey simply could not have happened without you. From babysitting to providing loads of firewood, from buying train tickets to taking me out on fishing trips, cooking meals and always being there for me and Jeannette, your all-encompassing support made it possible. Ma en Arjen, bedankt voor het geven van een huis voor ons voor twee jaar, je financiele en emotionele steun heeft dit mogelijk gemaakt. Pa en Elisangela, o seu apoio financeira quando precisávamos a mais foi mais apreciado. Dando-nos o feriados surpreendente foi sempre um ponto alto. Finalmente, obrigado pelo novo irmãozinho.

Mum, a special thanks goes to you for opening your house, providing years of train tickets and giving me the self-advocacy to be able to study while having a family. Dad, your endless babysitting, unconditional love and support, your care and roof made it all possible. We look forward to the opportunity of returning the favor. All those early mornings when you kicked me out at the train station are destined to become a fond memory. Making you proud, Mum and Dad, was a driving focus.

To my wife and children, your daily sacrifice and support made the difference. Yulia, you are now nine, your unconditional smiles through the entire eight and a half years of this journey were the best motivation anyone could ask for - you made it possible and I promise I will be a proper dad now $:-$. Jay, your first smiles progressed into cheeky sentences throughout the last few years. Xander, your first smiles turned into your first word "Daddy" and quickly progressed into "Daddy, you ca ca". The two of you coming into the world made the last three years unforgettable. The hourly reminders for me to check if I set my alarm were appreciated $:$. You three will grow up to do amazing things!

Finally, my wife, thank you for not making the $\mathrm{Ph}_{\mathrm{D}} \mathrm{stand}$ for divorce. Jeannette, you picked me up when I was down, you kicked me when I quit, you took the pen out of my hands when I needed a break, you were my much-needed psychologist and stats consultant. Thank you for every one of the 3,000 days when I have woken to your encouraging words and smile. You are a true blessing, being able to share every step with you is beyond words - I love you.

Yulia, Jay and Xander, this is for you. 


\section{TABLE OF CONTENTS}

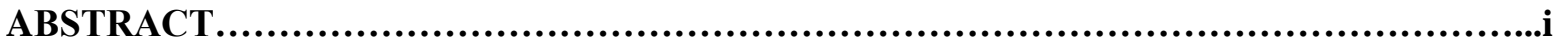

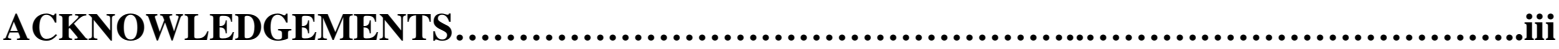

CHAPTER 1: INTRODUCTION............................................................................................... 1

1.1. Why it is important to study anger in international negotiations ......................................... 1

1.2. Incorporating individual differences to inform negotiators' responses to anger.......................2

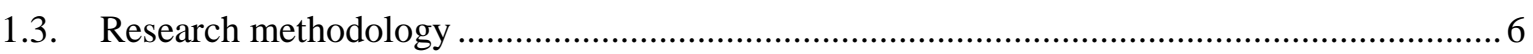

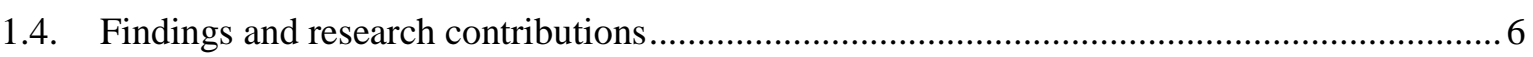

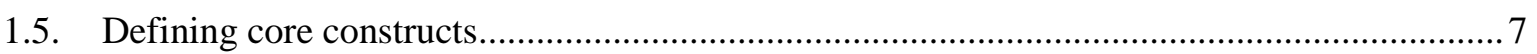

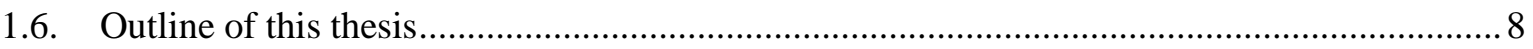

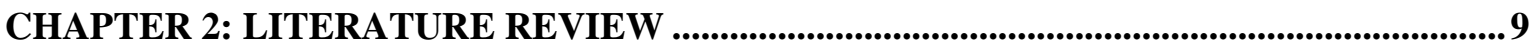

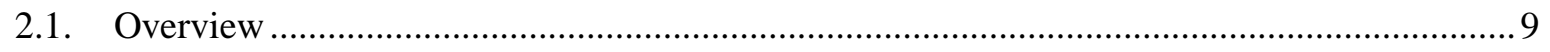

2.2. Anger in negotiation research ….................................................................................

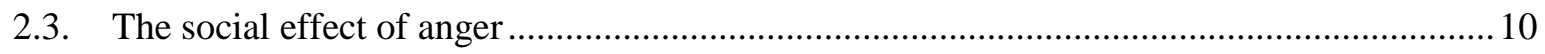

2.4. Emotions As Social Information model as a framework....................................................... 11

2.4.1. Moderator Category 1: Observer's information processing............................................ 13

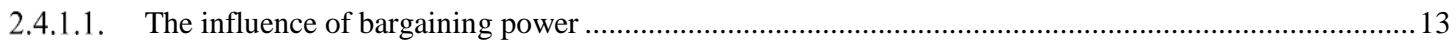

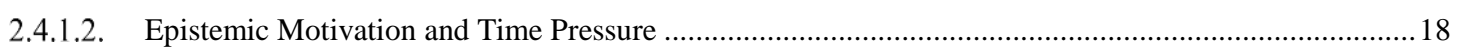

2.4.2. Moderator Category 2: Social Relational Factors ......................................................... 19

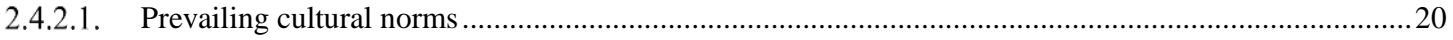

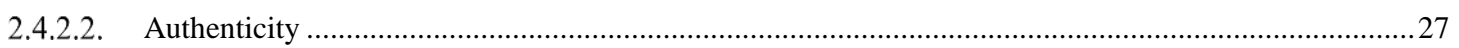

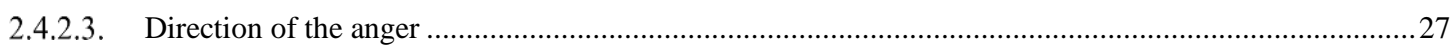

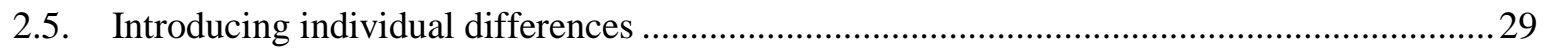

2.5.1. Theoretical framework of self-regulation......................................................................... 31

2.5.2. Measuring self-regulation: Action orientation and State orientation .................................. 33

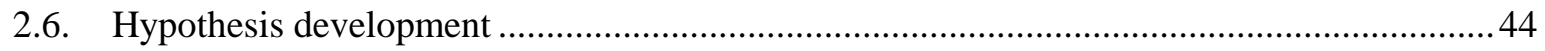

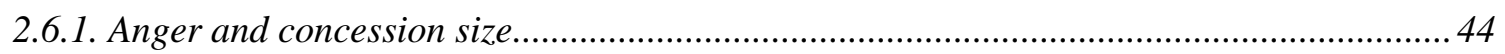

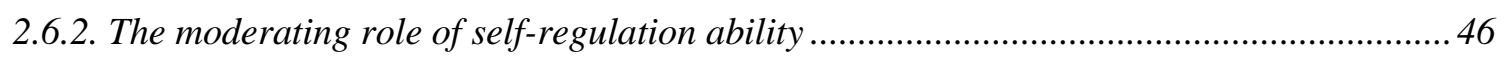

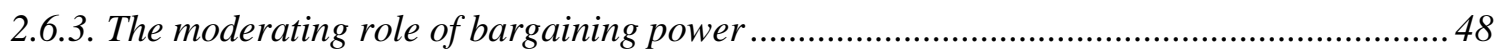

2.6.4. The joint influence of bargaining power and self-regulation ability ................................. 48

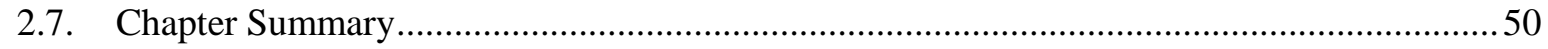

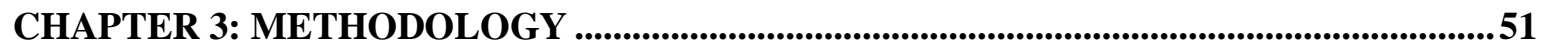

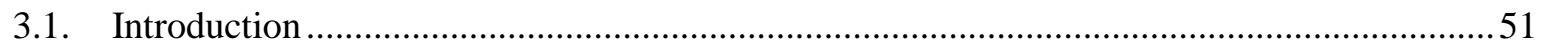

3.2. Appropriateness of the Research Design......................................................................... 51

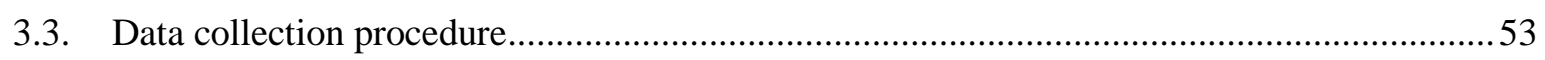

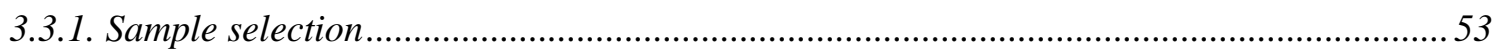




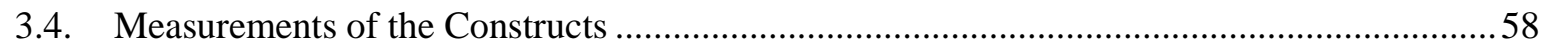

3.4.1. Dependent Measure - Negotiation Concession .................................................................. 58

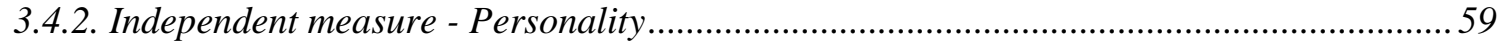

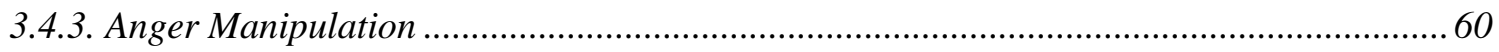

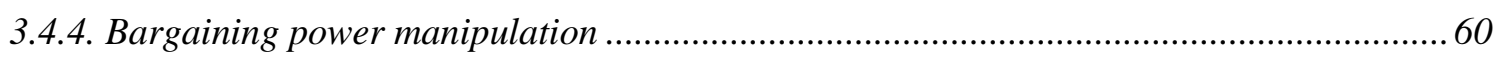

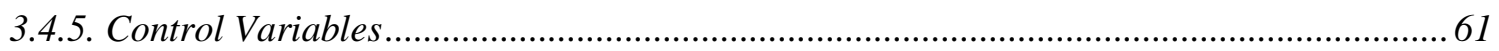

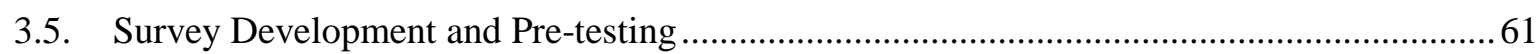

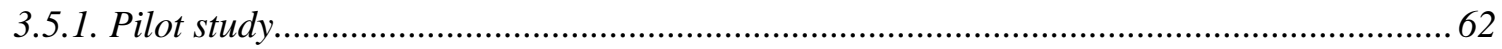

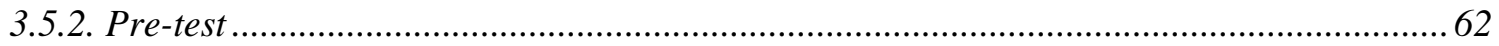

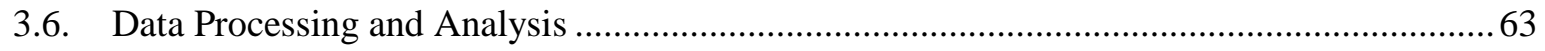

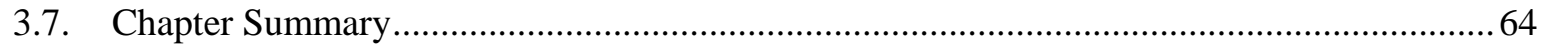

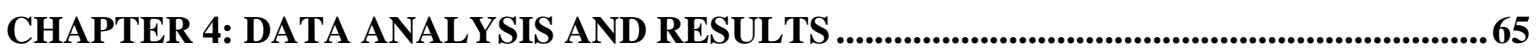

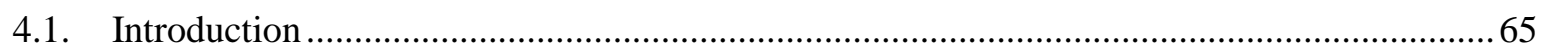

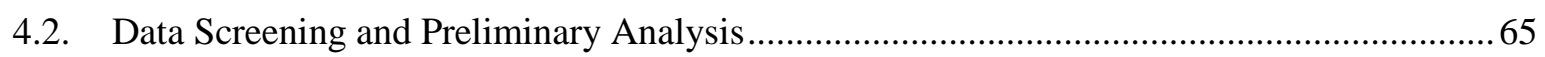

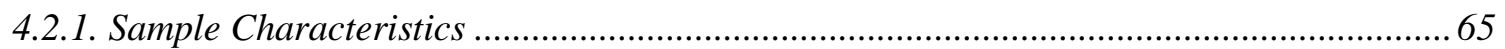

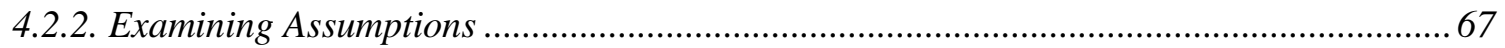

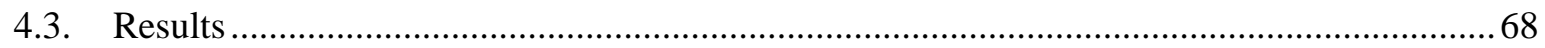

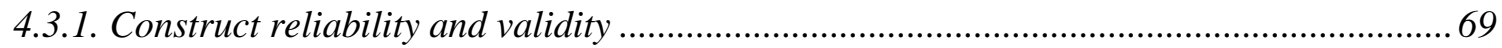

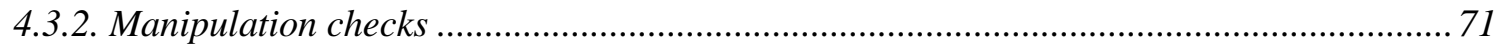

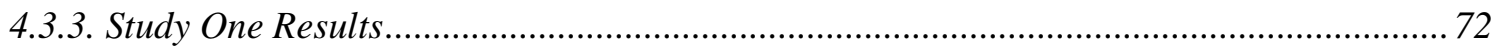

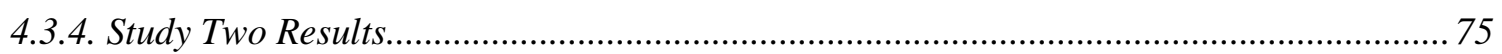

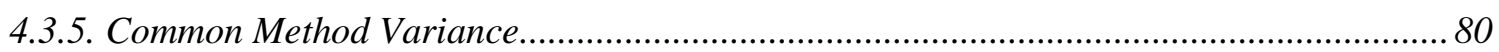

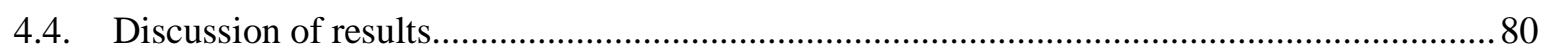

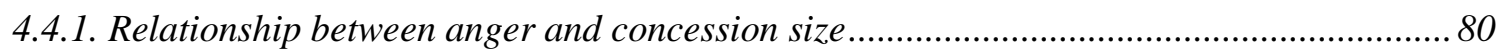

4.4.2. Influence of action versus state-orientation on concession size .......................................... 81

4.4.3. The influence of bargaining power on concession size ...................................................... 82

4.4.4. The joint influence of bargaining power and self-regulation ability ................................. 83

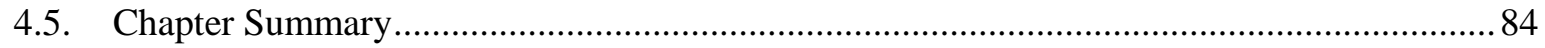

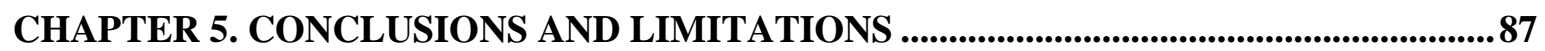

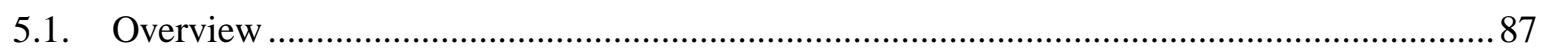

5.2. Theoretical, Empirical and Methodological Contributions ..................................................... 88

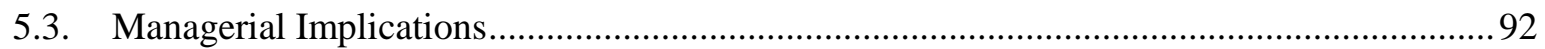

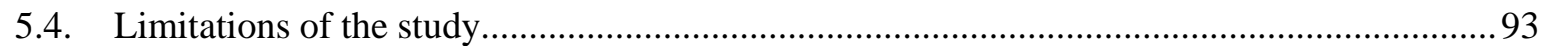

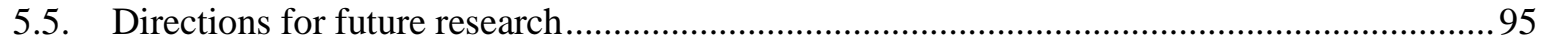

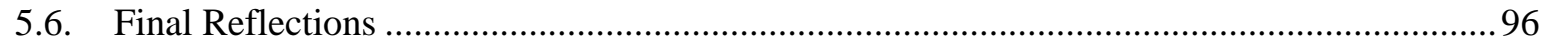


REFERENCE LIST .099

APPENDICES: 119

APPENDIX A: THEORETICAL APPROACHES OF VIEWING EMOTIONS 119

APPENDIX B: NEGOTIATION CASE AND INSTRUCTIONS ........................................120

APPENDIX C: SIMULATION PRE-PROGRAMMED OFFER STRATEGY ......................122

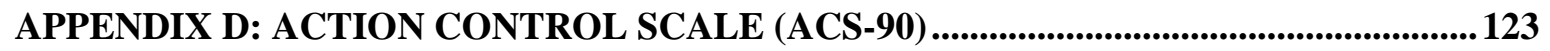

APPENDIX E: MANIPULATIONS AND CHECKS....................................................................... 127

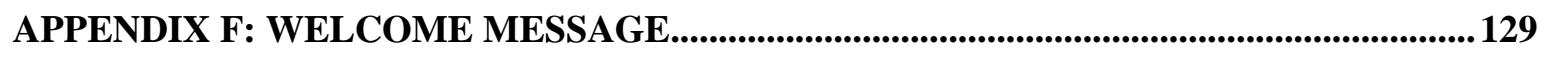

APPENDIX G: PILOT STUDY; INSTRUCTION MODIFICATIONS ................................130

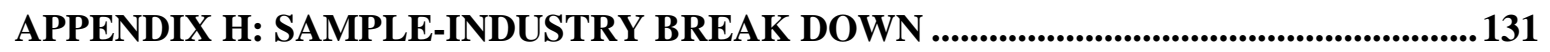

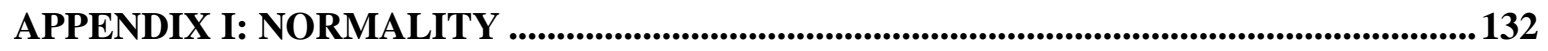

APPENDIX J: STUDY 2 CONCESSION SIZE PER POWER CONDITION FOR

PERSONALITY 


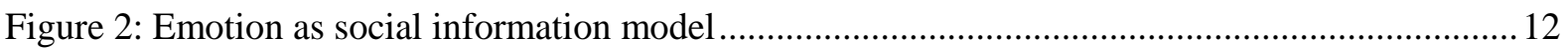

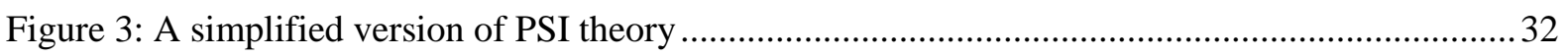

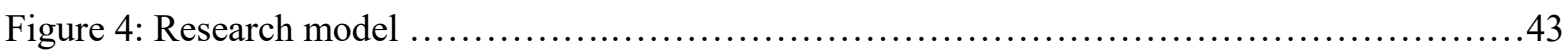

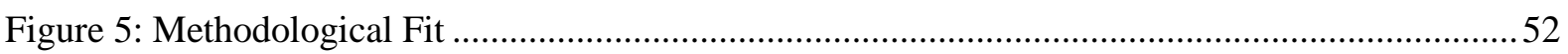

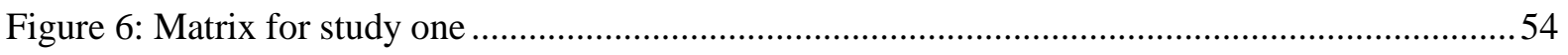

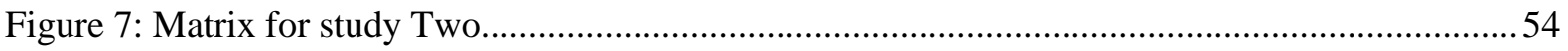

Figure 8: Concession size per personality - study one ..................................................................... 74

Figure 9: Three-way interaction for emotion, personality and power................................................. 76

Figure 10: Concession size per power condition in anger .............................................................. 76

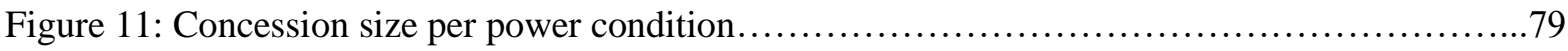

Figure 12: Revised Emotion as Social Information Model Incorporating Observer's Capability ........ 90

Table 1: An overview of the influence of the moderator category 1 on the social effect of anger ....... 14

Table 2: Summary of findings on social relational factors that moderate the social effect of anger....21

Table 3: Examples of action versus state orientation influencing behaviour......................................... 35

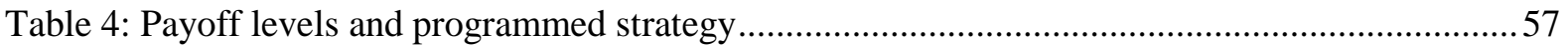

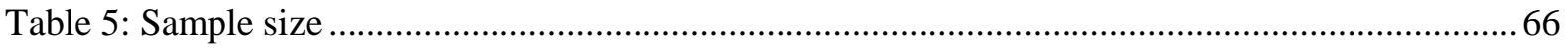

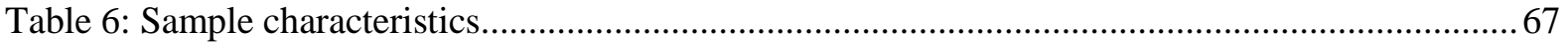

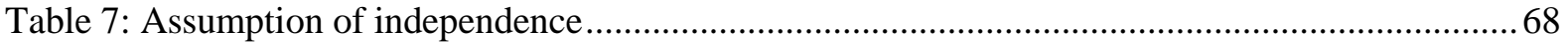

Table 8: Assumption of homogeneity of the regression of the slopes ................................................ 68

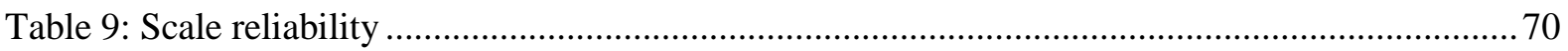

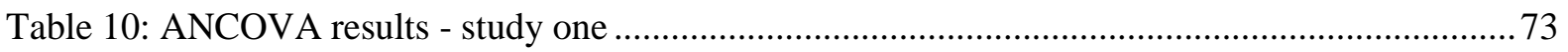

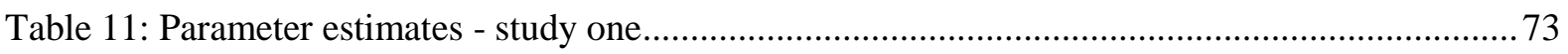

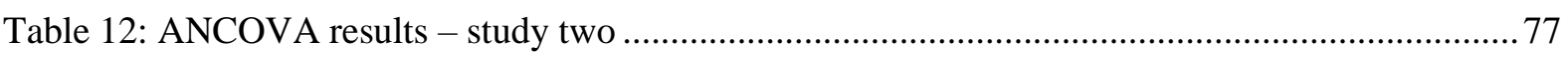

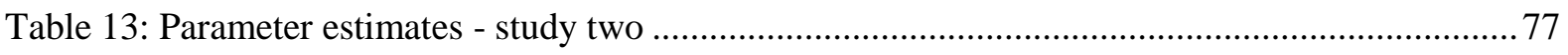




\section{Chapter 1: Introduction}

\subsection{Why it is important to study anger in international negotiations}

Increasing international trade and globalisation has seen a corresponding increase in the number of international negotiations (George, Jones, \& Gonzalez, 1998; Metcalf et al., 2006). There are myriad challenges when dealing with a foreign counterpart, because they operate with a different set of norms (Rivers \& Lytle, 2007). Arguably, one of the biggest challenges for negotiators is when the foreign counterpart gets angry (Adam, Shirako, \& Maddux, 2010; Kopelman \& Rosette, 2008). Although there are numerous studies that have investigated how negotiators respond to anger (e.g., Kopelman, Rosette, \& Thompson, 2006; Steinel, Van Kleef, \& Harinck, 2008; Van Kleef, De Dreu, \& Manstead, 2004a), their findings are contradictory (Hunsaker, 2017).

Van Kleef's (2008) emotion as social information (EASI) theory offers a unifying framework to understand the social effect of emotions during negotiations. This thesis follows Van Kleef's $(2008,2009)$ idea that negotiators respond either emotionally (competitively) or strategically (cooperatively) to displays of anger. I propose that incorporating individual differences will enhance his theoretical model.

Few negotiation researchers have focussed on the role of individual differences in response to displays of anger in international negotiations. For example, although we know that prosocial negotiators are more likely to concede than pro-self negotiators in mono-cultural negotiations (Van Kleef \& De Dreu, 2010), our understanding of personality traits in response to anger in negotiations in general, remains embryonic. This thesis addresses this gap and investigates personality traits to inform the understanding of how negotiators respond to displays of anger.

The personality difference investigated here is action orientation versus state orientation. This trait measures the capability of an individual to self-regulate in a demanding situation. In this thesis, I investigate the link between the personality trait of action orientation versus state orientation, and concessionary behaviour in response to anger during an international negotiation.

My findings, that action oriented negotiators adapt their behaviour better than state oriented negotiators, extend our understanding of negotiators' response to displays of anger. The 
implications of these findings are discussed with respect to the selection and development process of managers for international negotiations.

\subsection{Incorporating individual differences to inform negotiators' responses to anger}

In negotiation research, individual differences are defined as "any characteristics that can differ from one person to another, including everything from age and sex to height, personality, intelligence, and even attitudes" (Elfenbein, 2015, p. 131). Although the dominant view in negotiation research is that personality differences account for very little variance in negotiation behaviour (Bazerman, Curhan, Moore, \& Valley, 2000), there remains a persistent view that some negotiators are better suited to the task of negotiation (Elfenbein, 2013). Building on economic psychology work that demonstrated manipulated self-regulation strategies helped overcome the detrimental effects of anger (Jäger, Loschelder, \& Friese, 2017), this study investigates the idea that negotiators who are good at self-regulation (action oriented) will be more proficient negotiating with an angry counterpart than negotiators who are less able to self-regulate (state oriented).

In order to show that exploring individual differences will extend current understanding, it is necessary to provide a brief overview of the social effect of anger in negotiation research to date.

The findings of early studies on the effect of anger in negotiation were confusing because they produced conflicting results. Van Kleef and colleagues (2004a) found that anger was beneficial in negotiation, with displays of anger creating larger concessions from the other negotiator. However, Kopelman and her colleagues (2006) concluded that displaying anger did not lead to greater concessions than displaying happiness. Responding to these contradictory findings, negotiation researchers acknowledged the complexity of the social effect of anger and launched investigations that incorporated various moderators.

The relative power of the negotiators has been one of the most investigated moderators. We know from these studies that regardless of the source of power (see Van Kleef, De Dreu, Pietroni, \& Manstead, 2006), when negotiators have low power they are more likely to concede than when they have high power. It appears that the level of power influences the motivation, or amount of attention a negotiator gives to a display of anger (Van Kleef, 2010). When a negotiator has high power and good alternatives, they have the luxury of being 
intransigent when they are facing an angry counterpart (Van Kleef \& Côté, 2007) and can react competitively or cooperatively.

Other moderators that have been found to interact with anger include the target of the anger and the salience of the negotiation. Steinel and his colleagues (2008) and Lelieveld, Van Dijk, Van Beest, Steinel and Van Kleef, (2011) found that negotiators conceded more to displays of anger directed at their behaviour (the offer made) than to displays of anger directed at the person. Focusing on the salience of the negotiation, Harinck and Van Kleef (2012) found that when a negotiation was interests-based, negotiators were more likely to concede to a display of anger than when the negotiation was value-based, in which case they retaliated. The authenticity, or perceived genuineness of the display of anger, has also been established as an influential moderator. Côté, Hideg and Van Kleef (2013) found that when anger was perceived as sincere, negotiators conceded more than when no emotion was shown. By comparison, participants reacted competitively and demanded more when anger was perceived as fake, relative to no display of emotion.

In the context of international negotiations, the moderating effect of the cultural background of the negotiator displaying the anger has received attention. A study by Adam and Shirako (2013) showed that negotiators from the United States (U.S.) conceded more to East Asian negotiators (who were breaking the U.S. negotiators' expectations by expressing anger) than they conceded to an angry U.S. negotiator.

Together these studies demonstrate that there are a number of important factors in understanding how anger plays out in international negotiations. However, before arguing for the investigation of the moderating effect of individual differences (the purpose of my study), it is appropriate to acknowledge the moderating variables that have been incorporated into the dominant theoretical framework: Van Kleef's (2008) EASI theory, shown in Figure 1. 


\section{Figure 1: Emotion As Social Information (EASI) model in negotiation}

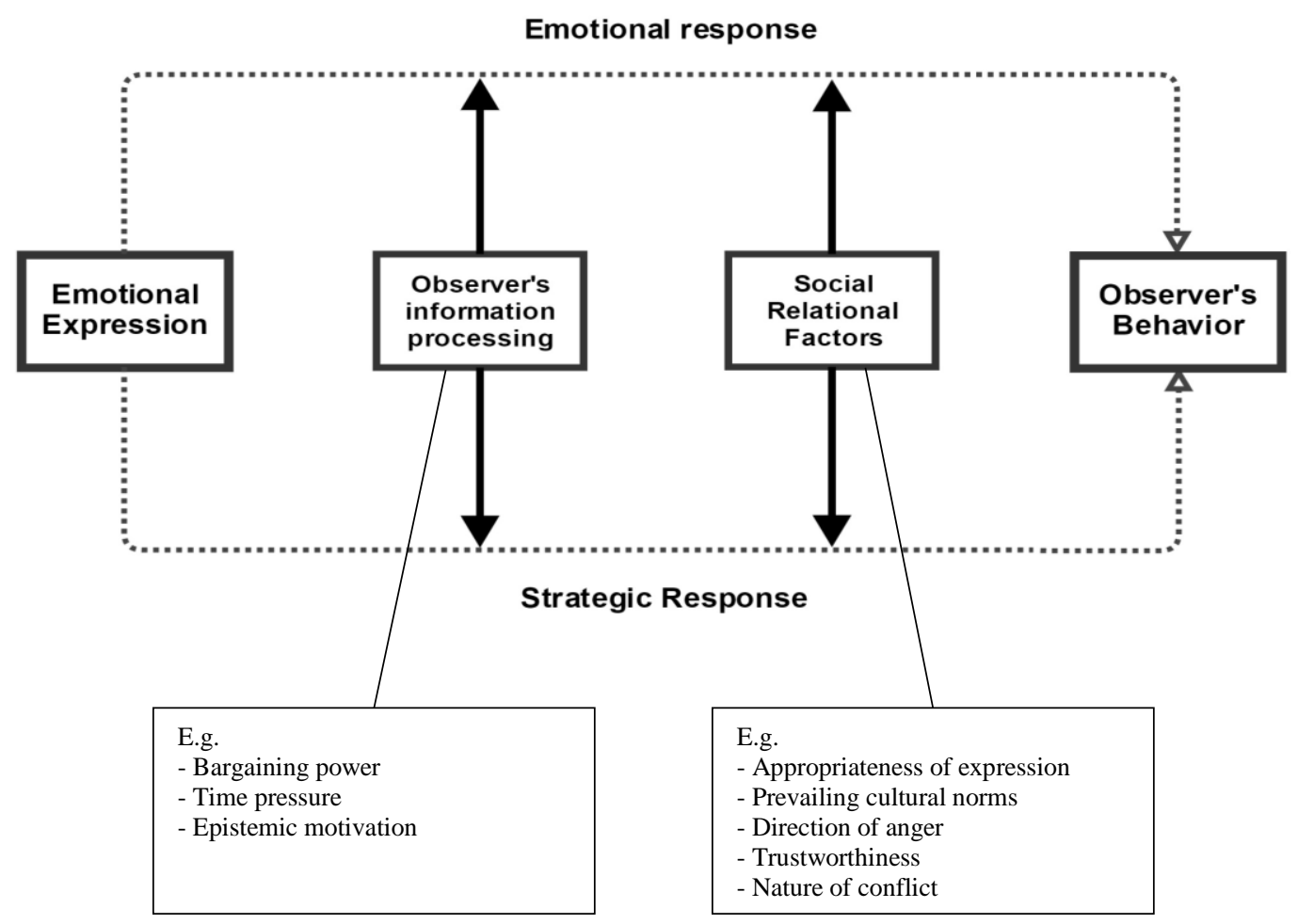

Source: Modified from Van Kleef (2009)

In a recent literature review of anger in negotiations, Hunsaker describes the EASI theory as "uniquely suited to help scholars explain why the same emotion can elicit different responses in different situations" (Hunsaker, 2017). According to the model, a negotiator on the receiving end of anger can have either an emotional response (Van Kleef calls this response an affective reaction) or a strategic response. It is important to note that these paths are not mutually exclusive, although they are portrayed as such in the model. Van Kleef explains that a negotiator will react both emotionally and strategically but in some situations the strategic response is sufficiently powerful that it overshadows the emotional response, and in other situations the reverse is true.

The two categories of moderators in the EASI theory are of interest here. Van Kleef's first category of moderators is 'observer's information processing' and encapsulates the motivation of a negotiator to interpret the information implicit in expressed anger. It includes bargaining power (discussed above), time pressure and epistemic motivation, which is needed for closure. His second category of moderators is 'social relational factors' which, as the name suggests, refers to the relationship between the two parties. Somewhat confusingly it 
does not include power (which is included in the other category) but does include status relationships (Van Kleef, 2009), as well as the various factors discussed above such as authenticity of the anger and the cultural background of the expresser. What EASI theory does not include is the moderating role of individual capabilities to process emotion.

It is the underlying tenet of this thesis that negotiators are inherently different in their ability to process information and emotions. Drawing on Kuhl's (2000) personality systems interactions (PSI) theory, I propose that negotiators' differences in self-regulation ability will interact with the moderators identified by Van Kleef in his EASI theory, and could help explain the contradictory findings in the field of social effect of anger in negotiations. It is worth noting that the potential contribution of the role of emotion regulation to inform the understanding of negotiation behaviour has been previously recognised (Brett, Northcaft, \& Pinkley, 1999; Van Kleef \& Sinaceur, 2013).

PSI theory explains that differences in self-regulation ability are related to peoples' proficiency in processing incoming information (Kuhl, Kazén, \& Koole, 2006) such as the display of anger by a negotiation counterpart. There have been a number of studies that have explored the difference between action vs. state orientation during decision making that have found that action oriented individuals perform better under pressure than state oriented individuals (Stiensmeier-Pelster, 1994). This superior performance is because action oriented individuals have a greater tendency to supress negative emotions (Allemand, Job, Christen, \& Keller, 2008) and are more inclined to let go of past events, which aids objective decision making (Van Putten, Zeelenberg, \& Van Dijk, 2010). Action oriented individuals have the ability to initiate a control strategy, or a mode of willpower enabling conscious choice, which stimulates flexible self-regulation of emotion (Koole \& Fockenberg, 2011). In comparison, a state oriented individual struggles to initiate and maintain intentions during demanding conditions (Kuhl, 1994a) such as an international negotiation where the counterpart displays anger.

The overarching research question addressed in this thesis is:

\section{How do negotiators' self-regulation abilities moderate their response to a display of anger in an international negotiation?}

Previous research has shown that various moderators affect concessionary behaviour when anger is shown. Given that international negotiations are by their very nature complex, it is logical to investigate the interaction of self-regulation with other variables. While it would be 
ideal to investigate such interactions with an array of variables, the time and budgetary limitations of this doctoral thesis mean that this exploration can only scratch the surface. Based on the overwhelming evidence of previous studies (e.g., Van Dijk, Van Kleef, Steinel, \& Van Beest, 2008; Van Kleef \& Côté, 2007; Van Kleef, De Dreu, Pietroni, et al., 2006), I have chosen to commence this task by investigating how power interacts with self-regulation capability when anger is displayed in an international negotiation.

The secondary research question is:

\section{How do negotiators' self-regulation ability and relative bargaining power moderate their response to a display of anger in an international negotiation?}

\subsection{Research methodology}

Six hypotheses were developed to address these research questions. These hypotheses were tested in two online negotiation studies where participants negotiated with a counterpart who they believed got angry. The simulation used was the mobile phone consignment case that has been widely used within the emotion and negotiation literature (e.g., Steinel et al., 2008; Van Kleef, De Dreu, \& Manstead, 2004b). The data were collected in the U.S. and, given the focus on international negotiations, the counterpart was described to the participants as Wang Wei from China. SPSS was used to conduct analysis of covariance (ANCOVA) and identify significant relationships.

\subsection{Findings and research contributions}

A significant main effect of personality was identified in the first study, with action oriented negotiators conceding significantly less than state oriented negotiators. In the second study a three-way interaction between emotion, personality and bargaining power was established. When action oriented negotiators had high power, they become more cooperative, in comparison state oriented negotiators did not change their behaviour across the conditions.

Although these results were somewhat different than hypothesised, they still provide evidence of the important role of personality differences to understand how negotiators respond to anger in international negotiations and warrant adding individual capability differences to EASI theory. The findings are a useful step in the long and ongoing process of exploring how negotiators respond to anger. 


\subsection{Defining core constructs}

It is useful to clarify the main terms used in this thesis: emotions, anger, power, and types of negotiations.

Emotions are commonly called affect by psychology researchers. Accordingly the definition is a distinct affective state, with a quick onset, intense, brief duration that is automatically recognized (Ekman, 1992a). It is worth distinguishing emotions from moods, which although similar, are less focal and have a lower intensity and may not have any salient cause (Forgas, 2002; Kraiger, Billings, \& Isen, 1989). Emotion research has established there are six distinct emotions that are universally recognised: happiness, surprise, fear, sadness, disgust and anger (Ekman, 1992b).

The focus in this thesis is on the emotion of anger. In his recent literature review, Hunsaker (2017) notes that few empirical anger in negotiation studies have formally defined anger. This thesis follows the definition he adopted. Anger is "an emotion that involves an appraisal of responsibility for wrong doing by another person or entity and often includes the goal of correcting the perceived wrong" (Gibson \& Callister, 2010).

A negotiator's bargaining power is their ability to influence their counterpart (Kim, Pinkley, $\&$ Fragale, 2005). In a negotiation, power can be derived from information, a person's position in an organization, their relationships with other people and contextual sources (French \& Raven, 1959; Lewicki, Saunders, \& Barry, 2015). In negotiations, a particularly common source of power is the availability of attractive alternatives. Such power is commonly referred to by the acronym BATNA, which means best alternative to a negotiated agreement.

This thesis utilized a distributive negotiation scenario; therefore, it is useful to distinguish the term from integrative negotiations and ultimatum negotiations. A distributive negotiation can be understood as a fixed pie (Filipowicz, Barsade, \& Melwani, 2011), in which negotiation outcomes become win-lose (Barry \& Friedman, 1998), that is, both sides cannot gain. An ultimatum negotiation is where one side receives a take it or leave it offer (Lewicki, Barry, \& Saunders, 2010). In an integrative negotiation, the goals of the sides are not mutually exclusive (Lewicki et al., 2010). These authors suggest both parties should be able to achieve their objectives, creating a win-win outcome. 


\subsection{Outline of this thesis}

The remainder of this thesis is laid out as follows. Immediately following this chapter, the literature review is presented in Chapter 2. It explains more fully the construct of action orientation versus state orientation and evaluates the interpersonal effect of anger in negotiation literature. From this review, six hypotheses are proposed.

Chapter 3 explains the research methods used to investigate the hypotheses and the positivist paradigm adopted. The results of the two studies are presented in Chapter 4 alongside a discussion of these findings. The final chapter in this thesis, Chapter 5, describes the theoretical and empirical contributions made, discusses the contribution to practice, and future research directions. 


\section{Chapter 2: Literature Review}

\subsection{Overview}

This chapter describes the literature on the social effect of anger and the literature on the personality traits of action orientation versus state orientation. From these reviews, I propose six hypotheses. I first explain where my research on the social effect of anger sits in the broader literature of emotions in negotiation. Turning to the early seminal studies, I explain how their varying results led to research that explored moderating relationships. I use the EASI model as the unifying framework for this discussion. As noted previously, individual differences have received scant attention in the social effects of anger research. The penultimate section discusses the literature on personality traits and how it can influence the impact of anger within the context of international negotiation. The chapter ends with the hypothesis development and research model.

\subsection{Anger in negotiation research}

Over the past two decades, understanding the role of emotions in negotiations has been the focus of a growing research program in the broader conflict management field (Hunsaker, 2017). Emotions play an important role in resolving divergent interests in negotiations by influencing both the thought processes and behaviour of negotiators and can shape the outcome of negotiations (Harinck \& Van Kleef, 2012).

Researchers have explored the influence of a wide array of emotions including anxiety (Brooks \& Schweitzer, 2011), sadness (Sinaceur, Kopelman, Vasiljevic, \& Haag, 2015), disappointment (Lelieveld et al., 2011), guilt (Van Kleef, De Dreu, \& Manstead, 2006), happiness (Yifeng, Tjosvold, \& Peiguan, 2007), and anger (Sinaceur \& Tiedens, 2006). Of these, anger is the most prominent and influential emotion during negotiations (Allred, 1999; Van Kleef, Van Dijk, Steinel, Harinck, \& Van Beest, 2008).

To understand the anger in negotiation literature, it is important to clarify the difference between the intrapersonal effect of anger and the interpersonal (social) effect of anger because these are two different lines of research. The terms social effect of anger and interpersonal effect of anger can be used interchangeably, for the sake of readability, this thesis will use the term social effect following Adam and Shirako (2013). 
Intrapersonal effects refer to a negotiator's own perceptions and behaviour changes when they feel an emotion such as anger (Van Kleef \& Sinaceur, 2013). For example, when a negotiator feels angry, they are more likely to act competitively, resulting in uncooperative behaviour and a decreased likelihood of a successful negotiation (Liu, 2009). Research into the social effect of anger, on the other hand, examines the effect a display of anger has on the counterpart's behaviours and thought patterns (Van Kleef, De Dreu, Pietroni, et al., 2006). For instance, when a negotiator expresses anger, the social effect of this anger can cause the counterpart to concede more (Van Kleef et al., 2004a).

In this thesis, I focus on the social effect of anger line of research, as the studies with divergent results are concerning the social effect of anger (Kopelman et al., 2006; Van Kleef et al., 2004a) opposed to the intrapersonal effects. Likewise the EASI model (Van Kleef, 2008), introduced in the previous chapter, was developed to unify the social effect of emotions line of research.

\subsection{The social effect of anger}

The earliest work on the social effect of anger during negotiations was by Allred, Mallozzi, Matsui, and Raia (1997) followed a few years later by Van Kleef and his colleagues (2004a) and by Friedman et al. (2006). Of these, it was Van Kleef et al.'s (2004a) study that was influential in the field.

Using a series of laboratory experiments with Dutch students (in which they negotiated the price, warranty and service period for a mobile phone shipment), they found that negotiators who faced an angry opponent conceded more than negotiators who faced an opponent expressing happiness or no emotion. These results indicated that anger might be used strategically in a negotiation, for instance, to help lower the demands from an opponent. Van Kleef et al. (2004a) suggested that the anger carried information about the counterpart's situation and signalled their intentions. On the other hand happiness implied that the counterpart was satisfied and did not aspire to a larger proportion of the fixed resource (Van Kleef et al., 2004a).

These results laid the foundation for the idea that negotiators could use anger strategically in a negotiation to elicit concessions from the other party. Van Kleef and his colleagues went on to replicate these results in another study published that year where moderators were included (see Van Kleef et al., 2004b). 
However, the alternate view that anger is not positive in negotiation was already evident.

Allred and his colleagues' (1997) study concluded that anger negatively influences negotiation outcomes. Likewise, Friedman and colleagues (2004) study analysed online disputes and established that expressions of anger triggered reciprocal anger, which reduced the likelihood of settlement. Similarly Kopelman and her colleagues (2006) found that anger had no strategic benefit in a negotiation. In her study, happiness was more effective than an expression of anger at eliciting concessions. Whereas Van Kleef et al. (2004a) argued that anger could be a signal of the negotiator's intentions, Kopelman's findings point to the idea that negotiators on the receiving end of anger respond by becoming angry and behave competitively rather than concede.

Understanding these contradictory results is challenging and additional research is necessary. It is important to note these inconsistent results came from different data collection contexts. Van Kleef used undergraduate students in a laboratory, whereas Kopelman used MBA students in an online study with a video of their counterpart getting angry. Regardless of the varied contexts, together these studies establish that the social effect of anger is influential in a negotiation and collectively, they have created the need to investigate why social effects of anger can be divergent.

\subsection{Emotions As Social Information model as a framework}

Before discussing the studies that have investigated the moderators of how anger influences negotiation responses, I present the EASI theory. EASI theory was first introduced by Van Kleef in 2008 and is helpful as a unifying framework because it explains and categorises the moderators that determine varied reactions to anger during a negotiation (Hunsaker, 2017). Van Kleef (2008) developed EASI theory over the existing dual process model (e.g., Van Kleef \& Côté, 2007; Van Kleef et al., 2004b) to explain the diverse findings of the field. According to EASI theory, a negotiator can react strategically or emotionally to an expression of anger (Van Kleef, 2009). I have reproduced the model below in Figure 2 to show the two paths as dotted lines. It is important to note that the two paths are not mutually exclusive and therefore, when applying EASI theory, it is helpful to presume this framework has just one path. Consider that this one path is a direct relationship between expressed anger and concessionary behaviour. If the negotiator reacted cooperatively to the anger and made a 
concession, Van Kleef labelled it a strategic reaction. When a negotiator reacted more competitively to the anger Van Kleef labelled it an emotional reaction.

\section{Figure 2: Emotion as social information model}

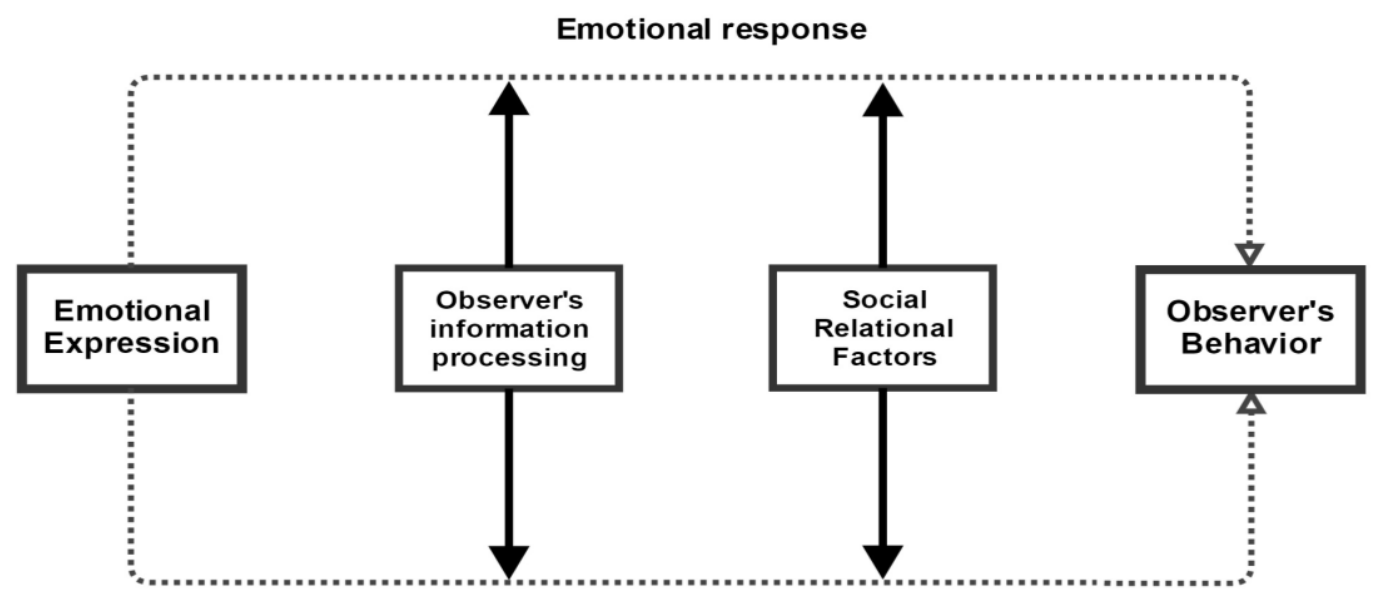

Strategic Response

Source: Modified from Van Kleef (2009).

The strategic reaction can be explained with classical theory with its roots in Darwinism (Darwin, 1872) which says that emotions have evolved to carry information about the expressed intention. When anger is expressed, it signals dissatisfaction, which may be interpreted by the counterpart as endangering a possible agreement and so he/she adjusts their offer (Barry, Smithey Fulmer, \& van Kleef, 2004) by making a concession. Similarly, the emotional response path can be supported by theory, in this case, contagion theory (Schoenewolf, 1990). Simply put, emotions such as anger can be contagious and spread from the expresser to the counterpart. When the counterpart also becomes angry he/she reacts competitively.

As noted in the previous chapter, both the strategic reaction and the emotional reaction are moderated by two categories of variables; that is, observer's information processing and social relational factors. These categories are useful in structuring the literature review and I begin below with the moderating category of observer's information processing. 


\subsubsection{Moderator Category 1: Observer's information processing}

Studies that are included within the observer's information processing category include investigations of the moderating effect of power, time pressure and epistemic motivation. Of these, power has received the most attention of all the moderating variables that have been investigated in the social effects of anger literature. This focus on power aligns with the attention that has been devoted to the study of power in the broader negotiation literature in the last 50 years, because power is so influential in determining negotiator behaviour (Greer \& Bendersky, 2013).

Summaries of studies that have explored observer's information processing moderators are presented in Table 1. The influence of power dominates this category with only one other study included, which considered epistemic motivation and time pressure. The first section of the table reviews the power studies that looked at the effect of BATNA (best alternative to a negotiated agreement.). The second section of the table reviews power studies that looked at sources of power other than BATNA. The final section of the table highlights the epistemic motivation and time pressure study. I have included a column describing the empirical setting of each study. Describing the setting is important because it demonstrates the diversity of the scenarios that have been used, and differences in types of participants. Such differences make comparisons problematic.

\subsubsection{The influence of bargaining power}

The twelve studies summarised in Table 1 show that power can come from different sources in a negotiation. From the earliest work, it was established that negotiators with low power react more cooperatively than negotiators with high power, when on the receiving end of a display of anger (Van Kleef et al., 2004b). In this study and four other studies, the power was derived from a negotiator's BATNA. 
Table 1: An overview of the influence of the moderator category 1 on the social effect of anger

\begin{tabular}{|l|l|l|l|}
\hline \multicolumn{3}{|l|}{ Study } & Key Findings \\
\hline $\begin{array}{l}\text { Van Kleef et al., } \\
\text { 2004b, } \\
\text { Experiment 3 }\end{array}$ & $\begin{array}{l}\text { Project manager case. - 82 managers } \\
\text { were used from Dutch companies. }\end{array}$ & $\begin{array}{l}\text { This study found that managers were more likely to concede to an angry opponent } \\
\text { compared to a happy one when they had a bad BATNA. }\end{array}$ \\
\hline $\begin{array}{l}\text { Sinaceur } \\
\text { Tiedens, 2006 }\end{array}$ & $\begin{array}{l}\text { Across two experiments, 216 } \\
\text { participants from USA, France and } \\
\text { Morocco. Study 1 used a case of sale } \\
\text { of technical equipment and study 2 } \\
\text { was a job contract. }\end{array}$ & $\begin{array}{l}\text { Across both studies, these authors found participants with low power conceded more. } \\
\text { results across the countries, with those with low power conceding more. }\end{array}$ \\
\hline $\begin{array}{l}\text { Van Kleef, De } \\
\text { Dreu, Pietroni, et } \\
\text { al., 2006 } \\
\text { Experiment 1-3 }\end{array}$ & $\begin{array}{l}\text { Five studies involving a range of } \\
\text { negotiation scenarios using students, } \\
\text { middle-level managers from Italy } \\
\text { and participants from the } \\
\text { Netherlands (N =261). }\end{array}$ & $\begin{array}{l}\text { The first three studies manipulated power with BATNAs. The first experiment found } \\
\text { they faced an angry opponent. The second study involved people selling products on the } \\
\text { internet and again the participants with low power were more likely to concede with an } \\
\text { angry opponent than with a happy opponent. }\end{array}$ \\
\hline $\begin{array}{l}\text { Van Kleef \& Côté, } \\
\text { 2007 }\end{array}$ & $\begin{array}{l}\text { Two studies used 468 postgraduate } \\
\text { students. Study 1 used a project } \\
\text { manager case, study 2 used a mobile } \\
\text { consignment case. }\end{array}$ & $\begin{array}{l}\text { These authors found that power and the appropriateness of anger jointly explained the } \\
\text { outcomes. That is, anger backfired when it was inappropriate and negotiators had high } \\
\text { power. No difference was found with low power negotiators, as they did not have the power } \\
\text { to be flexible with their behaviour. }\end{array}$ \\
\hline $\begin{array}{l}\text { Belkin, Kurtzberg, } \\
\text { \& Naquin, 2013 }\end{array}$ & $\begin{array}{l}\text { 156 participants in 78 dyads; all } \\
\text { interaction was via e-mail. This } \\
\text { study used the New Recruit } \\
\text { negotiation case. }\end{array}$ & $\begin{array}{l}\text { This study found expressing anger during an e-mail negotiation can signal more dominance } \\
\text { and help achieve higher gains relative to expressing happiness. }\end{array}$ \\
\hline
\end{tabular}




\begin{tabular}{|c|c|c|}
\hline Study & Empirical Setting & Key Findings \\
\hline \multicolumn{3}{|c|}{ The moderating influence of power from information } \\
\hline $\begin{array}{l}\text { Pillutla \& } \\
\text { Murnighan, } \\
1996\end{array}$ & $\begin{array}{l}\text { The study used } 118 \text { undergraduate students } \\
\text { in the U.S. The experiment context was } \\
\text { dividing a sum of money. }\end{array}$ & $\begin{array}{l}\text { This study found that negotiators who have more information are more likely to get angry } \\
\text { and subsequently reject an offer, compared to when they are in an equal information } \\
\text { condition. }\end{array}$ \\
\hline $\begin{array}{l}\text { Van Dijk et al., } \\
2008\end{array}$ & $\begin{array}{l}\text { This study included three experiments } \\
\text { based on an ultimatum bargaining } \\
\text { simulation that divided } 100 \text { chips. } 323 \\
\text { students from a major Dutch university } \\
\text { participated across the experiments. }\end{array}$ & $\begin{array}{l}\text { In an equal information situation, negotiators conceded and offered more to an angry } \\
\text { opponent, compared to a happy opponent. However, when there was asymmetric } \\
\text { information, an expression of anger backfired and negotiators with more information } \\
\text { (high power) reacted negatively to the anger, and offered less than they did when dealing } \\
\text { with a happy opponent. }\end{array}$ \\
\hline \multicolumn{3}{|c|}{ The moderating influence of power from positional status } \\
\hline $\begin{array}{l}\text { Van Kleef, De } \\
\text { Dreu, Pietroni, } \\
\text { et al., } 2006 \\
\text { Experiment } 4 \& \\
5\end{array}$ & $\begin{array}{l}\text { Experiment } 4 \text { used } 100 \text { employees from } \\
\text { the Netherlands and used a survey scenario } \\
\text { to purchase office chairs. Experiment } 5 \\
\text { used } 60 \text { Italian managers and used a project } \\
\text { management scenario. }\end{array}$ & $\begin{array}{l}\text { Employees in lower power positions (junior trainees) were more likely to concede to a } \\
\text { financial manager who expressed anger. In contrast, participants who held more power } \\
\text { (senior managers) were not influenced by the financial manager's expression of anger. } \\
\text { Study } 5 \text { manipulated power by strong support (high power) vs. low support (low power) } \\
\text { from top management. Again, the participants with low power conceded more to an } \\
\text { angry opponent. }\end{array}$ \\
\hline $\begin{array}{l}\text { Callister, } \\
\text { Geddes, \& } \\
\text { Gibson, 2017 }\end{array}$ & $\begin{array}{l}\text { An online survey targeting business alumni } \\
\text { from three U.S. universities }(\mathrm{N}=323) \text {. } \\
\text { Participants were asked to recall a recent } \\
\text { episode of anger at work. }\end{array}$ & $\begin{array}{l}\text { This study was interested in positional power during conflicts at work and found that the } \\
\text { status of supervisors made them less affected by anger from subordinates. On the other } \\
\text { hand, their power also made them less aware of the negative effect their anger had on } \\
\text { subordinates. Further, subordinates reported being more affected by the anger exhibited } \\
\text { by supervisors than was intended. }\end{array}$ \\
\hline \multicolumn{3}{|c|}{ The moderating influence of power from other sources } \\
\hline $\begin{array}{l}\text { Pietroni, Van } \\
\text { Kleef, } \\
\text { Rubaltelli, \& } \\
\text { Rumiati, 2008 }\end{array}$ & $\begin{array}{l}\text { One study with } 48 \text { Italian professionals. } \\
\text { The case was an ultimatum scenario to } \\
\text { divide } 1,000 \text { dollars. }\end{array}$ & $\begin{array}{l}\text { Power from smiling - These authors found that, compared to anger, happiness created } \\
\text { better offers from the counterpart and the relationship between both parties was better. } \\
\text { They suggested that smiling in some situations would point to greater power and, } \\
\text { therefore, generate a larger concession. }\end{array}$ \\
\hline
\end{tabular}




\begin{tabular}{|l|l|l|}
\hline Study & Empirical Setting & Key Findings \\
\hline $\begin{array}{l}\text { Lelieveld, Van } \\
\text { Dijk, Van } \\
\text { Beest, \& Van } \\
\text { Kleef, 2012 }\end{array}$ & $\begin{array}{l}\text { Across two, studies 267 students were } \\
\text { used. Both studies used an ultimatum } \\
\text { bargaining simulation that divided 100 } \\
\text { chips. }\end{array}$ & $\begin{array}{l}\text { Opponent had power - This study compared the effects of anger and disappointment. } \\
\text { The authors argue that disappointment is important to understand because an expression } \\
\text { of anger includes an element of disappointment. Participants had to counteroffer to an } \\
\text { emotional opponent that had either high or low power. They found that participants } \\
\text { offered more to a high-power opponent relative to a low-power opponent. Further, they } \\
\text { found that participants gave higher offers to a disappointed counterpart regardless of the } \\
\text { power level. }\end{array}$ \\
\hline $\begin{array}{l}\text { Hareli, David, } \\
\text { Akron, \& Hess, } \\
\text { 2013 }\end{array}$ & $\begin{array}{l}\text { This study used 248 Israeli undergraduate } \\
\text { students and an adapted version of the } \\
\text { mobile consignment case. }\end{array}$ & $\begin{array}{l}\text { Social power This study found that power was important at the start of the negotiation, } \\
\text { but as a negotiation progressed, anger became more important than the level of power. } \\
\text { It is important to note that the power manipulation was different than the other studies } \\
\text { mentioned in this table. In this study, the participants had to write about a situation where } \\
\text { they were socially powerful. }\end{array}$ \\
\hline $\begin{array}{l}\text { Van Kleef et } \\
\text { al., 2004b }\end{array}$ & $\begin{array}{l}\text { The first two experiments used the cell } \\
\text { phone consignment case with 218 Dutch } \\
\text { students. }\end{array}$ & $\begin{array}{l}\text { Epistemic motivation and time pressure The first experiment in this study found that } \\
\text { those with low need for cognitive closure (low epistemic motivation) conceded more to } \\
\text { an angry opponent than those with high need for cognitive closure, who were unaffected } \\
\text { by anger. The second experiment also manipulated time pressure and found that when a } \\
\text { participant had low time pressure, they thought more about the opponent's emotion } \\
\text { relative to those that had high time pressure. }\end{array}$ \\
\hline
\end{tabular}


When negotiators had a weak BATNA, expressed anger was interpreted as endangering a possible agreement and as the negotiator had no other attractive option, they had to cooperate. In contrast, when the negotiator had high power, or an attractive BATNA, they had less motivation to process the information contained in the expression of anger and thus conceded less.

In addition to BATNAs, researchers have also explored the effect of power from positional status and information asymmetry. For instance, when a finance manager expressed anger, a junior trainee was more likely to concede in comparison to another senior manager (Van Kleef, De Dreu, Pietroni, et al., 2006). A similar effect has been found with information: an individual with more information (high power) will not concede more to expressed anger in a negotiation (Van Dijk et al., 2008).

Taken together all the studies that explored the effect of power and the social effect of anger confirm that negotiators with low power are more influenced by anger. This finding was replicated in a number of contexts, including laboratory experiments, field simulations, and scenario studies across a range of participants, including the general population and managers. One of these studies suggested that negotiators with high power were immune to the counterpart's emotion (Van Kleef, De Dreu, Pietroni, et al., 2006).

Researchers have also investigated how power interacts with other variables. One study has shown that power and the appropriateness of the anger jointly predict the effect of anger (Van Kleef \& Côté, 2007). Although power sits in the observer's information processing category of moderators in the EASI model and perceived appropriateness of anger is best listed under the category of social relational factors (Van Kleef, 2009), I will discuss it here because of its joint relationship with power.

This relationship was demonstrated when both power and the appropriateness of anger were manipulated, a negotiator with low power conceded, regardless of the appropriateness of the anger (Van Kleef \& Côté, 2007). However, inappropriate anger directed at a negotiator with high power backfired, which can be understood as an emotional reaction with EASI theory. Rather than concede, negotiators with high power demanded more compared to when they faced an opponent expressing appropriate anger or no emotion. From these results, it can be concluded that a negotiator with low power performs better when they react strategically and do what is best for themselves. They had no other attractive option, so regardless of the appropriateness of the anger they had to react cooperatively (Van Kleef \& Côté, 2007). In 
comparison, a negotiator with high power had the luxury of choosing their reaction, so when faced by inappropriate anger they could retaliate and become more competitive.

To summarise, power has important interactions with the effect of anger during negotiations. Although, as shown in Table 1, power and the social effect of anger have received significant attention in negotiation literature. Most of these studies are monocultural studies, which do not test the effect of power during the context of an international negotiation. Thus, further work is required to understand the potential cross-cultural differences of the effect of power.

There is one study that made cross-cultural comparisons, however the negotiation dyads themselves were intracultural. The negotiations consisting of participants from the United States, France and Morocco were compared, and participants with a weak BATNA all conceded more than those with a strong BATNA (Sinaceur \& Tiedens, 2006).

Having reviewed the effect of power, I will now discuss the other moderators within the observer's information category of the EASI model: epistemic motivation and time pressure.

\subsubsection{Epistemic Motivation and Time Pressure}

Included in Table 1, the moderators of epistemic motivation and time pressure also influence the social effect of emotion. I will first discuss epistemic motivation, which is an individual level difference concerned with one's need for cognitive closure and one's desire to develop an understanding of the world (Van Kleef et al., 2004b). Even though there is just one study that has explored the effect of epistemic motivation in the negotiation and social effect of anger literature, it is worth describing it in depth because it is an individual difference, which is the focus of this thesis.

The results of the study demonstrated that individuals with a low need for cognitive closure were more affected by emotion, and as such they conceded more to an angry opponent compared to a happy opponent (Van Kleef et al., 2004b). In contrast, those with a high need for closure did not vary their behaviour across the emotion conditions. A similar result has been reported in team psychology research. Although the context was different, the reactions to emotion replicates the finding, that those with a low need for cognitive closure were more influenced by anger. Specifically, those with lower levels of epistemic motivation were negatively affected when their leader expressed anger, relative to happiness (Van Kleef et al., 2009). In this context, teams with a higher need for closure performed better when their leader expressed anger relative to when the leader expressed happiness. 
Returning to the negotiation study, participants with a low need for closure varied their behaviour as they were more likely to process the information carried within the anger, than individuals with a high need for closure (Van Kleef, 2010). However, it is hard to explain with EASI theory why those with a high need for closure did not take either path as their behaviour did not vary.

Time pressure was manipulated in the second experiment in the study, because it was argued to be one of the most common variables that affected epistemic motivation (Van Kleef et al., 2004b). Time pressure directly moderated the effect that anger had on concession size. Specifically, those with high time pressure did not process the information carried in the anger. This finding suggests that those with high time pressure do not think deeply about the implications of anger (Van Kleef et al., 2004b).

Based on this review of the moderators categorised as observer's information processing and how they interact with displays of anger, I have incorporated power as a moderating variable in my research design. Together these studies demonstrate that a negotiator with low power will react differently from a negotiator with high power. It is likely that the power an international negotiator holds will influence how they perceive displays of anger. Considering that there have been few studies in the international context that explored the effect of power, I decided to incorporate it in my research.

Having discussed the moderators within the observer's information processing category, the following section discusses the social relational factors.

\subsubsection{Moderator Category 2: Social Relational Factors}

Studies within the social relational factors category include the moderating effect of cultural norms, authenticity and direction of anger. Each will be discussed in turn beginning with cultural norms as this moderator has received the most attention within this category.

A summary of the studies that have explored social relational factors are presented in Table 2. Like the previous table, the second column of the table details the empirical setting, and again, this setting is important to consider, as it helps put comparisons between studies into perspective.

The first section of the table reviews the prevailing cultural norms. The second section reviews further social relational factors, including authenticity and direction of anger. The 
last section of the table includes the studies that are difficult to categorize, but are important to note.

\subsubsection{Prevailing cultural norms}

There are various complexities in international, or inter-cultural, negotiations compared to intra-cultural negotiations (Adam \& Shirako, 2013; Rivers \& Lytle, 2007). One important intricacy is the influence of culture, because different cultures have different norms relating to the open expression of emotion (Trompenaars \& Hampden-Turner, 2012). These

prevailing cultural norms are an important social relational factor that moderates the social effect of anger (Van Kleef, 2009).

Some of the earliest work that explored the social effects of anger in an international context compared how negotiators from Hong-Kong and Israel responded to an angry U.S. negotiator (Kopelman \& Rosette, 2008). It is important to note the negotiation case in this study was an ultimatum scenario, so rather than discuss concessionary behaviour over multiple rounds, I can only discuss whether the participants accepted or rejected the proposal.

They found that a negotiator from Hong Kong was less likely to accept a proposal from a U.S. negotiator if anger was expressed than when the U.S. negotiator expressed happiness. For Israeli participants, it did not matter whether the ultimatum was expressed with anger or happiness (Kopelman \& Rosette, 2008).

These results might be explained by differences in cultural norms and values. Happiness may have been more compatible with the cultural values of a Hong Kong negotiator and hence it was beneficial in eliciting cooperation (Kopelman \& Rosette, 2008). In comparison, a display of anger violated their cultural norm and this value clash may have caused the Hong Kong negotiators to feel disrespected, so they reacted competitively. 
Table 2: Summary of findings on social relational factors that moderate the social effect of anger.

\begin{tabular}{|c|c|c|}
\hline Study & Empirical Setting & Key Findings \\
\hline \multicolumn{3}{|c|}{ The moderating influence of culture on the display of anger } \\
\hline $\begin{array}{l}\text { Shenkar \& } \\
\text { Ronen, } 1987\end{array}$ & $\begin{array}{l}\text { A theoretical paper encouraging interdisciplinary } \\
\text { research between cross-cultural psychology and } \\
\text { other fields related to negotiation research. }\end{array}$ & $\begin{array}{l}\text { One of the earliest studies within the paradigm of culture, emotion and } \\
\text { negotiation, this study concluded that Western negotiators should } \\
\text { show emotional restraint when negotiating with Chinese negotiators. }\end{array}$ \\
\hline Salacuse, 1999 & $\begin{array}{l}\text { Surveyed negotiators from } 12 \text { countries; Brazil, } \\
\text { China, Mexico, U.K., U.S., Spain, Argentina, } \\
\text { Germany, Japan, Indonesia, Nigeria and France. }\end{array}$ & $\begin{array}{l}\text { This study proposed an index of emotionalism based on the data. Latin } \\
\text { American and Spanish people were the highest ranked emotional } \\
\text { cultural groups, while Japanese were ranked the least emotional. }\end{array}$ \\
\hline $\begin{array}{l}\text { Triandis, } \\
\text { Carnevale, } \\
\text { Gelfand et al., } \\
2001\end{array}$ & $\begin{array}{l}\text { Scenario study/negotiation regarding the supply of } \\
\text { materials to a company. Students from Hong Kong, } \\
\text { Japan, Korea, Greece, U.S., Australia, Germany and } \\
\text { the Netherlands }(\mathrm{N}=1583) \text { were used. }\end{array}$ & $\begin{array}{l}\text { After the use of deception during a negotiation, collectivist (Hong } \\
\text { Kong, Japan, Korea and Greece) experienced more negative emotions } \\
\text { than individualist (U.S., Australia, Germany and the Netherlands) } \\
\text { cultures. }\end{array}$ \\
\hline $\begin{array}{l}\text { Ulijn, } \\
\text { Rutkowski, } \\
\text { Kumar, \& } \\
\text { Zhu, 2005 }\end{array}$ & $\begin{array}{l}\text { Two groups of Chinese }(\mathrm{N}=62) \text { and Dutch }(\mathrm{N}=42) \\
\text { postgraduate students participated in a simulated } \\
\text { intra-cultural dyadic negotiation, using the data } \\
\text { printer case. }\end{array}$ & $\begin{array}{l}\text { Participants role-played for a certain time before they filled out a } \\
\text { questionnaire about their emotions. The study concluded that culture } \\
\text { carries social values, which in turn influences how individuals from } \\
\text { these different cultures experience emotions. }\end{array}$ \\
\hline $\begin{array}{l}\text { Kopelman \& } \\
\text { Rosette, 2008 }\end{array}$ & $\begin{array}{l}\text { Two studies were conducted using the wedding } \\
\text { catering company scenario. The participants were } \\
104 \text { MBA students from a range of East Asian } \\
\text { nations and Israel, negotiating against a U.S. } \\
\text { counterpart. }\end{array}$ & $\begin{array}{l}\text { They found East Asian negotiators to be more likely to accept an offer } \\
\text { delivered with happiness compared to an offer expressed with anger. } \\
\text { Further, Israeli negotiators were indifferent towards the expressed } \\
\text { emotion. }\end{array}$ \\
\hline
\end{tabular}




\begin{tabular}{|c|c|c|}
\hline Study & Empirical Setting & Key Findings \\
\hline $\begin{array}{l}\text { Oetzel, Garcia, } \\
\& \quad \text { Ting- } \\
\text { Toomey, } 2008\end{array}$ & $\begin{array}{l}\text { Participants completed a survey regarding attitudes } \\
\text { and behaviours of participants after they recalled a } \\
\text { conflict. This study used participants from China, } \\
\text { Germany, Japan and the U.S. }(\mathrm{N}=768) \text {. }\end{array}$ & $\begin{array}{l}\text { Participants were more likely to express emotions when they were less } \\
\text { concerned about another's face or image. Expression of emotion was } \\
\text { not correlated with individualistic or collectivist cultures. }\end{array}$ \\
\hline $\begin{array}{l}\text { Adam et al., } \\
2010\end{array}$ & $\begin{array}{l}\text { Across three studies, } 467 \text { students were used. Study } \\
\text { one used a negotiation case concerning selling } \\
\text { technical equipment. Studies two and three used the } \\
\text { mobile phone consignment case. }\end{array}$ & $\begin{array}{l}\text { Cultural norms affected the perceived appropriateness of the anger. } \\
\text { Anger was likely to backfire when directed at Asian negotiators in } \\
\text { comparison to when it was directed at U.S. negotiators. This affect } \\
\text { disappeared when the anger was considered to be expressed } \\
\text { appropriately. }\end{array}$ \\
\hline $\begin{array}{l}\text { Adam \& } \\
\text { Shirako, } 2013\end{array}$ & $\begin{array}{l}\text { Across four studies there were over } 600 \text { participants. } \\
\text { The majority were U.S. participants. However, the } \\
\text { third experiment used } 143 \text { students of East Asian } \\
\text { ethnicity from nine countries. Different cases were } \\
\text { used. In study one and two, an adapted version of the } \\
\text { project manager negotiation scenario case was used, } \\
\text { in study three, the 'student project' case was used, } \\
\text { and in study four the mobile consignment case was } \\
\text { used. }\end{array}$ & $\begin{array}{l}\text { These authors concluded that the cultural background of the negotiator } \\
\text { expressing the emotion influenced the effect of anger. When East } \\
\text { Asian negotiators openly expressed anger, they broke their } \\
\text { emotionally inexpressive stereotype and a U.S. negotiator was more } \\
\text { likely to concede. This result is relative to an angry European } \\
\text { American negotiator expressing anger. }\end{array}$ \\
\hline \multicolumn{3}{|c|}{ The moderating influence of the authenticity on the display of anger } \\
\hline $\begin{array}{l}\text { Côté et al., } \\
2013\end{array}$ & $\begin{array}{l}\text { Two experiments with } 270 \text { undergraduate students } \\
\text { were conducted with an adapted version of the blue } \\
\text { buggy negotiation exercise (negotiating the price of } \\
\text { a used car). }\end{array}$ & $\begin{array}{l}\text { This study found that deep anger created larger concessions relative to } \\
\text { no emotion. In comparison, surface level anger caused the anger to } \\
\text { backfire. }\end{array}$ \\
\hline $\begin{array}{l}\text { Tng \& Au, } \\
2014\end{array}$ & $\begin{array}{l}\text { Across two studies, } 192 \text { Singaporean undergraduate } \\
\text { students were used with the mobile consignment } \\
\text { case. }\end{array}$ & $\begin{array}{l}\text { This study measured perceived authenticity of the expressed anger and } \\
\text { found that inauthentic anger created competitive behaviour. Perceived } \\
\text { authentic anger created larger concessions. }\end{array}$ \\
\hline
\end{tabular}




\begin{tabular}{|l|l|l|}
\hline Study & Empirical Setting & Key Findings \\
\hline $\begin{array}{l}\text { Sinaceur, Van } \\
\text { Kleef, Neale, } \\
\text { Adam, \& series of computer-mediated negotiation } \\
\text { Haag, 2011 }\end{array}$ & $\begin{array}{l}\text { Anger that included a threat had a greater effect on concessions than } \\
\text { experiments (mobile phone consignment) of Masters } \\
\text { and undergraduate students }(\mathrm{N}=303) .\end{array}$ & $\begin{array}{l}\text { anger without a threat. Threats created a greater perception of poise to } \\
\text { the negotiator expressing emotion compared to anger without a threat. }\end{array}$ \\
\hline \multicolumn{2}{|c|}{ The moderating influence of the direction of anger } \\
\hline $\mathbf{2 0 0 8}$ & $\begin{array}{l}\text { A computer-mediated negotiation experiment } \\
\text { (mobile phone consignment) that used } \\
\text { undergraduate students (N=87). }\end{array}$ & $\begin{array}{l}\text { The impact of anger depended on whether the anger was directed } \\
\text { toward a person or toward their behaviour. Anger expressed at a } \\
\text { behaviour (their offer) was more successful at eliciting concessions, } \\
\text { than anger directed at a person. }\end{array}$ \\
\hline $\begin{array}{l}\text { Lelieveld et al., } \\
\text { 2011 }\end{array}$ & $\begin{array}{l}\text { This study used two experiments, with the second } \\
\text { using the mobile consignment case. Across these two } \\
\text { studies 177 Dutch students were used. }\end{array}$ & $\begin{array}{l}\text { This study looked at the impact of anger being directed at the person } \\
\text { or at the behaviour. When anger was directed at the offer it was found } \\
\text { to be successful at eliciting concessions, however, anger backfired } \\
\text { when it was directed at a person. The opposite effect was found for } \\
\text { expressed disappointment, which was comparatively more effective at } \\
\text { eliciting concessions when it was directed at the person. }\end{array}$ \\
\hline $\begin{array}{l}\text { Filipowicz, } \\
\text { Barsade, } \\
\text { Melwani, 2011 }\end{array}$ & $\begin{array}{l}\text { Across three studies these authors used 493 U.S. } \\
\text { university students. An adapted version of the mobile } \\
\text { phone consignment scenario was used for study one } \\
\text { and two. A face-to-face salary negotiation was used } \\
\text { for the final study. }\end{array}$ & $\begin{array}{l}\text { This study considered the effect of anger when it transitioned from } \\
\text { other emotions such as happiness. Transitioning from happiness to } \\
\text { anger during the negotiation was more effective at eliciting } \\
\text { concessions than staying consistently angry during the negotiation. }\end{array}$ \\
\hline
\end{tabular}




\begin{tabular}{|c|c|c|}
\hline Study & Empirical Setting & Key Findings \\
\hline \multicolumn{3}{|c|}{ How negotiators perceive the negotiation } \\
\hline $\begin{array}{lr}\text { Harinck } & \& \\
\text { Van } & \text { Kleef, } \\
2012 & \end{array}$ & $\begin{array}{l}\text { Two experiments with } 169 \text { Dutch university } \\
\text { students. Two different negotiation scenarios were } \\
\text { used: in study one, an employee was seeking a pay } \\
\text { rise. Study two was a negotiation between a trainee } \\
\text { and a personnel officer. }\end{array}$ & $\begin{array}{l}\text { When the negotiation was interest based, anger elicited greater } \\
\text { concessions relative to neutral emotion, but not when the negotiation } \\
\text { was value-based. }\end{array}$ \\
\hline $\begin{array}{l}\text { Dehghani, } \\
\text { Carnevale, \& } \\
\text { Gratch, } 2014\end{array}$ & $\begin{array}{l}\text { This paper used } 404 \text { U.S. participants using } \\
\text { hypothetical scenarios. }\end{array}$ & $\begin{array}{l}\text { This study compared the social effects of anger with the effects of } \\
\text { sadness. These authors found that when the negotiated resource had } \\
\text { moral significance, expressing anger was less successful at eliciting } \\
\text { concessions than expressing sadness. They suggested that if the } \\
\text { negotiated item had sacred value, anger was comparatively less } \\
\text { successful compared to sadness. Depending on the perceived moral } \\
\text { value, the effect of the above emotions differed. }\end{array}$ \\
\hline $\begin{array}{l}\text { Adam \& Brett, } \\
2015\end{array}$ & $\begin{array}{l}\text { Across two experiments, these authors used } 483 \text { U.S. } \\
\text { participants and the project manager negotiation } \\
\text { scenario for the first study, and the "at your service" } \\
\text { case in the second experiment. }\end{array}$ & $\begin{array}{l}\text { The authors concluded that expressing anger was less effective if the } \\
\text { negotiation was cooperative or competitive compared to balanced } \\
\text { negotiations. These authors concluded that their studies help } \\
\text { negotiators to know when it may be best to supress anger, e.g., if their } \\
\text { counterpart considers the negotiation cooperative or competitive. }\end{array}$ \\
\hline
\end{tabular}


EASI theory would explain these findings via the emotional reaction path (Van Kleef, 2008, 2009). When the cultural values of the negotiator were broken, they reacted emotionally (and became competitive) rather than strategically. The behaviour of these Hong Kong and Israeli negotiators can be supported with existing cultural value theory: neutrality vs. affectivity, which categorises and ranks countries as being affective or neutral (Trompenaars \& Hampden-Turner, 1998). Cultures high in affectivity are more likely to express their feelings openly, e.g., by gesturing, smiling or even scowling. In neutral cultures, feelings and emotions are expressed in a more subdued manner (Trompenaars \& Hampden-Turner, 2012). It is important to note, that China is among the countries where it is least acceptable to exhibit emotion openly, which suggests that anger in the Kopelman and Rosette (2008) study was probably against the cultural values of Hong Kong negotiators. In contrast, Israel is ranked in the upper part of the affective spectrum and therefore their indifference to the expressed anger in this situation, accords with cultural value theory.

The influence of cultural values was supported in a later study where the appropriateness of the anger was manipulated by Adam and colleagues (2010). That is, when anger was manipulated to be seen as appropriate, it was considered as not breaking cultural norms and there was no difference in concessionary behaviour between Asian and U.S. negotiators. However, when anger was expressed and there was no manipulation to make it appropriate, the Asian negotiators reacted competitively relative to U.S. negotiators. In summary, it can be concluded that cultural norms can explain why negotiators from different cultures react to anger differently.

In light of these results, it is important that researchers consider the influence of the cultural values of the country of origin of the negotiators on how displays of anger are viewed. Researchers need to consider both the acceptability of emotional displays for the negotiator on the receiving end, and the probable stereotypes that negotiator holds of the counterpart who displayed the anger.

For example, from a New Zealand negotiator's perspective, the Spanish are often stereotyped as being emotionally expressive, whereas a New Zealand negotiator is likely to expect more reserved behaviour from a Chinese counterpart. This expectation is important to consider, as breaking these cultural stereotypes has important implications for the social effect of anger.

This idea has been illustrated with U.S. negotiators' stereotypes of East Asian negotiators. American negotiators who were found to stereotype East Asian negotiators as being 
emotionally inexpressive were more likely to concede to them when they expressed anger than when a European American negotiator expressed anger (Adam \& Shirako, 2013). Asian negotiators who broke their cultural stereotype were considered more threatening and tougher than an angry U.S. negotiator (Adam \& Shirako, 2013). The negotiators did not concede more when they did not hold the emotionally inexpressive stereotype about the East Asians. This study reiterates the importance of considering how cultural values influence perceptions of displays of anger.

Studying the influence of anger in an international negotiation context relies on two assumptions. Firstly, it is necessary to assume that anger is universally recognised and uniformly expressed. That is, anger displayed by a foreign counterpart will be recognised as anger. Going back to the EASI model and the assertion that anger is social information, the second assumption is that the negotiator who is on the receiving end of anger from a foreign counterpart will read that anger as meaning the same thing as a display of anger from a counterpart who is from the same culture as the receiving negotiator.

Theoretically, adopting both of these assumptions involves taking a universal approach to emotions. This approach is consistent with the Darwinian view that holds that emotions have evolved as a survival function, and therefore emotions are expressed and recognised uniformly across cultures (Cornelius, 2000). This thesis too adopts a universal approach to studying anger. Much of the literature reviewed in this thesis compares anger with happiness: both these emotions have been established as universal in seminal work by Ekman and Friesen (1971). In their study, a series of emotions including anger was shown to an 'untouched' tribe in Papua New Guinea. This tribe could consistently correctly label six primary emotions including anger.

It is worth acknowledging the alternative viewpoint. The relativist perspective says that information carried by emotion varies across cultures (Berry, Poortinga, Breugelmans, Chasiotis, \& Sam, 2011). That is, although anger may be correctly recognised, different information is expressed by the emotion. Using a relativist perspective, it is possible to argue that in Kopelman \& Rosette's study, the Hong Kong negotiators may have interpreted a different meaning from the display of anger than the Israeli negotiators.

Based on the subsequent studies that demonstrated the link between the perceived appropriateness of the anger and breaking cultural norms, I have chosen to adopt a universal approach to studying anger in this thesis. It is beyond the scope of this thesis to describe in 
detail the different theoretical approaches to studying emotions, however these are briefly described in Appendix A.

\subsubsection{Authenticity}

Having established the important role of cultural norms on the social effect of anger, the following section focuses on the moderating role of authenticity.

Intuitively, one would expect a negotiator to react differently to anger if they suspected the anger was feigned rather than genuine. In the literature, this result is referred to as the moderating effect of authenticity. Authenticity is the perceived genuineness of a negotiator's expression of emotion.

When anger is considered genuine, a negotiator will react cooperatively, or strategically, to the anger compared to neutral emotion (Côté et al., 2013; Tng \& Au, 2014). In contrast, a negotiator will react competitively or emotionally to inauthentic anger compared to neutral emotion. Reacting competitively to perceived feigned anger can be explained by a lack of trust (Côté et al., 2013) as fake anger reduces levels of trust and so a negotiator reacts emotionally. However, it has been argued genuine anger elicits concessions as the expresser of the anger is perceived as being tougher (Côté et al., 2013).

The importance of the authenticity of the display of anger is important in designing studies of anger and comparing the results. In the Kopelman (2006) study, anger was expressed via a video recording. Arguably, a video recording of anger may not be perceived as authentic if the actors did not voluntarily enact the required facial muscles to express a genuine emotion (Ekman, Roper, \& Hager, 1980). In Van Kleef's (2004a) seminal study, anger was displayed using electronic text and this approach was less likely to be perceived as inauthentic.

\subsubsection{Direction of the anger}

Because the social effect of anger is complex, researchers have considered a number of other social relational factors in addition to perceived authenticity. The first of these is the direction of the anger.

When anger is directed at a negotiator's behaviour, it is more successful at eliciting concessions compared to when anger is directed at the negotiator (Lelieveld et al., 2011;

Steinel et al., 2008). This is because anger directed at a behaviour carries more information 
about a negotiator's situation relative to anger directed at a person (Steinel et al., 2008). That is, anger directed towards behaviour raises the observer's estimates of the angry negotiator's limits and leads them to react strategically by becoming cooperative. In comparison, anger directed at a person does not carry such information and consequently does not affect the appraisals of the counterpart's limits (Steinel et al., 2008). Negotiators who were faced with anger directed at them personally were likely to respond with an emotional reaction.

It is interesting to note that when disappointment is expressed in the person instead of in the anger, it is successful at eliciting cooperation. This change is because disappointment creates a feeling of guilt and causes a negotiator to concede (Lelieveld et al., 2011).

A similar emotional response can be expected when the purpose of a negotiation is contrary to the values of the negotiator. When a negotiator believes an issue is contrary to what they think is important in life, they respond competitively (Harinck \& Van Kleef, 2012). A negotiator will also reciprocate displays of anger if the negotiation breaks their values because they feel morally justified in doing so (Harinck \& Van Kleef, 2012). For example, negotiating time off work for a holiday is considered interest based, however when the time off is to support a sick family member it is considered value based. When a negotiator faced anger during an interest based negotiation, they conceded; that is, they reacted strategically.

This interest based versus value based difference may in part explain why the seminal studies of Van Kleef et al. (2004a) and Kopelman et al. (2006) had differing results. The negotiation in Kopelman's study was a scenario concerning arrangements for a wedding, and this issue may have been perceived as value based. However, Van Kleef's issue concerned a cell phone shipment and was more likely to be perceived as interest based.

The final social relational factor I consider is the individual difference of pro-social and proself-orientation. A pro-self negotiator is one who aims for maximum outcomes for themselves, compared to a pro-social oriented negotiator who aims for maximum joint outcomes (Van Kleef \& De Dreu, 2010). Initially, a pro-social negotiator responds to anger in a similar way to a pro-self negotiator, however a difference occurs if an apology is received. A pro-social negotiator becomes more cooperative compared to a pro-self negotiator after an apology (Van Kleef \& De Dreu, 2010). Although this study focuses on more than an expression of anger in a negotiation, this finding is still important because it highlights the role of personality differences in negotiations. 
In summary, there is a range of social relational factors and observer's information processing moderators that inform our understanding of the social effect of anger during international negotiations. The findings are diverse and at times hard to aggregate, however it is evident that both power and culture are particularly salient in influencing the effect of anger. Although EASI theory is helpful for categorising the many variables that may influence the impact of the anger, it does little to explain the effect of individual differences negotiators may have. In the following section, I review the relevant literature on individual differences in negotiations.

\subsection{Introducing individual differences}

Exploring the influence of individual differences in negotiation has experienced a resurgence the past few years. In the decades up to the 1990s, it was largely accepted that individual differences were helpful in understanding negotiation processes and outcomes (Barry \& Friedman, 1998). However, the consensus turned and individual differences became less popular as a topic in negotiation research. Influential scholars in the field argued individual differences played only a minimal role (e.g., Thompson, 1990). Others challenged the link between personality and negotiation performance (e.g., Lewicki, Litterer, Minton, \& Saunders, 1994). The emergence of this new research led to a growing consensus that individual differences play a limited role in predicting negotiation behaviour and outcomes. Only recently has this consensus been challenged (e.g., Elfenbein, 2013; 2015; Sharma, Bottom, \& Elfenbein, 2013). These studies advocate the importance of individual differences and suggest that future work explore their impact in negotiation.

Negotiation researchers developed some 'personality differences' to help explain and measure a person's behaviour in conflict situations. The most renowned of these is the Thomas-Kilmann Conflict Mode Instrument (TKI) (Thomas \& Kilmann, 1974) with five individual traits: competing, accommodating, avoiding, collaborating and compromising. These are based on the two separate dimensions of cooperation and assertiveness (Kilmann \& Thomas, 1977). For example, the mode competing has a high concern for self (Shell, 2001) and is high on assertiveness, but low on cooperativeness (Kilmann \& Thomas, 1977). An accommodating mode is low on assertiveness, but high on cooperativeness, whereas the avoiding mode is low on both dimensions (Zhang, Ting-Toomey, \& Oetzel, 2014). In comparison, collaborating is high in both assertiveness and cooperativeness, while compromising is naturally a balance between assertiveness and cooperativeness (Kilmann \& 
Thomas, 1977). The TKI model is not an innate measure of an individual's capability, but rather a measure of one's predisposition towards one or more of these conflict-handling modes (Shell, 2001).

Individual differences have received some, albeit limited, attention in the literature on the social effect on anger. For example, as mentioned earlier, the individual difference of epistemic motivation has been investigated by Van Kleef et al., (2004b). Although not a distinct personality trait, differences in need for closure were shown to influence negotiation behaviour. Also discussed above, pro-self and pro-social negotiators behaved differently post negotiation, however they varied little in their reaction to displays of emotion (Van Kleef \& De Dreu, 2010). The configuration of personalities has also been shown to change the social effect of emotion during dyadic negotiations (Wilson, DeRue, Matta, Howe, \& Conlon, 2016). When personalities were similar, positive emotion displays led to less conflict and shorter negotiations compared to when the personality configurations were dissimilar.

These studies confirm that individual differences can help us understand the social effect of emotion. However, the role individual differences play in the social effect of anger remains unclear and much more research is needed to better understand the role they play.

Individual differences have also received limited attention in the economic psychology literature. For example, studies found that manipulated self-regulation strategies helped participants overcome the detrimental social effects of anger (Jäger et al., 2017). Similar findings have been shown in the field in response to the intrapersonal effect of anger (Fabiansson \& Denson, 2012). Although neither study measured an innate individual difference, they demonstrated the beneficial effect of self-regulation during negotiations.

As an aside, it is worth noting that it is difficult to accommodate the influence of individual differences under either of the moderating categories within EASI theory. The observer's information processing category of moderators captures the motivation of a negotiator to interpret the information implicit in expressed anger, rather than the actual capability of a negotiator. The social relational factors, on the other hand, are concerned with the relationship between the two parties. Neither classification is useful in explaining how inherent differences in ability may influence behaviour in response to anger. Thus, it can be argued that EASI theory assumes that negotiators feel and react to emotion uniformly.

It is an underlying intention of this thesis that EASI theory be extended by studying how individual differences in negotiators' capabilities influence their response to an angry 
counterpart. This capability to respond to emotion is a negotiator's self-regulation ability. The term 'regulation of emotion' refers to the intrinsic and extrinsic processes that an individual uses to suppress or intensify the way they experience and express emotion (Gross, 2008;

Gross \& Thompson, 2007). In other words, it is the ability to respond moment-by-moment to control one's feelings and behaviour (Cole, Michel, \& O’Donnell Teti, 1994; Niven, Totterdell, \& Holman, 2009). Being able to self-regulate is an inherent ability that can be considered a personality trait. The following section provides the theoretical framework for viewing self-regulation as an intrinsic personality difference.

\subsubsection{Theoretical framework of self-regulation}

There are two theories that explain how individuals manage their thoughts and emotions: the Personality Systems Interactions (PSI) theory and the limited strength model. In this section, I explain how Kuhl's (2000) PSI theory provides a way of measuring different people's inherent capability to self-regulate.

The alternative way of considering differences in individuals' self-regulation is the limited strength model (see Muraven \& Baumeister, 2000) which says that such differences are due to capacity differences. In the context of an international negotiation, this theory would argue that a negotiator has a finite supply of resources to respond to a display of emotion and each "expenditure" of self-regulation will deplete the negotiator's limited resources. Differences in behaviour would reflect differences in negotiators' capacities. A serious weakness of the limited strength model approach is that self-regulation capacity is controlled by one cognitive system or a single subset of control processes (Muraven \& Baumeister, 2000). That is, the term self-regulation refers to a single measurement of capacity (Cervone, Shadel, Smith, \& Fiori, 2006).

The attractiveness of Kuhl's (2000) PSI theory is that it says that self-regulation is a process that involves interactions between both cognitive and affective systems (Kuhl et al., 2006). That is, individuals differ in their ability to self-regulate due to impairments or proficiencies of these psychological functions (Kuhl et al., 2006). These differences in self-regulation are created by the differences in people's ability to trigger and use one of their four cognitive systems, for example their intention memory (Kuhl, 2000). In Figure 3 below, I depict the key mechanisms of PSI theory and show the four cognitive systems that underpin selfregulation: extension memory, intention memory, intuitive behaviour control and object 
recognition. I will briefly explain the interactions between these systems that influence behaviour.

\section{Figure 3: A simplified version of PSI theory}

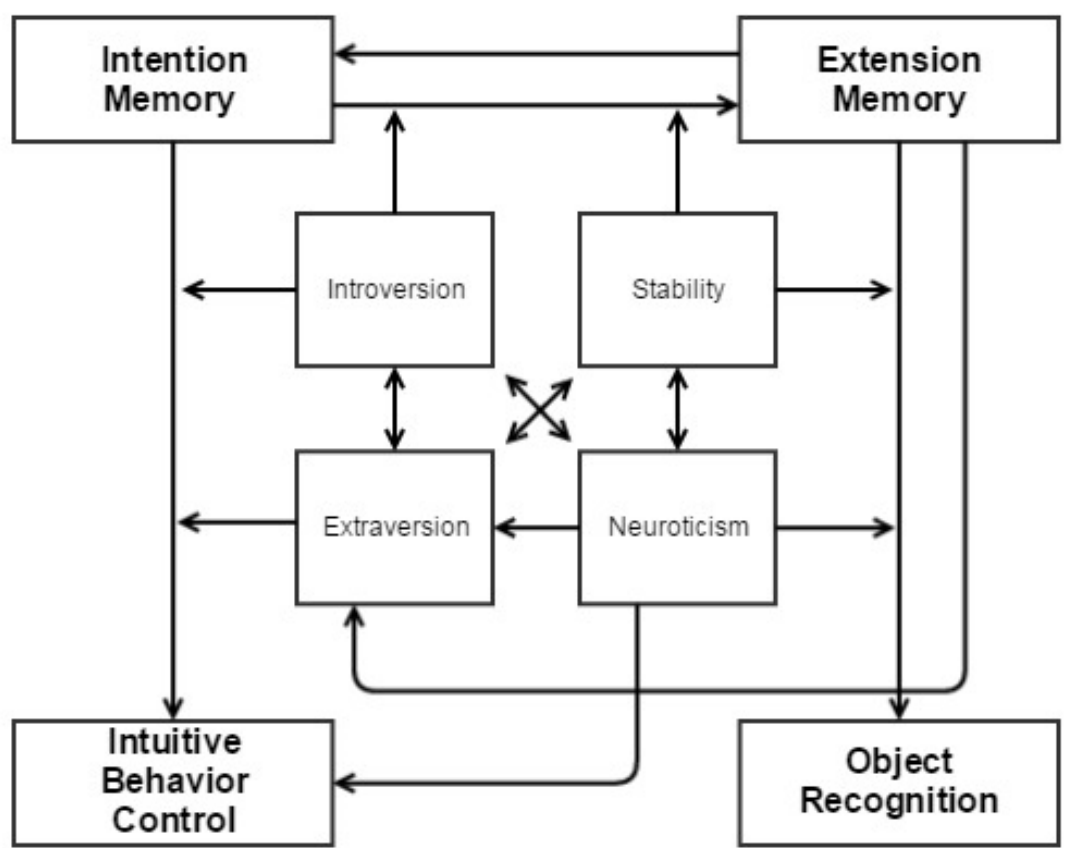

Source: Modified from Kuhl (2000).

The extension memory system represents the wants of a person, their database of preferred outcomes, behaviour, thoughts and emotions. When a person uses their extension memory, the decisions that are triggered are close to their core values. When a person is in a demanding situation (such as facing an opponent in a negotiation), their extension memory may be inhibited (Kazén, Baumann, \& Kuhl, 2003). This would then activate the object recognition system. Object recognition occurs when an individual is subject to unwanted or unexpected emotions, thoughts and needs, and can be understood as the loss of concentration (Kuhl, 2000).

The intention memory system is the analytical system that relies on logic and it is often triggered when an intended plan does not work. Such circumstances lead to triggering the intuitive behaviour control system, which leads to an individual implementing their intentions into behaviour. When that process occurs, behaviour and decisions are not as close 
to the core values of the individual compared to when they trigger their extension memory (Kazén et al., 2003).

In addition to these four key systems, I have included four personality dispositions, namely introversion, stability, extraversion and neuroticism. In his PSI theory, Kuhl (2000) has suggested that these personality constructs also influence the sensitivity one has for emotion (Kuhl, 2000).

PSI theory suggests that some individuals are able to trigger their extension memory more effectively than other people and they initiate self-regulatory strategies, which means they are less affected by displays of anger. Individuals who do not have good self-regulation capability, make decisions with less influence from their extension memory. In the context of this thesis, an international negotiation, depending on a negotiator's self-regulation proficiency, they will trigger these different cognitive systems when they are making decisions. Individuals who are able to initiate self-regulatory strategies are said to be actionoriented (Kuhl, 1994a). Those without this proficiency are said to have be state-oriented.

\subsubsection{Measuring self-regulation: Action orientation and State orientation}

Action orientation and state orientation are the labels of the personality trait that describes an individual's ability to self-regulate in a demanding situation such as an international negotiation. Individuals who are action-oriented have the capability to initiate a 'control strategy' (a mode of will power) that enables conscious choice and stimulates flexible selfregulation (Koole \& Fockenberg, 2011; Kuhl \& Goschke, 1994). Conversely, state-oriented individuals struggle to self-regulate in demanding situations like negotiations (Koole, Jostmann, \& Baumann, 2012). It is important to acknowledge that action orientation vs. state orientation measures distinct, personal-level characteristics that are not represented in other constructs, (Diefendorff, Hall, Lord, \& Strean, 2000). Like other personality traits, action orientation and state orientation are relatively stable over time (Koole \& Fockenberg, 2011; Kuhl, 1994a) and there is approximately an even 50-50 split across a given population (Koole, Kuhl, Jostmann, \& Vohs, 2005).

Investigating the influence of action orientation and state orientation is important for negotiation research, as it can advance understanding of how personality influences negotiation behaviour and outcomes. This personality measure could also be helpful in 
extending EASI theory by adding the influence of a negotiator's individual capability to social relational factors and information processing moderators.

Although the impact of self-regulation has not been investigated in a negotiation context, it has been widely studied in a range of other contexts and I provide an overview of these in the following paragraphs.

Extant literature across several domains has established that the personality trait of action orientation versus state orientation influences behaviour. These domains include social psychology (e.g., Allemand et al., 2008; Van Putten, 2015) educational psychology (e.g., Bossong, 1994; Brunstein, 1994), consumer research (e.g., Bagozzi, Baumgartner, \& Yi, 1992), decision making (e.g., Stiensmeier-Pelster, 1994; Van Putten et al., 2010), sport science (e.g., Strang, 1994), and work place performance (Diefendorff et al., 2000). An overview of these studies is provided in Table 3 .

Taken together, these studies demonstrate that action orientation versus state orientation is an individual difference that influences thinking, behaviour, decision making and consequently performance in a range of settings. State-oriented individuals have a high level of preoccupation and they dwell on past negative emotion, which weakens the likelihood that their intentions will become their behaviour. In comparison, action-oriented individuals have an ability to self-regulate and, consequently, they make decisions closer to their core objectives. Self-regulating emotion helps them become more task-focused, with an ability to perform better in stressful situations.

As presented in the table, some of the earliest work examined the behavioural differences between action-oriented and state-oriented athletes. Their orientation was found to have an important influence on performance both at a physical level (Strang, Wegener, \& Schwarze, 1987) and at a cognitive (decision-making) level (Roth, 1993). Semi-professional basketball players who were state-oriented produced weaker playing performance as they were hesitant and more easily disturbed, compared with action-oriented players (Heckhausen \& Strang, 1988). Overall, action-oriented athletes were found to be comparatively better and quicker at decision-making under stress (Strang, 1994). Although these examples focused on athletes, these studies collectively provide empirical support for differences in behaviour between action orientation and state orientation in stressful situations. 
Table 3: Examples of action versus state orientation influencing behaviour

\begin{tabular}{|c|c|c|}
\hline Study & Empirical Setting & Key Findings \\
\hline & & Sport Science \\
\hline Strang, 1986 & $\begin{array}{l}\text { Experiment with } 37 \text { high- } \\
\text { performance tennis players } \\
\text { (unpublished thesis). }\end{array}$ & $\begin{array}{l}\text { The author primed the athletes with success or failure. He found that action-oriented } \\
\text { athletes were more adept at changing their performance after failure, compared to those } \\
\text { who were state-oriented. Performance involved hitting the tennis ball into a specific } \\
\text { target. }\end{array}$ \\
\hline Strang et al., 1987 & $\begin{array}{l}\text { Experiment with } 110 \text { sport } \\
\text { students. }\end{array}$ & $\begin{array}{l}\text { This study found that state-oriented students preformed comparatively worse at motor } \\
\text { performance after failure compared to action-oriented students. The authors explained } \\
\text { that state-oriented students have more task-irrelevant thoughts. }\end{array}$ \\
\hline $\begin{array}{l}\text { Heckhausen \& } \\
\text { Strang, } 1988\end{array}$ & $\begin{array}{l}\text { Experiment with } 26 \text { semi- } \\
\text { professional basketball players. }\end{array}$ & $\begin{array}{l}\text { These authors found that action-oriented athletes achieved better results in stressful } \\
\text { situations. In comparison, state-oriented athletes were prone to being disturbed and } \\
\text { were hesitant. The context involved a playing situation that included dribbling and } \\
\text { shooting. }\end{array}$ \\
\hline Roth, 1993 & $\begin{array}{l}\text { Two experimental studies, } \\
\text { using } 30 \text { experienced soccer } \\
\text { players and } 30 \text { sports students. }\end{array}$ & $\begin{array}{l}\text { This study explored the speed and quality of the tactical decision-making of athletes. } \\
\text { When the athletes were asked to focus on quality, state-oriented athletes took longer, } \\
\text { but did not perform better relative to action-oriented participants. When they were in a } \\
\text { low stress situation (rest condition), they still took longer but they made relatively } \\
\text { better decisions. }\end{array}$ \\
\hline \multicolumn{3}{|r|}{ Educational Psychology } \\
\hline $\begin{array}{l}\text { Bossong \& von } \\
\text { Saldern, } 1984\end{array}$ & $\begin{array}{l}\text { Survey of } 128 \text { high school } \\
\text { students (average age: } 15 \text { ). }\end{array}$ & $\begin{array}{l}\text { This study found that state-oriented high school students had comparatively higher } \\
\text { levels of both worry and emotionality, because they were preoccupied with the idea of } \\
\text { failure. }\end{array}$ \\
\hline
\end{tabular}




\begin{tabular}{|l|l|l|}
\hline Study & Empirical Setting & Key Findings \\
\hline $\begin{array}{l}\text { Brunstein \& } \\
\text { Olbrich, 1985 }\end{array}$ & $\begin{array}{l}\text { 35 undergraduate students - } \\
\text { experimental design. }\end{array}$ & $\begin{array}{l}\text { These authors found that, after a manipulation of failure, state-oriented students } \\
\text { performed worse in discrimination tasks relative to action-oriented students. }\end{array}$ \\
\hline Brunstein, 1989 & $\begin{array}{l}90 \text { students - experimental } \\
\text { design. }\end{array}$ & $\begin{array}{l}\text { The authors manipulated an academic failure situation and action-oriented students } \\
\text { either maintained or improved their performance level with discrimination tasks. In } \\
\text { comparison, state-oriented students demonstrated a decline in performance. }\end{array}$ \\
\hline $\begin{array}{l}\text { Stiensmeier-Pelster } \\
\text { John \& Stulik, 1989 }\end{array}$ & $\begin{array}{l}\text { An experimental study that used } \\
\text { 142 German psychology } \\
\text { students. } \\
\text { experiment involving various } \\
\text { dice games. }\end{array}$ & $\begin{array}{l}\text { This study concluded that action-oriented individuals had less fear of making incorrect } \\
\text { decisions than state-oriented individuals. Under time pressure conditions, action- } \\
\text { oriented people performed better than state-oriented people because of their natural } \\
\text { tendency to make expectancy decisions quickly with comparatively less fear of making } \\
\text { an incorrect decision. }\end{array}$ \\
\hline $\begin{array}{l}\text { Allemand et al., } \\
2008\end{array}$ & $\begin{array}{l}\text { Survey of 210 undergraduate } \\
\text { students in Switzerland. }\end{array}$ & $\begin{array}{l}\text { This study found that action-oriented individuals had a greater tendency to forgive } \\
\text { compared to state-oriented students. These authors argued that action oriented people } \\
\text { were able to down play negative emotion and ruminate less, and therefore had a greater } \\
\text { tendency to forgive. }\end{array}$ \\
\hline $\begin{array}{l}\text { Van Putten et al., } \\
2010\end{array}$ & $\begin{array}{l}\text { Laboratory-based study with 75 } \\
\text { Dutch students. }\end{array}$ & $\begin{array}{l}\text { This study focused on economic decision making and found that state oriented } \\
\text { individuals were less inclined to let go of past events and thus more susceptible to the } \\
\text { sunken cost fallacy than action oriented individuals. That is, their decisions were less } \\
\text { rational and comparatively more influenced by past emotional events than action- } \\
\text { oriented individuals' decisions. }\end{array}$ \\
\hline
\end{tabular}




\begin{tabular}{|c|c|c|}
\hline Study & Empirical Setting & Key Findings \\
\hline \multicolumn{3}{|r|}{ Psychology } \\
\hline Fuhrer, 1994 & 22 university students. & $\begin{array}{l}\text { This study observed behaviour in social situations. They found that action-oriented } \\
\text { individuals adapted better and interacted with others in social situations more than } \\
\text { state-oriented individuals. This study compared crowded and low-density situations. }\end{array}$ \\
\hline Kuhl \& Weiß, 1994 & $\begin{array}{l}100 \text { university students }- \\
\text { experimental design. }\end{array}$ & $\begin{array}{l}\text { The authors found that when state-oriented participants experienced failure (which was } \\
\text { out of their control), their performance was reduced, relative to action-oriented } \\
\text { individuals where performance was not negatively affected. Performance was } \\
\text { measured with anagram problems. }\end{array}$ \\
\hline Palfai, 2002 & \begin{tabular}{lrr} 
Questionnaire & \multicolumn{2}{r}{ concerning } \\
personality and & health \\
behaviour using 218 & female \\
undergraduate students.
\end{tabular} & $\begin{array}{l}\text { Overall, state-oriented individuals were not as efficient at regulating their eating } \\
\text { compared to action-oriented students. Action-oriented individuals had the ability to } \\
\text { change their eating behaviour, as they were influenced less by the external cues that } \\
\text { cause excessive eating. }\end{array}$ \\
\hline $\begin{array}{l}\text { Koole \& Jostmann, } \\
2004\end{array}$ & $\begin{array}{l}\text { A series of laboratory studies } \\
\text { comprising of } 213 \text { Dutch } \\
\text { university students. }\end{array}$ & $\begin{array}{l}\text { These authors found that action-oriented students were able to regulate negative } \\
\text { emotion to help achieve their goals better than state-oriented students. For example, in } \\
\text { a demanding situation, action-oriented students were significantly better at detecting } \\
\text { happy faces in an angry crowd than state-oriented students. }\end{array}$ \\
\hline $\begin{array}{l}\text { Jostmann, Koole, } \\
\text { van der Wulp, \& } \\
\text { Fockenberg, } 2005\end{array}$ & $\begin{array}{l}\text { Laboratory study with } 92 \text { Dutch } \\
\text { undergraduate students. }\end{array}$ & $\begin{array}{l}\text { The authors researched the subconscious contagion effect of emotion and found that } \\
\text { state-oriented students were comparatively more affected by facial expressions than } \\
\text { action-oriented students. After being confronted, state-oriented students felt stronger } \\
\text { levels of emotion than action-oriented students. The authors concluded that action } \\
\text { oriented individuals are able to 'shield themselves' against a basic emotional } \\
\text { contagion. }\end{array}$ \\
\hline
\end{tabular}




\begin{tabular}{|c|c|c|}
\hline Study & Empirical Setting & Key Findings \\
\hline $\begin{array}{l}\text { Jostmann \& Koole, } \\
2006\end{array}$ & $\begin{array}{l}\text { Two laboratory experiments } \\
\text { with } 200 \text { Dutch university } \\
\text { students. }\end{array}$ & $\begin{array}{l}\text { Action-oriented students had a better memory when visualizing a demanding person } \\
\text { than when visualizing an accepting person. In contrast, state-oriented students were } \\
\text { more efficient with their working memory compared to action-oriented students when } \\
\text { facing an accepting person. Furthermore, state-oriented students had a better memory } \\
\text { when visualizing an accepting person compared to a demanding person. }\end{array}$ \\
\hline $\begin{array}{l}\text { Song, Wanberg, } \\
\text { Niu \& Xie, } 2006\end{array}$ & $\begin{array}{l}\text { Three waves of surveys } \\
\text { administered over eight months, } \\
\text { using } 328 \text { unemployed Chinese } \\
\text { jobseekers. }\end{array}$ & $\begin{array}{l}\text { This study suggested action oriented individuals have a greater ability to channel } \\
\text { intention into action than state oriented individuals. State oriented individuals still had } \\
\text { the intention to seek employment, but were less likely to transform this intention into } \\
\text { behaviour. }\end{array}$ \\
\hline $\begin{array}{l}\text { IJzerman \& Van } \\
\text { Prooijen, } 2008\end{array}$ & $\begin{array}{l}\text { Experimental design presented } \\
\text { as four unrelated studies, using } \\
49 \text { Dutch students. }\end{array}$ & $\begin{array}{l}\text { This study examined the just-world phenomenon. A state-oriented individual is more } \\
\text { likely to believe the world is fair, and that one gets what one deserves than action- } \\
\text { oriented individuals. The authors suggest that state-oriented citizens are more likely } \\
\text { than action-oriented individuals to support radical politicians after horrendous acts. }\end{array}$ \\
\hline $\begin{array}{l}\text { Koole \& } \\
\text { Fockenberg, } 2011\end{array}$ & $\begin{array}{l}\text { Three laboratory studies using } \\
160 \text { Dutch participants }\end{array}$ & $\begin{array}{l}\text { This study looked at how action versus state orientation regulated implicit emotion in } \\
\text { a demanding condition. The authors found that action-oriented participants were less } \\
\text { affected by negative emotion under demanding circumstances than state-oriented } \\
\text { participants. }\end{array}$ \\
\hline $\begin{array}{l}\text { Chatterjee, } \\
\text { Baumann \& } \\
\text { Osborne, } 2013\end{array}$ & $\begin{array}{l}\text { Experimental design with } 151 \\
\text { U.S. and } 152 \text { German } \\
\text { undergraduate students }\end{array}$ & $\begin{array}{l}\text { This study researched how to mitigate the effect of state orientation in demanding } \\
\text { conditions. The authors found that higher social relatedness increased the self- } \\
\text { regulation ability of state oriented students in a negative mood. }\end{array}$ \\
\hline Van Putten, 2015 & $\begin{array}{l}\text { Laboratory design involving } \\
\text { three studies and } 259 \text { students. }\end{array}$ & $\begin{array}{l}\text { This study looked at the effect of brooding on past emotion. This effect was } \\
\text { particularly important for state-oriented negotiators, as they ruminate about past } \\
\text { negative events comparatively longer. State oriented negotiators felt both negative and } \\
\text { positive emotion longer, compared to action-oriented negotiators. The authors point } \\
\text { out the potential benefits of feeling positive emotion longer. }\end{array}$ \\
\hline
\end{tabular}




\begin{tabular}{|l|l|l|}
\hline Study & Empirical Setting & Key Findings \\
\hline $\begin{array}{l}\text { Fischer, Plessow, } \\
\text { Dreisbach, \& } \\
\text { Goschke, 2015 }\end{array}$ & $\begin{array}{l}\text { Experimental design, using } \\
\text { German students (N =62) }\end{array}$ & $\begin{array}{l}\text { These authors, using only extreme scores of either action or state orientation, found } \\
\text { that individuals who were state oriented exhibited a less proficient use of cognitive } \\
\text { strategies in a response interference task than action-oriented individuals. }\end{array}$ \\
\hline $\begin{array}{l}\text { Wiedemann et al., } \\
1994\end{array}$ & $\begin{array}{l}\text { A survey-based study of 138 } \\
\text { males who showed clinical } \\
\text { hypertension. }\end{array}$ & $\begin{array}{l}\text { This study found differences in how action and state-oriented individuals dealt with } \\
\text { stress. Among other things, state-oriented individuals were found to use fewer positive } \\
\text { appraisal strategies than action-oriented individuals. The authors conclude that state- } \\
\text { oriented individuals have lower social competence relative to action oriented- } \\
\text { individuals. }\end{array}$ \\
\hline $\begin{array}{l}\text { Blunt \& Pychyl, } \\
2005\end{array}$ & $\begin{array}{l}\text { A psychotherapeutic case study } \\
\text { on a 34-year-old male }\end{array}$ & $\begin{array}{l}\text { These authors showed it was possible to change an individual's orientation with } \\
\text { intervention. After a fifteen-month period involving a stage of motivational } \\
\text { counselling, this individual managed to change his state orientation into more action } \\
\text { orientation. }\end{array}$ \\
\hline Bagozzi et al., 1992 & $\begin{array}{l}\text { Two surveys regarding future } \\
\text { intentions, personality and past } \\
\text { behaviour. 149 female staff of a } \\
\text { major university. }\end{array}$ & $\begin{array}{l}\text { (Consumer research) The difference between intention and action is also evident } \\
\text { within the field of marketing; action orientation moderates the intention of coupon } \\
\text { usage for grocery shopping. Action versus state orientation impacts the importance of } \\
\text { attitudinal weighting towards the intention of coupon usage. }\end{array}$ \\
\hline $\begin{array}{l}\text { Diefendorff et al., } \\
2000\end{array}$ & $\begin{array}{l}\text { Survey design with a } \\
\text { questionnaire also going to the } \\
\text { participant's supervisor (N } \\
\text { 247). 6 studies with university } \\
\text { students (N = 945). }\end{array}$ & $\begin{array}{l}\text { (Workplace performance) Action-oriented individuals received higher overall job } \\
\text { performance evaluations from their supervisors, relative to their state-oriented } \\
\text { counterparts. The authors concluded that the scale was useful for understanding work- } \\
\text { related issues. }\end{array}$ \\
\hline
\end{tabular}


Further evidence can be found in the educational psychology literature as shown in the next section of the table. Naturally, a lot of this literature was based on students and involved a range of experimental contexts using tools such as discrimination tasks. Discrimination tasks test cognitive performance by asking participants to discern differences and similarities between objects. This method was one of the earliest used to evaluate the performance of action-oriented and state-oriented students.

For example, when students were primed to feel failure, action-oriented students performed comparatively better in discrimination tasks than state-oriented students (Brunstein \& Olbrich, 1985). Similarly, action-oriented students also maintained or increased their performance in discrimination tasks after academic failure. In comparison, state-oriented students had a lower level of performance after such a failure (Brunstein, 1989). Similarly, action-oriented students also maintained or increased their performance in discrimination tasks after academic failure. In comparison, state-oriented students had a lower level of performance after such a failure (Brunstein, 1989). These findings demonstrate how individual differences in self-regulation influenced the students' responses after failure. It is interesting to consider how these findings in a student population may play out in an international negotiation. International negotiations often involve numerous meetings, and offers can be rejected during these meetings. The responses to such rejections could be informed by the students' responses to failure in this study. The study would suggest that action-oriented negotiators will cope better than state-oriented negotiators when they encounter rejections during international negotiations.

The next section in Table 3 shows differences in decision making between action-oriented and state-oriented individuals, which has been the focus of several studies (e.g.,StiensmeierPelster et al., 1989; Van Putten et al., 2010). Overall, when considering decision-making, action-oriented individuals had a natural tendency to make quicker decisions and had comparatively less fear of making incorrect decisions than state-oriented individuals (Stiensmeier-Pelster et al., 1989).

One of the explanations for slower decisions by state-oriented individuals is that they are more influenced by past emotional events than action-oriented individuals. Van Putten and colleagues' (2010) study based on behavioural economic theory found that decision-making by state-oriented individuals was less rational and more influenced by past emotions than decision-making by action-oriented individuals, resulting in state-oriented individuals being 
susceptible to the sunken cost fallacy. This difference was due to state-oriented individuals being less efficient at self-regulating their emotions and thoughts and longer preoccupied than action-oriented individuals.

Again, the consequences for negotiation research must be considered. State-oriented individuals have been shown to be more influenced by past emotional events (Allemand et al., 2008). This result, combined with the evidence that state-oriented individuals ruminate longer over past emotions than action-oriented individuals, suggests that state-oriented negotiators will be less effective in pursuing their goals when they are on the receiving end of a display of anger than action-oriented negotiators.

Action-oriented individuals were comparatively better at regulating their response to anger than state-oriented individuals, because they have the ability to reduce their emotional states in order to achieve their goals (Koole \& Jostmann, 2004). Drawing on PSI theory, this result can be explained as the extension memory exerting a greater influence on the decisionmaking process, such that decisions that are made more closely align with the values of the individual.

This difference in self-regulation ability is also incorporated in the measure of actionorientation and state-orientation. The difference of putting intentions into action can be illustrated with the actions of seeking employment and exercising dietary restraint. For example, Song and colleagues (2006) studied unemployed Chinese citizens over a period of eight months. They found that both action-oriented and state-oriented individuals had the same intention to seek employment, but there was a difference in acting on these intentions, with the state-oriented subjects having less follow through than the action-oriented subjects. Further evidence can be found in overeating (state-oriented individuals) and exercising dietary restraint (action-oriented individuals) (Palfai, 2002). This capability of individuals to convert their intentions into actions is also likely to play out in negotiation.

Action orientation versus state orientation may explain why two negotiators with similar skills and information may have divergent results in a negotiation. Firstly, I argue that in a stressful situation like an international negotiation, a state-orientated negotiator will not have the ability to self-regulate their behaviour unlike an action-oriented negotiator. Therefore, state-oriented negotiators will struggle to self-regulate in a demanding situation such as an international negotiation, causing them to be less successful. 
Turning to EASI theory, the ability to self-regulate is likely to influence whether a negotiator responds to a display of anger strategically or emotionally. A negotiator's ability to control the way they experience anger will influence their thoughts and behaviours in response. For instance, if a negotiator reduces their level of anger, their behaviour will be less competitive compared to a negotiator with higher levels of anger. Likewise, supressing emotion would likely increase a negotiator's ability to process information and react strategically.

This review of the literature on the effect of the personality traits of action orientation and state orientation has demonstrated that investigating how these individual differences could help explain why negotiators have divergent responses to displays of anger. The following section introduces the research model and the hypotheses to test the impact of individual differences in international negotiations. 
Figure 4: Research model

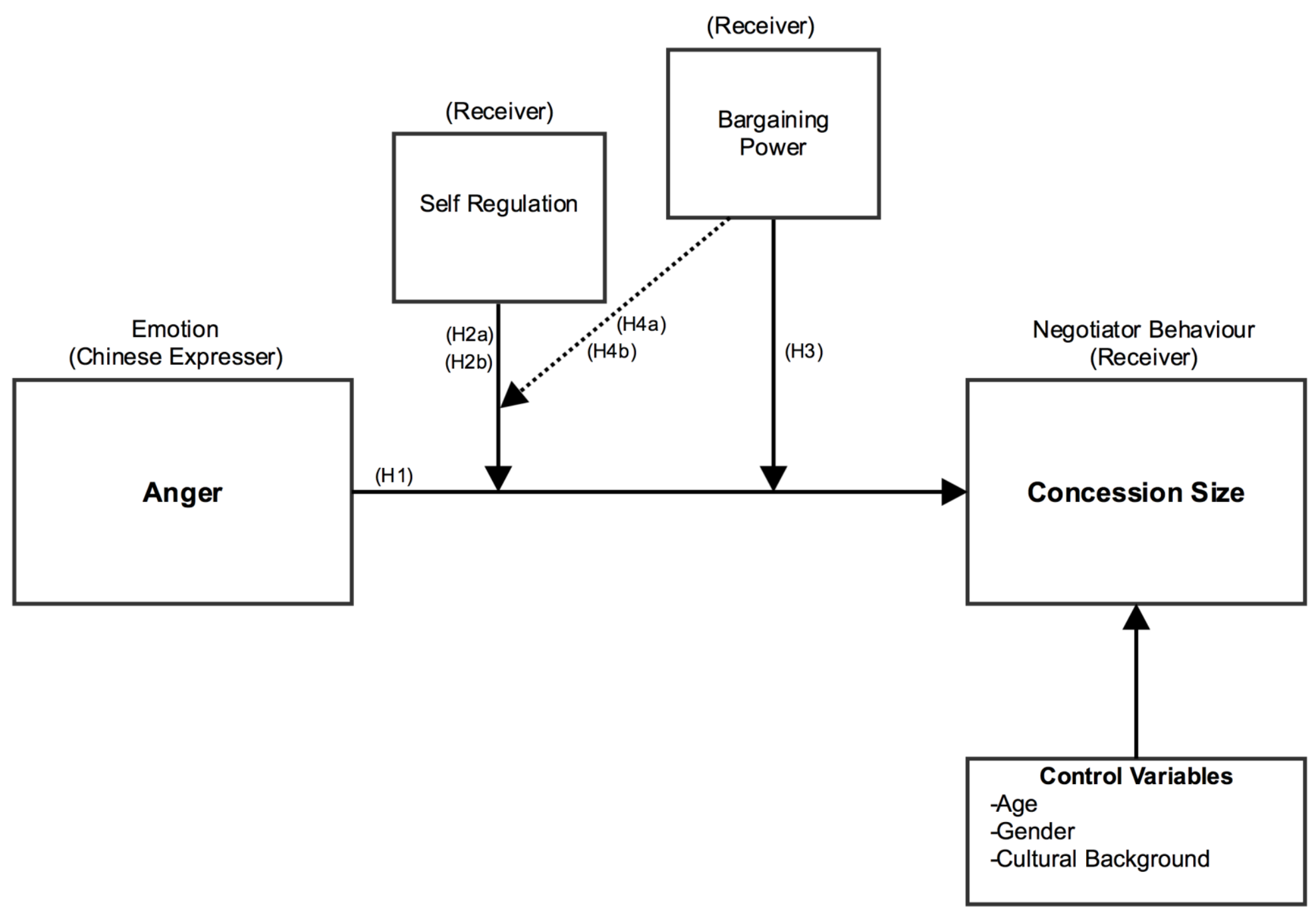




\subsection{Hypothesis development}

A research model is provided in Figure 4 that includes the impact of individual differences on the social effects of anger in international negotiations. PSI theory, introduced in the preceding sections, explains that individuals are inherently different in their proficiency to use their self-regulatory systems, resulting in information being processed differently (Koole \& Fockenberg, 2011). These differences lead to different responses to anger, which I propose will also be measurable in an international negotiation.

The research model proposes several testable relationships. Firstly, the model shows that an expression of anger from a counterpart (who is from a different culture in the context of an international negotiation) will influence the receiving negotiator to concede. Secondly, individual differences in self-regulation ability (action orientation versus state orientation) will moderate this relationship. Finally, the model shows that the level of bargaining power and individual differences jointly predict concession size when on the receiving end of a display of anger. Each of these relationships will be discussed in turn.

However, before each relationship is discussed, it is necessary to briefly explain the context in which the relationships will be tested. The setting of this research project is an international negotiation, so it is appropriate to explain the selection of the cultural identity of the negotiators. As is evident from the research model, a Chinese negotiator is the expresser of the anger. The counterpart will be a U.S. negotiator. As I explain in depth in the next chapter, the chosen method (an online negotiation simulation) led to the decision to collect a convenience sample in the U.S. All the participating negotiators identified as U.S. born Americans of European heritage. A Chinese counterpart was selected following the research from Adam and Shirako (2013) and Adam and colleagues (2010).

\subsubsection{Anger and concession size}

The review of EASI theory suggested that negotiators respond to displays of anger in one of two ways. If they reduce the size of their offer when they are on the receiving end of a display of anger, by inferring the position or intentions of the expresser, it is considered a strategic (or cooperative) reaction. Alternatively, if a negotiator reciprocates the anger and reacts competitively, it is considered an emotional reaction. According to EASI theory, an 
emotional (competitive) response will lead to a lower concession than a strategic (cooperative) response.

In the context of an international negotiation, how will a U.S. negotiator respond to a display of anger shown by a Chinese counterpart? Based on the following arguments, I hypothesize that a U.S. negotiator will react strategically (cooperatively) to a display anger expressed by a Chinese negotiator and make a concession.

Recall from the literature review that national cultures have different display rules for anger and other emotions. Trompenaars and Hampden-Turner (1998) labelled this difference neutral versus affective and China is considered a neutral country which means they do not display anger openly. The U.S. is considered more affective in its display of emotion.

When it is culturally acceptable to express anger, as it is in the U.S., it is likely that negotiators will not react emotionally to displays of anger (Kopelman \& Rosette, 2008). In contrast, when it is the norm not to openly express anger (such as in China), negotiators are likely to feel mistreated or disrespected by a display and anger and, react emotionally/competitively.

Accordingly, if the negotiation were between two U.S. negotiators and one of them displayed anger, it is predicted that the negotiator on the receiving end of the display of anger would respond strategically and cooperate with their counterpart by making a concession. This prediction was empirically supported by the findings of Adam and Brett (2015). However, it is more complex when the counterpart is from China because the U.S. negotiator's view of what they expect from their Chinese counterpart must be considered. Because China is widely recognised as being neutral and Chinese constrain their emotions in comparison to Americans, it is likely that U.S. negotiators would be surprised by a display of anger from a Chinese counterpart. A study by Adam and Shirako (2013) showed that U.S. negotiators responded strategically (cooperatively) to East-Asian negotiators who displayed anger. This suggests that in my study, the U.S. subjects will react strategically/cooperatively.

This argument is in line with the strategic response path in EASI theory: that is, emotions have evolved to carry information (Van Kleef, 2008). It is expected that the U.S. negotiators will take this path and interpret the anger expressed at their counteroffer as a signal of dissatisfaction. Dissatisfaction will be seen as an endangerment to a possible agreement. Consequently, the U.S. negotiator will react strategically by lowering the subsequent offer. 
Based on this argument, it is hypothesized:

Hypothesis 1: U.S. negotiators dealing with a Chinese counterpart who shows anger will concede significantly more than U.S. negotiators dealing with a Chinese counterpart who shows neutral emotion.

\subsubsection{The moderating role of self-regulation ability}

Before testing the moderating role of self-regulation ability on the relationship between anger and concession size, hypothesis 2 a directly tests the effect of personality on concessions. This hypothesis responds to recent calls in the negotiation literature for a renewal of efforts to explore the impact of individual differences (Elfenbein, 2015; Sharma et al., 2013).

PSI theory was used to explain that individuals differ in their capability to self-regulate in a demanding situation like an international negotiation and these capability differences are likely to be significant. This measurable trait is called being action-oriented or state-oriented.

The empirical differences in the behaviour of action and state-oriented individuals were described in section 2.5. Overall, the differences in proficiency in self-regulation showed that action-oriented individuals make better decisions and perform better than state-oriented individuals when they are in cognitively challenging situations. It is expected a similar difference will be found between action and state-oriented negotiators when they encounter a Chinese counterpart in a multi round negotiation, regardless of any emotion expressed.

Recall, from the review of the research on state and action oriented responses, that stateoriented individuals are more prone to dwelling on past negative events, and therefore their decisions and behaviour are more influenced by such events in comparison to action-oriented individuals (Van Putten, 2015). In the context of an international negotiation that has multiple rounds, such focus on past events could be detrimental, as each rejection and subsequent counter offer can trigger these state-oriented negotiators to ruminate negatively. The influence of the external environment means state-oriented individuals make decisions with less influence from their core values (Kazén et al., 2003), or their extension memory (which is the system that helps an individual make decisions in accordance with their preferred outcomes) than action-oriented individuals.

Because an international negotiation with multiple issues creates a demanding situation, it is argued that action oriented negotiators will use different cognitive systems to make decisions 
to achieve their preferred outcomes. In this study, negotiators will be given the objective of maximising personal gain. State-oriented individuals will be more influenced by any rejections in the previous rounds and will dwell on these events and struggle to make decisions close to their core values. Building on the above logic and wider empirical evidence, it is hypothesized that:

\section{Hypothesis 2a: Action-oriented U.S. negotiators dealing with a Chinese} counterpart will concede significantly less than state-oriented U.S. negotiators dealing with a Chinese counterpart.

This hypothesis tests the moderating role of self-regulation ability on the relationship between anger and concession size. It is anticipated that the effect that personality has on concession size will be stronger when a Chinese counterpart expresses anger. It is difficult to predict the direction of this relationship using EASI theory. EASI theory suggests that negotiators will either react strategically (cooperatively) or emotionally (competitively) to expressed anger. However, EASI theory does not include a consideration of individuals' capability differences in choosing one path over the other.

PSI theory suggests that state-oriented individuals do not have the capability to change behaviour in demanding situations. Further, PSI theory says that action-oriented individuals are less affected by internal and external stimuli, such as anger, compared to state-oriented individuals (Koole et al., 2012).

Because action-oriented individuals can regulate their own emotion as well as their response to others' emotion, they can continue to access their extension memory (Kazén et al., 2003) and will make decisions closer to their ideals (Jostmann et al., 2005) and are therefore more effective than state-oriented negotiators.

It is expected that state-oriented negotiators will be less able to regulate their anger and have less control of their feelings when on the receiving end of anger expressed by their Chinese counterpart in comparison to action-oriented negotiators.

Taken together, it is hypothesized that:

Hypothesis 2b: Action-oriented U.S. negotiators dealing with a Chinese counterpart who shows anger will concede significantly less than state-oriented U.S. negotiators dealing with a Chinese counterpart who shows anger. 


\subsubsection{The moderating role of bargaining power}

Unlike personality, I do not measure the direct effect that bargaining power has on concession size but instead focus on its moderating role. The discussion on bargaining power in section 2.4 demonstrated its moderating role on the relationship between displays of anger and concessionary behaviour. EASI theory suggests that bargaining power influences the level of motivation a negotiator has to process information such as a display of anger (Van Kleef, 2008). In simple terms, the level of power determines whether a negotiator takes their counterpart's display of emotion into account when they make decisions (Van Kleef, De Dreu, Pietroni, et al., 2006). A negotiator with high bargaining power will pay comparatively less attention to the information carried within the anger than a negotiator with low power.

The overwhelming evidence of the studies reviewed earlier shows that a negotiator with a good alternative offer (with high bargaining power) will concede less than a negotiator who has no alternative offer (has low bargaining power). This is because negotiators with low power have a greater motivation to pay attention to the social environment and are more attuned to the information expressed by anger in a negotiation than negotiators with high power negotiators. It is in the best interests of a negotiator with no attractive alternative to reach an agreement in a negotiation, because they do not have anything to fall back on.

In the context of international negotiations, little is known about the interaction of power and displays of anger across cultures, although we do know that low power negotiators in three different countries responded by making concessions to displays of anger (e.g., Sinaceur \& Tiedens, 2006).

Following the relationship identified in previous research, it is hypothesized:

Hypothesis 3: U.S. negotiators with high bargaining power dealing with a Chinese counterpart who shows anger will concede significantly less than U.S. negotiators with low bargaining power dealing with a Chinese counterpart who shows anger.

\subsubsection{The joint influence of bargaining power and self-regulation ability}

It is expected bargaining power and personality orientation jointly predict the social effect of anger during international negotiations inasmuch that action-oriented and state-oriented negotiators will behave differently when they hold high power or low power when they are 
dealing with an angry counterpart. Again, EASI theory does not address how these individual-level differences will play out.

Continuing the discussion of high power addressed in the previous hypothesis, when a negotiator has high power, they have the luxury of not conceding to a show of anger (Van Kleef \& Côté, 2007). However, I expect a difference in behaviour between action-oriented and state-oriented individuals when they have high power because of the differences in their capabilities (Koole \& Fockenberg, 2011; Kuhl \& Goschke, 1994). It is expected that negotiators who are state-oriented will struggle to make a considered decision in a demanding international negotiation. PSI theory argues that state-oriented individuals are influenced by emotion and past failure, as they struggle to both self-regulate and use their extension memory to make decisions (Van Putten, 2015; Van Putten et al., 2010). So, even when they have high power and the opportunity to ignore the anger and not make a concession, it is likely they will be influenced by the demanding context and concede more than an actionoriented negotiator.

By comparison, it is expected that action-oriented negotiators will be able to regulate their response to displays of emotion (Koole \& Jostmann, 2004) and make a considered decision. In their reaction, they will be less influenced by the anger. Without such influence, actionoriented negotiators will be able to maximise their individual profit and concede less compared to a state-oriented negotiator.

When the focal negotiator has low power, and is dealing with an angry counterpart, this difference is not expected to occur. An action-oriented negotiator with low power should use their extension memory (Kazén et al., 2003) and make a considered decision to concede. It is expected that a state-oriented negotiator will also concede, but for a different reason. Stateoriented negotiators will concede because they are in a demanding situation and have less of an ability to regulate their response to the display of anger (Koole et al., 2012). Regardless of the reason, it is expected that concession behaviour in a low power situation will be similar for action and state-oriented negotiators.

In the same vein, when no emotion is expressed, it is expected there will be little difference between action-oriented and state-oriented negotiators across the power conditions. Neutral emotion does not carry any information that an action-oriented individual can use and again; state-oriented individuals are expected to be unable to react in a considered way within a stressful situation in an international negotiation. 
In summary, it is anticipated that because state-oriented negotiators do not have the ability to adapt their behaviour in a stressful situation, they will not show a difference in concession size, regardless of emotion or bargaining power levels. However, action-oriented negotiators' ability to self-regulate means they are more adaptable and so when an action oriented negotiator has high power and faces an angry counterpart, they are expected to take advantage of the situation and not concede. This summary leads to:

Hypothesis 4a: Action-oriented U.S. negotiators with high bargaining power dealing with a Chinese counterpart who shows anger will concede significantly less than action-oriented U.S. negotiators with low bargaining power dealing with a Chinese counterpart who shows anger.

Hypothesis 4b: Action-oriented U.S. negotiators with high bargaining power dealing with a Chinese counterpart who shows anger will concede significantly less than state-oriented U.S. negotiators with high bargaining power dealing with a Chinese counterpart who shows anger.

\subsection{Chapter Summary}

In this chapter, I presented a research model that proposes that the individual difference of action orientation and state orientation moderates the influence of anger during international negotiations and that power interacts with this individual capability.

From my discussion of the EASI model, my critical review of the studies that have investigated the social effect of anger in negotiation, and incorporation of PSI theory, I proposed six hypotheses for testing.

The next chapter explains the methods selected to test these hypotheses. 


\section{Chapter 3: Methodology}

\subsection{Introduction}

In Chapter 2, I proposed six hypotheses that together will inform the relationship between anger, bargaining power and personality orientation during international negotiations. These hypotheses state how concessionary behaviour is expected to differ between action and stateoriented negotiators. Differences were hypothesised across anger versus neutral situations and high versus low bargaining power situations. This chapter describes the methods chosen to investigate these hypotheses. First, the positivistic paradigm and experimental design are justified. Then the sample selection, measurement of the constructs and research instrument are explained. Finally, the statistical analysis, a between-subjects analysis of the covariance, is described.

\subsection{Appropriateness of the Research Design}

As with all research, the philosophical foundation needs to be considered and discussed. There are two distinct philosophical positions on viewing research: ontology and epistemology (Lincoln \& Guba, 2000). Epistemology can be understood as "the nature of knowing" and ontology can be understood as "the nature of existence" (Berry et al., 2011, p. 283). I adopt an ontological philosophy through the post-positivism paradigm. Postpositivism is the belief that language can be used to bring us closer to reality, but such observations may involve error (Mertens, 2014).

Underlying this post-positivist approach to looking at the world are some core philosophical assumptions that need to be mentioned. Firstly, the ontological question must be asked on how reality is perceived (Lincoln \& Guba, 2000). A post-positivist approach assumes that reality exists, but acknowledges that it can only be studied imperfectly (Mertens, 2014). Further, post-positivism assumes that the investigator and the subject are not two separate identities; that is, the researcher can influence what is being studied (Mertens, 2014; Reichardt \& Rallis, 1994). However, the researcher should strive to achieve objectivity through rigorously following a systematic approach. Finally, it is assumed that the information that is observed is not a mirror of reality, and that replication of findings alone can bring us closer to reality. That is, knowledge is progressed through experimentation which enables researchers to rule out incorrect theories (Berry et al., 2011). 
Within the post-positivist paradigm, I follow the trend of the majority of research in the anger in negotiation field and undertake a quantitative study with an experimental design. An online experimental design gave me the opportunity to create a balance between experimental control and a naturalistic setting. This design allowed me to test the new relationships that were proposed in the research question. The research question, the research design and existing literature should be consistent and fit together (Edmondson \& McManus, 2007). This relationship between the existing state of literature and the type of methodology is illustrated in Figure 5.

\section{Figure 5: Methodological Fit}

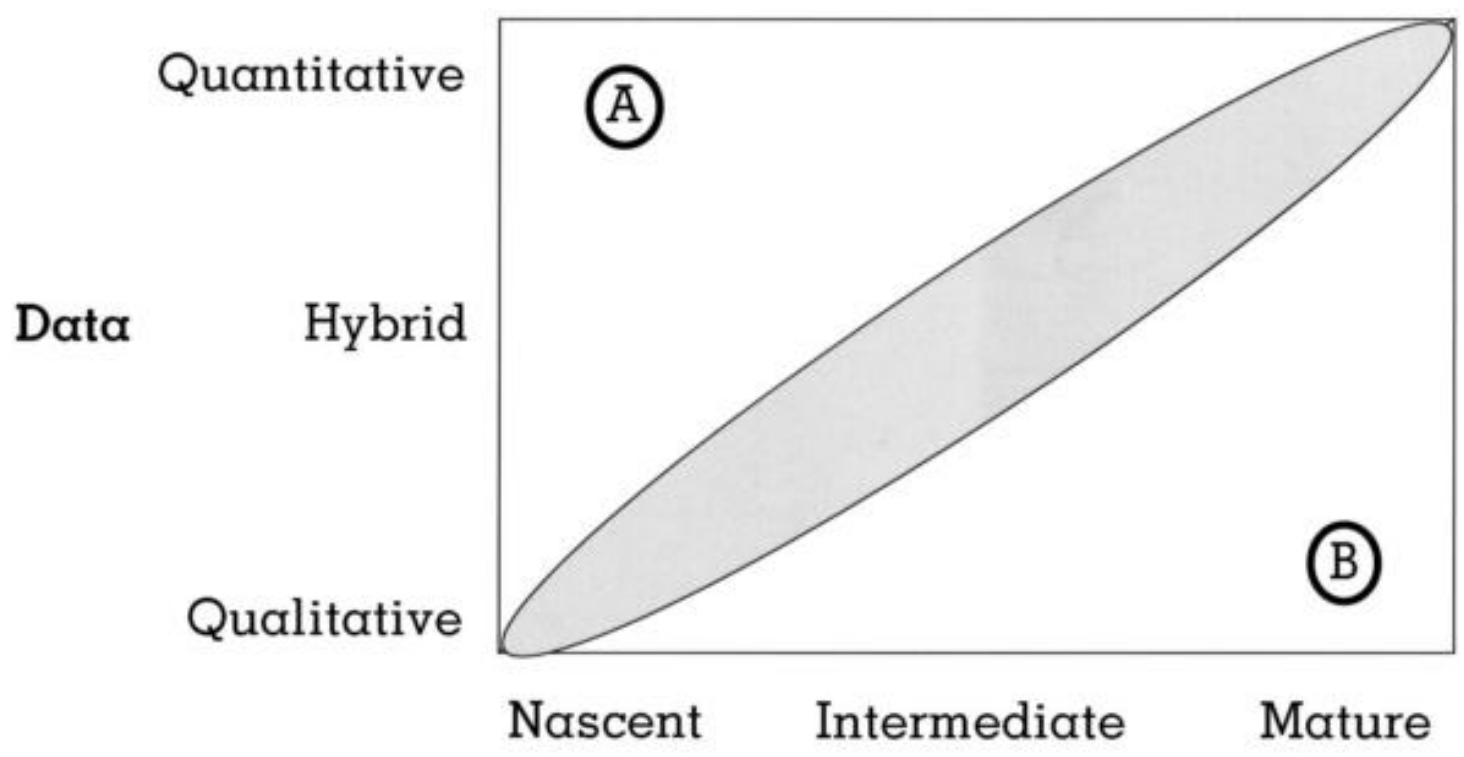

\section{Theory}

Source: Edmondson \& McManus, 2007, p. 1168

The existing state of the anger negotiation literature can be understood as being at an 'intermediate stage', meaning current studies will often introduce new constructs and propose relationships between this new construct and existing theory (Edmondson \& McManus, 2007). An intermediate nature suggests that the research question should inquire about the relationships of theoretically relevant variables; depending on the research question, both quantitative and qualitative research designs can be used. I undertook a quantitative study with an experimental design, which gave the opportunity to use working professionals as participants. 


\subsection{Data collection procedure}

\subsubsection{Sample selection}

I used participants in full time employment to extend current literature, which has largely used students. Additionally, I focused only on those with a Caucasian cultural background to control for culture. These participants were sourced from a Qualtrics panel, an online survey company. Panel data could address these demographic requirements and additionally, the format created a balance between experimental control and a naturalistic setting, thus strengthening external validity (Aguinis \& Lawal, 2012; Landers \& Behrend, 2015).

The panels were selected from Qualtrics because they offered access to over one million adults in the U.S. (Long, Bendersky, \& Morrill, 2011). Panel data has recently grown in popularity as a source of experimental data amongst social scientists (Paolacci \& Chandler, 2014) and studies utilising Qualtrics panel data are now being published in leading journals (e.g., Gromet, Hartson, \& Sherman, 2015; Hagtvedt, 2011; Long et al., 2011).

Two consecutive online studies were conducted and 399 participants completed the negotiation task. The studies had 159 and 240 participants respectively, who received monetary compensation through Qualtrics. Study one (see Figure 6) tested hypotheses 1, 2a and $2 \mathrm{~b}$, which proposed differences between U.S. action-oriented and state-oriented negotiators when confronted with an angry Chinese counterpart. 
Figure 6: Matrix for study one

\section{Self-regulation}

Action orientation State orientation

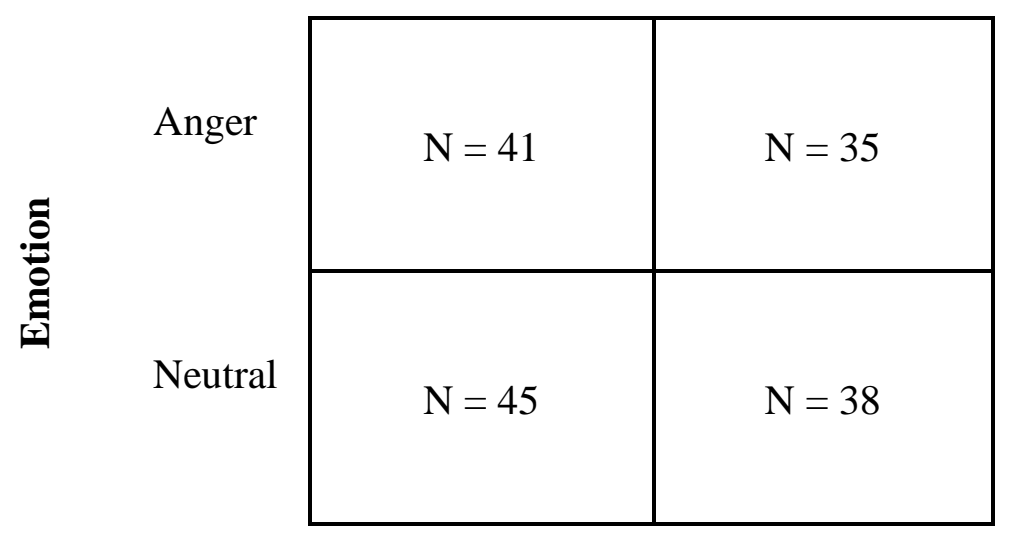

Hypothesis 3, 4a and 4b were tested in the second study (see Figure 7). This study followed the same procedure as study one, with the added condition of high versus low bargaining power.

In both studies, data collection was stopped when a minimum of 30 participants per condition (quadrant of the grid) had been collected. This minimum of 30 participants follows the suggestion of Cozby and Bates (2011). The personality orientation of the negotiators was measured after data collection, which resulted in an uneven number of participants in each quadrant.

Figure 7: Matrix for study Two

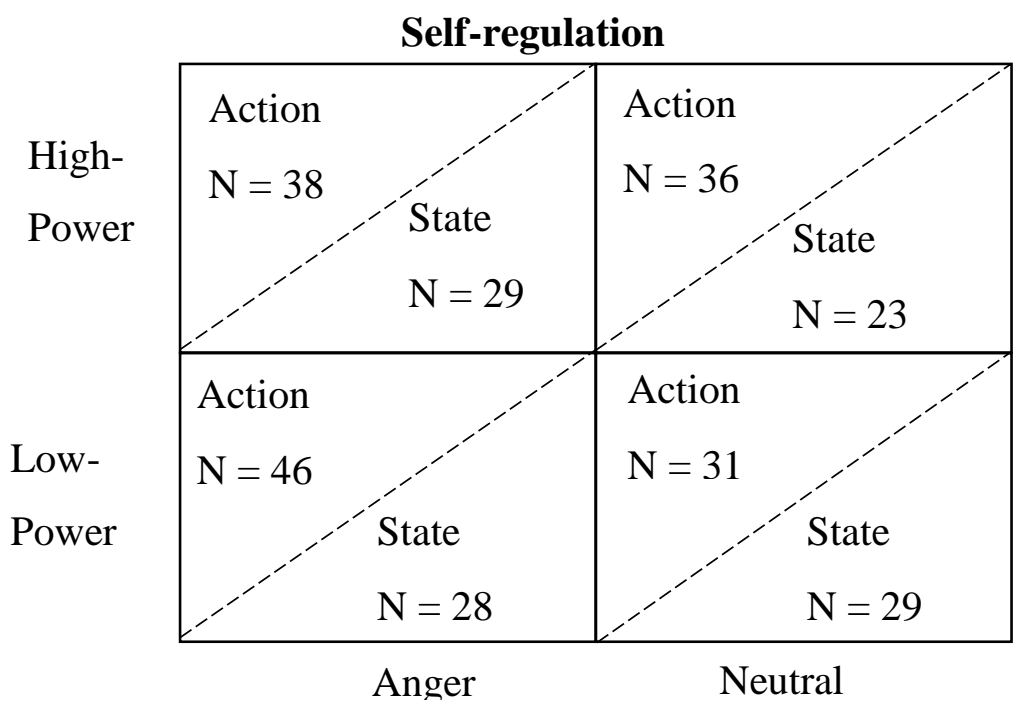




\subsubsection{Data Collection Procedure}

To study how individual differences in emotion management influence international negotiations, data were collected from two online negotiation simulations and accompanying questionnaires. The first study explored the effect of self-regulation and anger, while the second study included the additional variable of power.

The chosen negotiation simulation (the mobile phone consignment case) had three issues concerning a cell phone shipment: price, the amount of warranty and the service contract. The web-based simulation is shown in full in Appendix B. This negotiation was selected because it has been widely used within the emotion in negotiation literature (e.g., Steinel et al., 2008; Van Kleef, De Dreu, \& Manstead, 2004b) and had the characteristics of a real-life negotiation where a distributive offer-counteroffer sequence exists (Van Kleef et al., 2004b). The negotiation was conducted over six rounds with the emotion manipulation occurring in rounds two, four and six. The sequence is shown in full in Appendix C.

There is a paucity of literature that evaluates the use of intercultural web-based negotiation scenarios, however their use is growing amongst both negotiation scholars (e.g., Adam \& Brett, 2015; Hine, Murphy, Weber, \& Kersten, 2009) and intercultural negotiation researchers (e.g., Adam \& Shirako, 2013; Dinkevych, Wilken, Aykac, Jacob, \& Prime, 2017; Vignovic \& Thompson, 2010). Further, a vast proportion of the literature is based on computer-mediated negotiations with the same scenario as adapted in this study (e.g., Van Kleef et al., 2004a, 2004b). Results from such computer-mediated negotiations in the social effect of emotion literature have been found to be extended to face-to-face negotiations (Sinaceur \& Tiedens, 2006; Van Kleef et al., 2004b).

Participants received all information and instructions electronically and were told they were participating in a study that had three sections: questions about themselves (the personality test), a global negotiation simulation and finally, questions about the negotiation.

The panel provider initiated data collection with a screening process asking questions about cultural background and current employment status. The target participants then received a welcome message from the current study, which confirmed both confidentiality and ethics approval and informed them that the study included three segments. This welcome message is shown in Appendix F. 
The participants were instructed there was no 'right' way to behave and encouraged to act as they would in the real world. Further, a message was shown assuring anonymity and confidentiality. These messages are an important part of reducing common method variance (Chang, van Witteloostuijn, \& Eden, 2010). Such instructions have been shown to reduce the prospect of participants adapting their responses to be more acquiescent or socially desirable (Podsakoff, MacKenzie, Lee, \& Podsakoff, 2003) and so were incorporated in the procedure for both studies.

To reduce possible carryover effects, detailed instructions for the negotiation simulation were given after the personality assessment survey. Each of the 36 questions of the personality questionnaire forced a response from the participant.

After completing the personality assessment, the participants were told they would be taking part in an online negotiation and would be randomly assigned to either the role of the buyer or the seller. However, all participants were assigned the role of the seller, and all received the same payoff table. This table was adapted from Van Kleef et al. (2004a) and is shown in Table 4. This table shows that each of the three issues (price, warranty and service period) had different payoffs for the participant.

The table showed participants which outcomes would secure them the most points. For example, the phone price had a range from $\$ 110$ to $\$ 150$ and the respective points ranged from 0 to 400, so participants should aim to earn 400 points by selling the phone for $\$ 150$. Both warranty period and service contract ranged from nine months down to one month in duration and the participants' payoff for the service contract was double that of the warranty period.

Because this thesis is interested in international negotiations, participants were led to believe they were negotiating with a Chinese opponent. The buyer, (the computer program) was presented as being Wang Wei (a common Chinese name) adapted from Adam and Shirako (2013). The post-negotiation questionnaire requested that the participants recall the cultural background of their 'counterpart.' This question was part of an attention check to ensure the quality of responses. Respondents who failed this attention check were excluded from the data. 
Table 4: Payoff levels and programmed strategy

\begin{tabular}{|c|c|c|c|c|c|c|}
\hline \multicolumn{5}{|c|}{ Participant's payoff } & \multicolumn{2}{|c|}{ Service Contract } \\
\hline Level & Price & Payoff & Warranty & Payoff & Service & Payoff \\
\hline $\mathbf{1}$ & $\$ 150$ & 400 & 1 month & 120 & 1 month & 240 \\
\hline 2 & $\$ 145$ & 350 & 2 months & 105 & 2 months & 210 \\
\hline 3 & $\$ 140$ & 300 & 3 months & 90 & 3 months & 180 \\
\hline 4 & $\$ 135$ & 250 & 4 months & 75 & 4 months & 150 \\
\hline 5 & $\$ 130$ & 200 & 5 months & 60 & 5 months & 120 \\
\hline 6 & $\$ 125$ & 150 & 6 months & 45 & 6 months & 90 \\
\hline 7 & $\$ 120$ & 100 & 7 months & $30 *$ & 7 months & 60 \\
\hline 8 & $\$ 115$ & $50 *$ & 8 months & 15 & 8 months & $30 *$ \\
\hline 9 & $\$ 110$ & 0 & 9 months & 0 & 9 months & 0 \\
\hline
\end{tabular}

*The computer's opening offer.

Payoff matrix adapted from Van Kleef et al. (2004a)

Participants were asked to read all instructions carefully and to take the role seriously. They were told to maximise their points and, if they did not reach an agreement, they would get zero points. In the second study, to further enhance involvement, these points were turned into lottery tickets, which led to a chance of winning a voucher. The lottery system was included in the second study as part of the bargaining power manipulation. Across both studies, all participants were remunerated for their time.

To start the negotiation, participants were told their opponent (the buyer) would initiate the negotiation and give their first offer and that the negotiation would continue until an agreement was achieved for a maximum of six rounds. A six round maximum was chosen as prior research suggests that up to this point few participants suspect they are negotiating against a computer (De Dreu \& Van Lange, 1995; Van Kleef et al., 2004a). Due to a programming error, the negotiation in study one was terminated after the computer's offer in the sixth round; in study two, a final counteroffer from the participant was allowed in the sixth round. This error is important to note, as it resulted in study two having one extra round and thus the data are not directly comparable.

The computer's first offer was 8-7-8 (price-warranty-service). In the following rounds, the pre-programmed offers were 8-7-7 (Round 2), 8-6-7 (Round 3), 7-6-7 (Round 4), 7-6-6 (Round 5) and finally 6-6-6 (Round 6). This sequence follows the work of De Dreu and Van Lange (1995) and Van Kleef et al. (2004a) and has face validity, as the offers progress with 
both cooperativeness and competitiveness (Van Kleef et al., 2004b). The participants could either accept the offer or reject the offer and submit a counteroffer, with the option of sending a message to the buyer. If their counteroffer equalled or exceeded the pre-set next offer, their offer was accepted.

When a participant accepted the first offer from the program, the negotiation was terminated for not following instructions of maximising their points and their data was omitted from the analysis. If a participant entered $9-9-9$ or 8-8-8 as a counter-offer in the first round, a warning message was given reiterating the need to maximise their points (Level 1-1-1 was maximum points).

After completing the negotiation, participants were directed to the third section of the study. The questions included randomized manipulation check questions and an attention check question. This attention check question was related to the cultural background of the counterpart and has been described above. The study ended with a note explaining the need to create the perception that their negotiation was against another human. This debrief was part of the ethics requirement considering that the participants were misled.

\subsection{Measurements of the Constructs}

My research model, introduced in the previous chapter, proposed a relationship between anger and concessions, and argued that this relationship is moderated by personality and bargaining power. All constructs used to measure these variables were adapted from prior studies. Each of the constructs is discussed in turn below.

\subsubsection{Dependent Measure - Negotiation Concession}

The dependent measure in the research model was the negotiator's total concession during the negotiation. This measure was operationalized as the participant's final offer minus their first offer, following the procedure of Van Kleef, De Dreu, Pietroni et al. (2006). It was calculated by transforming the points offered for price, warranty and service length into an index revealing their total sum of points for the first round and for the final round. These two totals were subtracted from each other to calculate the total concession made by the participant in their negotiation. An overview of available points for the participants is provided in Table 4. 
This method for measuring concessions was chosen as it included all participants, regardless of which round they came to an agreement in. This method was chosen in order to strengthen external validity, as I did not want to base my study on impasses. This way of measuring concessions differs from a lot of studies that use this negotiation case, as they exclude participants that come to an agreement during the negotiation. For example, in the seminal study from van Kleef et al. (2004a), across their three experiments approximately ten percent of the participants came to an agreement, and were consequently excluded from the analysis. Their technique of measuring concessions compared demand level for each of the six rounds and could only be used with participants who negotiated all six rounds. However, such a method was not appropriate in my study, because it would require excluding the majority of the sample from the analysis as most of my participants came to an agreement before the final round. Hence the total concession procedure from Van Kleef, De Dreu, Pietroni et al. (2006) was used.

\subsubsection{Independent measure - Personality}

Each negotiator's personality trait of action orientation versus state orientation was measured with the established and validated (Diefendorff et al., 2000) action control scale (ACS-90) developed by (Kuhl, 1994a), which contains 36 questions. This scale was chosen over traditional personality questionnaires as it measures a variance in self-regulation behaviour not recorded in these traditional scales (Diefendorff et al., 2000). Secondly, the ACS-90 is a powerful measurement tool as it asks about the personal significance of a specific mental state rather than the frequency of its occurrence (Kuhl, 1994b). Participants were asked to "select the answer that is most like them" from two alternatives for each of the 36 questions. Sample questions include question one: When I have lost something that is very valuable to me and I can't find it anywhere: A. I have a hard time concentrating on something else B. I put it out of my mind after a little while. And question four: When I have to solve a difficult problem: A. I usually don't have a problem getting started on it. B. I have trouble sorting out things in my head so that I can get down to working on the problem. The full ACS-90 is provided in Appendix D.

The ACS-90 has three subscales, which were administered together as suggested by Kuhl, (1994a). However, the analysis focused on the first subscale: action orientation subsequent to failure versus preoccupation (AOF). The AOF is comprised of 12 questions and was selected 
as it captures individual's self-regulation ability of negative emotions and coping with failures. This coping strategy was of particular relevance to the current study as the participants were faced with an angry opponent repeatedly rejecting their offer during this simulation. The decision to use only the AOF subscale of the ACS-90 follows similar studies focusing on decision making and stressful situations (e.g., Allemand et al., 2008; Chatterjee et al., 2013).

\subsubsection{Anger Manipulation}

The anger manipulation used during the negotiation scenario followed the protocols of Van Kleef and colleagues (2004a; 2004b), where anger was manipulated as part of the message in response to the participant's offer. The messages with the anger manipulation were given in rounds two, four and six along with the counteroffer. As an example, the message in round two (in response to the participants' first offer) was: “This offer makes me really angry, I think I will offer 8-7-7”. In comparison, the message with the counteroffer in the neutral condition was: "I think I will offer 8-7-7".

The effectiveness of the emotion manipulation was checked with six questions asking about the participant's perception of the opponent's emotion. All questions were rated on a fivepoint Likert scale anchored by 1 (strongly agree) and 5 (strongly disagree), adapted from Van Kleef et al. (2004a) and Van Kleef, De Dreu, Pietroni, et al. (2006). An example of a manipulation check question is: "The opponent appeared irritated during the negotiation". The emotion manipulation and manipulation check are provided in Appendix E.

\subsubsection{Bargaining power manipulation}

In the second study, the additional variable "bargaining power" was introduced to test hypotheses 3, 4a and 4b, which proposed that higher levels of bargaining power would reduce the effect of self-regulation on concession size when facing an angry opponent. The perceived level of bargaining power was manipulated following the protocols of Sinaceur and Tiedens (2006) and Van Kleef, De Dreu, Pietroni, et al. (2006). To create high power, participants were told if they did not reach a deal during the negotiation, they would receive $75 \%$ of the maximum points (or 570 points). To manipulate low power, participants were told they would receive just $25 \%$ of the maximum points (or 190 points) if they did not reach an 
agreement. The participants were incentivised to maximise their points by being told that the points earned went into a lottery draw for a gift voucher.

The effectiveness of the power manipulation was checked by four questions adapted from Van Kleef and colleagues (2004b). These questions were rated on a five-point Likert scale ranging from 1 (strongly agree) to 5 (strongly disagree). The questions included items such as I felt I was dependent on my opponent (reverse coded) and I felt I had a powerful negotiation position. The full bargaining power manipulation and manipulation check are provided in Appendix E.

\subsubsection{Control Variables}

Three control variables were included in both studies: age, gender and cultural background of the participant.

Age and gender have been shown to be important demographic factors that influence negotiator behaviour and outcomes (Butt, Choi, \& Jaeger, 2005). Although there is limited evidence to suggest they play a role in understanding the social effect of anger they were included to test whether there is any influence from them based on findings from wider negotiation literature. The age and gender of the participants were asked in the post negotiation questionnaire.

Because cultural background influences how negotiators respond to emotion (Trompenaars \& Hampden-Turner, 2012), I controlled the sample so only one cultural background completed the simulation. The targeted cultural group were Caucasian Americans.

\subsection{Survey Development and Pre-testing}

With such an online study, it is important to follow rigorous and established methodological practices (Chidlow, Ghauri, Yeniyurt, \& Cavusgil, 2015). These authors suggest that one issue to consider is language: although the U.S. has the same language as New Zealand, it does have a different culture and employ different vocabulary. For example, I used the term Caucasian rather than European. Further, as part of a rigorous process, I conducted both a pilot study and a pre-test. 


\subsubsection{Pilot study}

To enhance face validity, a pilot study was conducted. My study was adapted from a laboratory simulation, so it was important to ensure it was effective in the online context. Eight academic colleagues at Victoria University of Wellington evaluated the study. Academics were chosen as they had the ability to validate the effectiveness of the instrument (Hansen \& Couper, 2004). They were asked to evaluate the intent of the question, how easy it was to understand and the time to complete the study.

In response to their feedback, various modifications were made. Some questions from an additional measure for self-regulation were deleted and the instructions were simplified. Suggestions on font usage were incorporated and a minor programming error was rectified. Because issues such as the intent of the question may not be apparent from assessing respondent behaviour alone (Presser et al., 2004), completing this process helped improve face validity.

\subsubsection{Pre-test}

Following the pilot study, a non-overlapping sample of 56 Caucasian Americans was recruited from Qualtrics panels to conduct a pre-test, which strengthens the ability to argue cause-effect relationships, as it helps establish a true control condition (Aguinis \& Vandenberg, 2014; Cook, Campbell, \& Peracchio, 1990). Although an established simulation and anger manipulation were used, it was important to test the manipulation within the online context.

The pre-test was undertaken on the Qualtrics host platform, which allowed identification of potential issues such as display properties, programming errors and overall usability (Baker, Crawford, \& Swinehart, 2004; Dillman \& Redline, 2004; Hansen \& Couper, 2004). The results showed that 23 participants needed to be excluded, as they had not correctly followed instructions. To avoid this issue in the data collection, an additional comprehension check was added. When the participant accepted the first offer and did not follow the instruction of maximising their points, the use of the comprehension check led to the termination of the survey. In such instances, it was considered an incomplete response and excluded from the data. An alteration to the payoff chart was also made in response to the findings of the pre- 
test. Visual-based instructions were added for those who do not read all the written instructions, and this change is presented in Appendix G.

\subsection{Data Processing and Analysis}

To test the hypotheses, SPSS was used to conduct analysis of covariance (ANCOVA). Similar to an analysis of variance, this method gave the opportunity to test whether groups varied on more than one of the variables (Cox \& McCullagh, 1982; Rutherford, 2001). An ANCOVA gives the additional opportunity to test the relationship between the control variable and dependent measure. When a (control) variable is suspected to influence the dependent variable, adding it as a covariate will remove the noise of this particular variable (Field, 2013; Miller \& Chapman, 2001).

Further, ANCOVA was selected because it allowed the comparison of variance from three or more groups (Field, 2013). The alternative, a t-test, would only allow comparison of mean of two groups. Using multiple t-tests in the analysis of interaction relationships would have increased the risk of familywise error rate (FWER) or a type one error (Field, 2013). In addition, if multiple t-tests were used, they would not be independent, and subsequently, the error rate would increase (Mason \& Perreault, 1991), consequently, an ANCOVA was used to analyse both studies. Field (2013) suggests including control variables as covariates to reduce within-group error variance and to eliminate confounds.

Before analysing the data with ANCOVA, the underlying assumptions of using this technique were tested. An ANCOVA makes the usual assumptions for an analysis of variance, normality and homogeneity of variance, as well as the two additional assumptions of independence of the covariate and treatment effect and homogeneity of regression slopes (Field, 2013).

To check normality for each group, I examined the skewness and kurtosis of each variable (Field, 2013). Secondly, homogeneity of variances was checked, which is the assumption that all variables have the same finite variance and therefore have a constant spread from their population mean or have an equal relative variation (Field, 2013; Schultz, 1985).

Homogeneity was tested with Levene's test (Glass, 1966).

Considering I used an ANCOVA, I also checked the homogeneity of the regression of the slopes (Field, 2013). This was checked by conducting a preliminary analysis in SPSS to test if the regression slopes were equal; that is, to confirm there was no interaction between a 
covariate and manipulations (Olejnik \& Algina, 2003). Finally, an important assumption of ANCOVA is the independence of the covariate and the treatment effect (Field, 2013). This independence was checked by conducting an analysis of the variance of the treatment groups on the covariates (Miller \& Chapman, 2001).

After checking these assumptions, the data in study one were analysed to measure the influence of a display of anger on negotiation performance (H1) and to measure the influence of self-regulation on negotiation performance $(\mathrm{H} 2 \mathrm{a} \& \mathrm{H} 2 \mathrm{~b})$. As previously noted, negotiation performance was measured by total concession. Sizes of concessions were submitted to a two (self-regulation: action versus state orientation) by two (emotion: anger versus neutral) between-subjects ANCOVA.

In study two, the data were analysed to test the influence of bargaining power on concessions (H3), and on the effect of self-regulation (H4a, H4b \& H4c). Sizes of concessions were submitted to a two (self-regulation: action versus state orientation) by two (power: high versus low) by two (emotion: anger versus neutral) between-subjects ANCOVA.

\subsection{Chapter Summary}

This chapter described the research methodology used to explore the role of personality when facing an angry opponent in an international negotiation. Based on a post-positivistic paradigm, an experimental design was chosen. An online negotiation simulation was selected because it offered the best balance between experimental control and a naturalistic setting, thus strengthening external validity and the capacity to apply the findings to real international negotiators. Both the negotiation case and construct measures were derived from established scales. The study was pre-tested with both academic colleagues and full-time employees to enhance face validity. Two online studies were conducted, with full-time employees in the United States. Finally, details and assumptions of a factorial ANCOVA were described as they were used to test the hypotheses of this study. 


\section{Chapter 4: Data Analysis and Results}

\subsection{Introduction}

Having outlined the chosen methodology for examining the hypotheses, this chapter provides the results of the studies. The first section presents the screening and preliminary analysis from the observed responses. Following this presentation, the chapter demonstrates the testing of the hypotheses by presenting the results from an analysis of covariance (ANCOVA) and provides a discussion of the results.

\subsection{Data Screening and Preliminary Analysis}

\subsubsection{Sample Characteristics}

The data collection was initiated by Qualtrics sending an invitation to their online panels, in March and April 2016 (study 1) and May and June 2016 (study 2). From the 1,103 individuals who started the online study, 429 responses were completed and used for analysis. Across studies, 675 individuals were screened out when they failed to meet one of the following criteria: born in the U.S.; identified as Caucasian; in full-time employment. I only targeted those in fulltime employment as I wanted a sample that is a good proxy for negotiators. In comparison, most research to date in this field is conducted with university students. International business research has suggested there may be limitations to external validity when using students as surrogates of mangers (Bello, Leung, Radebaugh, Tung, \& van Witteloostuijn, 2009). Other studies have suggested there is value in replicating existing findings in a setting more representative of the field (e.g., Rosette, Kopelman, \& Abbott, 2013). I addressed these concerns by using only those in full-time employment.

All questions forced a response from the participants; accordingly, this strategy helped prevent missing data (Meade \& Craig, 2011). Participants that stopped partway through the study were considered an incomplete response and were excluded from the data set. Only complete responses were purchased from the panel provider. Considering the participants were led to believe they were negotiating with another person, it was not possible for them to pause the study and continue at a later time.

Furthermore, ten participants were omitted from the data set for either straight-lined responses or carelessness (Johnson, 2005; Meade \& Craig, 2011). For example, participants who misread instructions and/or gave the same response to every question were excluded. 
This collection method yielded a response rate of 24.13 percent, which is not surprising considering the long duration of this simulation (approximately 30 minutes) and our specific sampling frame requirements (e.g., control for cultural group and the requirement of full-time employment). Similar response rates are reported for online experimental studies (e.g., Baack et al., 2015; Long et al., 2011). The full response rate detailed by study can be found in Table 5 .

The sample size was selected based on recommended benchmarks for experimental research for each condition or cell size. The cell size is a vital step to ensure the sample is sufficiently powerful to detect significant effects (Simmons, Nelson, \& Simonsohn, 2011). For an experimental study with multiple conditions, the benchmark is to have a cell size of 20 to 30 participants (Cozby \& Bates, 2011; Simmons et al., 2011). The cell sizes ranged from 35 to 45 in study one and 23 to 46 in study two. A detailed list of cell sizes for both studies is provided in Table 5. There was no equal split of action-oriented and state-oriented participants, so the sample sizes varied across the conditions. Combining all cells resulted in a total sample of 159 for study one, and 260 for study two.

Table 5: Sample size

\begin{tabular}{lllcc}
\hline Study & $\begin{array}{l}\text { Power } \\
\text { Condition }\end{array}$ & Emotion & $\begin{array}{l}\text { Personality } \\
\text { State }\end{array}$ & Action \\
\hline One $(\mathrm{N}=159)$ & & Neutral & 38 & 45 \\
& & Anger & 35 & 41 \\
Study Two $(\mathrm{N}=260)$ & \multirow{2}{*}{ High Power } & Neutral & 23 & 36 \\
& & Anger & 29 & 38 \\
& \multirow{2}{*}{ Low Power } & Neutral & 29 & 31 \\
& & Anger & 28 & 46 \\
\hline
\end{tabular}

Table 6 shows the participant profile from the online negotiation simulations. The average age was 38 for study one and 33 for study two. The sample had a relatively even gender split. Across the studies, over 70 percent of participants reported having been in full-time employment for more than five years ( $87.7 \%$ study one; $74.6 \%$ study two). The respondents were currently employed in a wide range of industries, with no one industry accounting for more than $11 \%$ of the sample. Such a broad cross-section of industries strengthens the external validity of the study. The industry breakdown is shown in full in Appendix H. 
Table 6: Sample characteristics

\begin{tabular}{|c|c|c|c|c|}
\hline & \multicolumn{2}{|c|}{ Study one $(\mathrm{N}=159)$} & \multicolumn{2}{|c|}{ Study two $(\mathrm{N}=270)$} \\
\hline & Number & $\%$ & Number & $\%$ \\
\hline \multicolumn{5}{|l|}{ Response rate } \\
\hline invitations & 605 & & 1173 & \\
\hline \multicolumn{5}{|l|}{ accepted } \\
\hline Screened out & 200 & $33 \%$ & 475 & $40 \%$ \\
\hline Usable responses & 159 & $26 \%$ & 270 & $23 \%$ \\
\hline \multicolumn{5}{|l|}{ Gender } \\
\hline Male & 73 & $45.9 \%$ & 121 & $46.5 \%$ \\
\hline Female & 86 & $54.1 \%$ & 139 & $53.5 \%$ \\
\hline \multicolumn{5}{|l|}{ Age } \\
\hline Average (SD) & 38 (12.14) & & $33(12.76)$ & \\
\hline $15-24$ years & 3 & $1.9 \%$ & 25 & $9.6 \%$ \\
\hline $25-34$ years & 43 & $27 \%$ & 89 & $34.2 \%$ \\
\hline $35-44$ years & 37 & $23.3 \%$ & 62 & $23.8 \%$ \\
\hline $45-54$ years & 41 & $25.8 \%$ & 46 & $17.7 \%$ \\
\hline $55-64$ years & 30 & $18.9 \%$ & 31 & $11.9 \%$ \\
\hline 65 years + & 5 & $3.1 \%$ & 7 & $2.7 \%$ \\
\hline \multicolumn{5}{|l|}{ Employment } \\
\hline$<1$ year & 2 & $1.3 \%$ & 11 & $4.2 \%$ \\
\hline $1-5$ years & 18 & $11.3 \%$ & 55 & $21.2 \%$ \\
\hline $5-10$ years & 26 & $16.4 \%$ & 59 & $22.7 \%$ \\
\hline$>10$ years & 113 & $71.1 \%$ & 135 & $51.9 \%$ \\
\hline
\end{tabular}

\subsubsection{Examining Assumptions}

Before analysing the data, various assumptions were examined, namely normality, homogeneity of variance, independence of the covariate and treatment effect and homogeneity of regression slopes. I tested normality by examining the skewness and kurtosis of each group, following the benchmark of absolute skewness and kurtosis scores of less than 2.58 (Hair, Black, Babin, \& Anderson, 2010). The results show that normality can be assumed, as the results presented a range between -1.151 and 1.412 for study one and between -1.258 and 2.471 for study two. The full result per group is provided in Appendix I.

Homogeneity is the assumption that all variables have the same finite variance and therefore have either a constant spread from their population mean, or have an equal relative variation (Field, 2013; Schultz, 1985). This assumption was tested with Levene's test (Glass, 1966), which revealed non-significant results in both studies (study one: $\rho=0.385$ and study two: $\rho$ $=0.574)$. Accordingly, it was assumed that the variance of the dependent variable (concession size) was equal across the various conditions, and the assumption of homogeneity was not violated. 
Further, the assumption of the independence of the covariate from the treatment effect was examined for each study by performing an analysis of variance (ANOVA) of the treatment groups with the covariate as the outcome variable (Miller \& Chapman, 2001). The results in Table 7 show no significant difference in the covariates for the groups in both study one and two, therefore this assumption was met.

Table 7: Assumption of independence

\begin{tabular}{lcccc}
\hline \multicolumn{1}{c}{ Constructs } & \multicolumn{2}{c}{ Study One } & \multicolumn{2}{c}{ Study Two } \\
& Age & Gender & Age & Gender \\
\hline Anger & $p=0.6$ & $p=0.778$ & $p=0.725$ & $p=0.897$ \\
Power & --- & --- & $p=0.479$ & $p=0.118$ \\
\hline
\end{tabular}

The final assumption tested was the homogeneity of the regression of the slopes and this was tested with a preliminary analysis to check that there was no interaction between a covariate and manipulations (Olejnik \& Algina, 2003). The results in Table 8 show that this assumption was met for both studies.

Table 8: Assumption of homogeneity of the regression of the slopes

\begin{tabular}{lcccc}
\hline \multicolumn{1}{c}{ Constructs } & \multicolumn{2}{c}{ Study One } & \multicolumn{2}{c}{ Study Two } \\
& Age & Gender & Age & Gender \\
\hline Anger & $p=0.314$ & $p=0.728$ & $p=0.091$ & $p=0.843$ \\
Power & --- & --- & $p=0.941$ & $p=0.291$ \\
\hline
\end{tabular}

Data from each variable in the model were assessed for outliers, as they might strongly influence the results (Rousseeuw \& Hubert, 2011). An outlier was considered a score that was overtly different from other responses. A response with a $z$-score of more than 3.29 was considered an outlier (Field, 2013). The analysis revealed no responses that had a $z$-score of greater than the benchmark. Considering the attention checks throughout the study and subsequent data cleaning, this result was not surprising.

\subsection{Results}

A between-subjects factorial ANCOVA was used to test the hypotheses. ANCOVAs provide the opportunity to test whether different groups varied on more than one of the tested variables (Cox \& McCullagh, 1982; Rutherford, 2001). This analysis controlled for the impact of the two control variables (age and gender). Essentially, ANCOVA is the same as an analysis of variance, but with the addition of the control variables. 
Firstly, it is important to determine the degree of validity of the constructs used. Construct validity is an overarching term for assessing whether a test measures what it purports to measure (Borsboom, Mellenbergh, \& van Heerden, 2004). It refers to the "vertical correspondence" between the abstract level of a construct and the operational definition of a measurement (Peter, 1981). It is important to note, the purpose of construct reliability is to determine the level of validity rather than whether the constructs are valid or not (Borsboom et al., 2004; Cronbach \& Meehl, 1955; Messick, 1989).

\subsubsection{Construct reliability and validity}

Cronbach's alpha is the most common measure of scale reliability (Field, 2013) reported for constructs that have multiple items. An alpha of 0.70 is generally considered an acceptable cut-off point to claim that the items are sufficiently related (Field, 2013; Kline, 1999). The Cronbach's alpha should be reported per subscale rather than for the entire construct (Cronbach, 1951). Therefore, in the present study, the procedure was applied and reported separately for the AOF subscale rather than for the entire ACS-90.

The reliability for anger and personality is reported in Table 9 below. Both constructs in study one were above the threshold of 0.70 . For example, the AOF scale (personality) had an alpha of 0.77 .

In study two, the reliability levels of anger and personality were consistent with study one. However, the Cronbach's alpha of power was below the desired 0.70 benchmark $(\alpha=0.55)$. The item-total statistics analysis revealed that item three and four of the power construct did not sufficiently relate to the other items in the construct. It is convention to remove items that substantially decrease the reliability (Field, 2013). The reliability of the power increased when one item was deleted, however, the Cronbach's alpha remained below the 0.70 threshold. Consequently, a second item was removed which increased the reliability above the acceptable degree of reliability. Deleting these items resulted in a two-item construct for the manipulation check of power with an alpha of 0.74 . 
Table 9: Scale reliability

\begin{tabular}{|c|c|c|c|c|}
\hline \multirow[t]{2}{*}{ Constructs } & \multicolumn{2}{|c|}{ Study one } & \multicolumn{2}{|c|}{ Study two } \\
\hline & $\begin{array}{c}\text { Number of } \\
\text { items }\end{array}$ & $\begin{array}{c}\text { Cronbach's } \\
\text { alpha }\end{array}$ & $\begin{array}{c}\text { Number of } \\
\text { items }\end{array}$ & $\begin{array}{c}\text { Cronbach's } \\
\text { alpha }\end{array}$ \\
\hline Anger & 3 & 0.93 & 3 & 0.90 \\
\hline Personality & 12 & 0.77 & 12 & 0.77 \\
\hline Power & --- & --- & 2 & 0.74 \\
\hline
\end{tabular}

The use of two items for the power manipulation check is consistent with prior studies. In the literature, the manipulation checks for similar studies range from one item (Wang, Northcraft, \& Van Kleef, 2012) to four items (Van Kleef et al., 2004b). Further, it is important to note, that this construct was for a manipulation check only, and was not used to test the model, thus removing the two items has a minimal impact on the findings.

Having established confidence in construct reliability, attention here turns to construct validity. Normally, to determine construct validity, both convergent and discriminant validity are measured, however considering the nature of my study it is not necessary for me to test either. I will discuss both in turn.

Convergent validity tests whether the construct measures what it is expected to measure. That is, are the items that should relate to others in the same construct actually related (Cozby \& Bates, 2011)? For instance, the Likert scores on one item for measuring a variable should have a strong correlation with the other items measuring that same variable. Generally, convergent validity is established with a confirmatory factor analysis or a principle component analysis (Hair et al., 2010).

The only scale that was included in testing the model was the AOF scale, which is a binary scale, consequently it is not necessary to test convergent validity. There is no need to check if the average scores correlate with each other, as there is only one scale. Further, considering the AOF scale categorizes the participants as zero or one, it is not necessary to compare averages as it would be with a scale containing items on a Likert scale. This reasoning is in line with the existing literature in the field that does not include the AOF scale in factor analysis (e.g., Allemand et al., 2008; Dholakia, Tam, Yoon, \& Wong, 2016; Van Putten, 2015).

Discriminant validity on the other hand, is used to test if the scales used are independent from each other. That is, results from theoretically different constructs should not be related 
(Cozby \& Bates, 2011). Again, considering there was only one scale used in the research model (the ACS-90), it is not necessary to test discriminant validity.

However, earlier studies have compared the ACS-90 to other personality scales in order to establish discriminant validity (e.g., Bagozzi et al., 1992; Diefendorff et al., 2000). Both of these studies found that a considerable proportion of the variance in the ACS-90 could not be accounted for with other personality and cognitive ability measures, confirming construct validity.

\subsubsection{Manipulation checks}

Having discussed construct reliability and validity, attention now turns to the data analysis. Firstly, to check whether the anger and power manipulations were successful, independent sample $t$-tests were completed. The manipulation checks were measured on a scale of 1 to 5 , where $1=$ strongly agree and $5=$ strongly disagree.

A pre-test with 56 non-overlapping participants confirmed that the anger manipulation was successful. The respondents were randomly assigned to either an angry $(\mathrm{N}=27)$ or neutral emotion condition $(\mathrm{N}=29)$. As expected, the participants with the angry opponent had significantly higher ratings of anger $(M=2.62, S D=1.24)$, compared to those with a neutral counterpart $(M=3.71, S D=0.85), t(45.97)=3.826, \rho<0.001$.

Anger was the only manipulation in study one and results similar to the pre-test were obtained. Participants subjected to an angry opponent $(\mathrm{N}=76)$ rated the opponent as more angry $(M=2.05, S D=0.96)$ in comparison to those that negotiated with a counterpart expressing neutral emotion $(\mathrm{N}=83),(M=3.39, S D=0.78), t(157)=9.703, \rho<0.001$.

In study two, there was a manipulation for both anger and bargaining power. As expected for the anger manipulation, the participants within the anger condition $(\mathrm{N}=141)$ rated the counterpart as more angry $(M=1.99, S D=0.87)$ compared to those that were subjected to a neutral counterpart $(\mathrm{N}=119),(M=3.41, S D=0.84), t(258)=13.350, \rho<0.001$.

Participants with high bargaining power $(\mathrm{N}=126)$ rated themselves as having significantly more power $(M=2.56, S D=1.01)$ compared to those that were in the low bargaining power condition $(\mathrm{N}=134),(M=2.82, S D=1.01), t(258)=2.143, \rho=0.033$.

Having established successful manipulations in both studies, the next section discusses the analysis to answer the hypotheses. 


\subsubsection{Study One Results}

The first three hypotheses were tested in study one $(\mathrm{N}=159)$. The dependent variable, concession size, was calculated by aggregating all three negotiated issues into an index, after which the final offer was subtracted from the participants' initial offer. This dependent measure was submitted to a two (opponent's emotion: anger vs. neutral) by two (personality: action versus state-orientation) between-subjects ANCOVA. The two control variables in study one, age and gender, were added as covariates into the ANCOVA. The results reveal no significant difference for age $(\rho=0.369)$ and gender $(\rho=0.570)$. Considering these variables do not significantly influence the findings, the results for study one are reported collapsed across these two variables.

The results revealed a significant main effect of personality, $F(1,153)=5.684, \rho=0.018, \eta_{\mathrm{p}}^{2}$ $=0.04$. In summary, action-oriented participants made significantly lower concessions $(M=$ 114.19) compared to state-oriented participants $(M=161.64)$. The analysis in study one did not reveal any other significant results. The ANCOVA results for study one are reported in Table 10 and Table 11.

Further, it is important to report the effect size (Ellis, 2010). Personality was the only explanatory variable in study one and its effect size can be considered small $\left(\eta_{\mathrm{p}}{ }^{2}=0.04\right)$. The confidence interval for the significant main effect contains a zero (Table 11), which raises questions regarding the robustness of study one. Therefore, it was important to replicate study one in which the confidence intervals suggest a robust study. 
Table 10: ANCOVA results - study one

\begin{tabular}{l|cccc}
\hline \multicolumn{1}{l}{ Points Conceded } & df & F & Sig. & Partial Eta Squared \\
\hline Corrected Model & 5 & 1.311 & 0.262 & 0.041 \\
Intercept & 1 & 5.212 & 0.024 & 0.033 \\
Age & 1 & 1.099 & 0.296 & 0.007 \\
Gender & 1 & 0.336 & 0.563 & 0.002 \\
Personality & 1 & 5.684 & 0.018 & 0.036 \\
Anger & 1 & 0.146 & 0.703 & 0.001 \\
Personality * Anger & 1 & 0.051 & 0.822 & 0.000 \\
Error & 153 & & & \\
Total & 159 & & & \\
Corrected Total & 158 & & & \\
\hline
\end{tabular}

a. $\mathrm{R}^{2}=.041$ (Adjusted $\mathrm{R}^{2}=.010$ )

Table 11: Parameter estimates - study one

\begin{tabular}{|c|c|c|c|c|c|c|}
\hline \multicolumn{7}{|l|}{ Points Conceded } \\
\hline & & & & & \multicolumn{2}{|c|}{$95 \%$ Confidence Interval } \\
\hline & B & SE & $\mathrm{t}$ & Sig & Lower Bound & Upper Bound \\
\hline Intercept & 73.585 & 48.849 & 1.476 & .142 & -24.896 & 172.066 \\
\hline Age & 9.698 & 9.250 & 1.048 & .296 & -8.575 & 27.972 \\
\hline Gender & -12.733 & 21.961 & -.580 & .563 & -56.120 & 30.654 \\
\hline PersonalityAOF & 48.500 & 32.046 & 1.513 & .132 & -14.809 & 111.809 \\
\hline Anger & 3.405 & 29.570 & .115 & .908 & -55.012 & 61.823 \\
\hline PersonalityAOF $*$ Anger & 9.842 & 43.714 & .225 & .822 & -76.518 & 96.203 \\
\hline
\end{tabular}

Interestingly, hypothesis one (U.S. negotiators dealing with a Chinese counterpart who shows anger will concede significantly more than U.S. negotiators dealing with a Chinese counterpart who shows neutral emotion) was not supported; there was no main effect of emotion on concessions $(\rho=0.70)$.

Although the negotiators did not concede significantly more to an angry opponent than to a neutral opponent, there was a significant difference between action and state-oriented negotiators, as can be seen in Figure 8. This difference was predicted in hypothesis two (a). Accordingly, hypothesis two (a) is supported (Action oriented U.S. negotiators dealing with a Chinese counterpart will concede significantly less than state-oriented U.S. negotiators dealing with a Chinese counterpart). A two-way ANCOVA revealed a significant main effect 
of personality, $F(1,153)=5.684, \rho=0.018$. As portrayed in the figure below, action-oriented participants made significantly lower concessions $(M=114.19)$ compared to state-oriented participants $(M=161.64)$.

\section{Figure 8: Concession size per personality - study one}

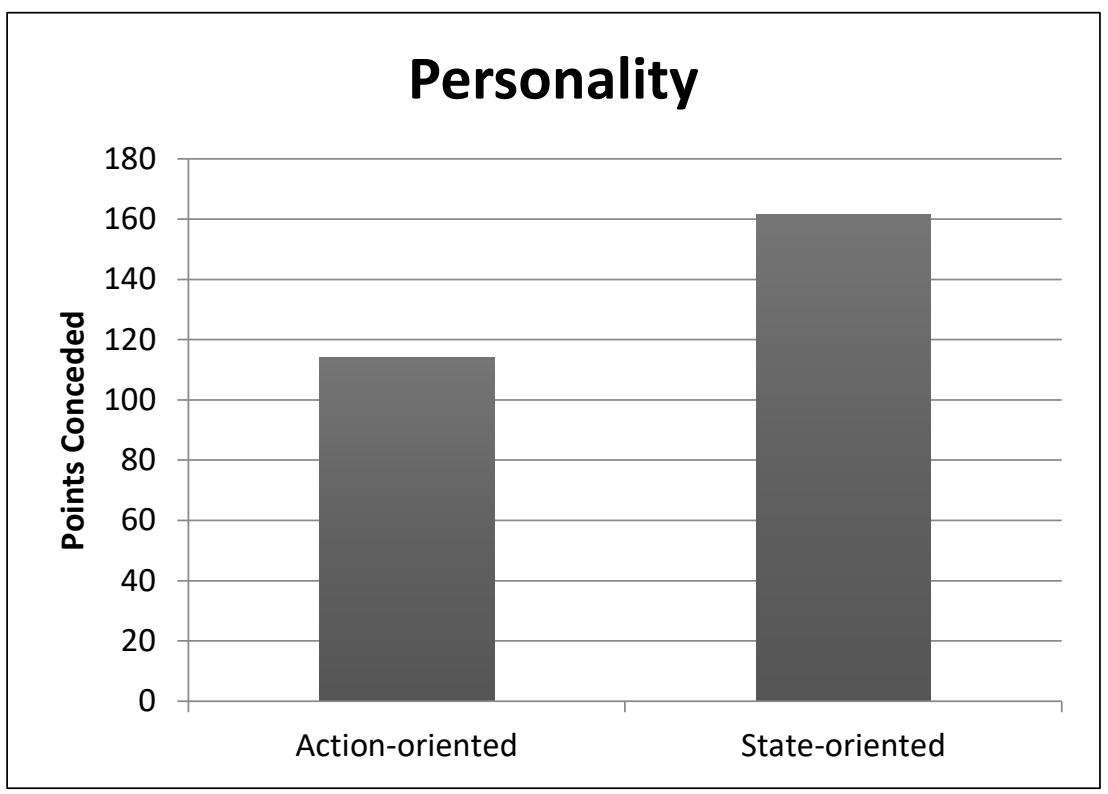

What is interesting in this data is that there was no significant difference between action and state-oriented individuals between the emotion conditions. In hypothesis two (b), it was predicted that the significant difference in hypothesis two would be magnified (Action oriented U.S. negotiators dealing with a Chinese counterpart who shows anger will concede significantly less than state oriented U.S. negotiators dealing with a Chinese counterpart who shows anger). In summary, hypothesis two (b) was not supported; there was no significant interaction between emotion and personality $(\rho=0.98)$.

The results in study one highlight personality as playing an important role in cross-cultural negotiation research. That is, negotiation outcomes are dependent on whether a negotiator is action-oriented or state-oriented. Regardless of the emotion expressed, action-oriented negotiators have the ability to adapt their behaviour and outperform those who are stateoriented. Although no difference was found between the emotion conditions, there could be a number of contexts in an international negotiation where emotion and personality are still important. Bargaining power has been found to influence a negotiator's reaction to an angry opponent. Study two investigates the role of personality between bargaining power, anger and negotiation concessions. 


\subsubsection{Study Two Results}

A non-overlapping sample of 260 employees was used to test hypotheses three and four. The experimental design was similar to the previous study with the added condition of bargaining power. Participants were randomly assigned to one of four experimental conditions: angry or neutral emotion expression and high or low bargaining power. Personality orientation scores were calculated after the data collection. Accordingly, the design for the second study was a two (emotion: angry versus neutral expression) by two (bargaining power: high versus low) $\mathrm{x}$ two (personality: action versus state) between-subjects ANCOVA. In line with study one, age and gender were controlled for and added as a covariate. Consistent with study one results, there was no significant difference for either age $(\rho=0.766)$ or gender $(\rho=0.962)$.

This analysis revealed a significant three-way interaction for emotion, personality and power, $F(1,250)=4.850, \rho=0.029$. The interaction can be seen below in Figure 9. Simple effects analyses revealed that action-oriented participants displayed a significant difference in concessions in the anger condition, $F(1,250)=6.753, \rho=0.010$, such that the action-oriented participants conceded more in the high-power condition $(M=183.42)$ than in the low-power condition $(M=101.30)$. This difference can be observed below in Figure 10. The ANCOVA results for study two are reported in Table 12 and Table 13.

The confidence intervals for the significant three-way interaction presented in Table 13 did not contain a zero. Further, the effect size for the explanatory variables (the interaction, between personality, power and emotion) in study two can be considered small $\left(\eta_{\mathrm{p}}{ }^{2}=0.02\right)$. 
Figure 9: Three-way interaction for emotion, personality and power.

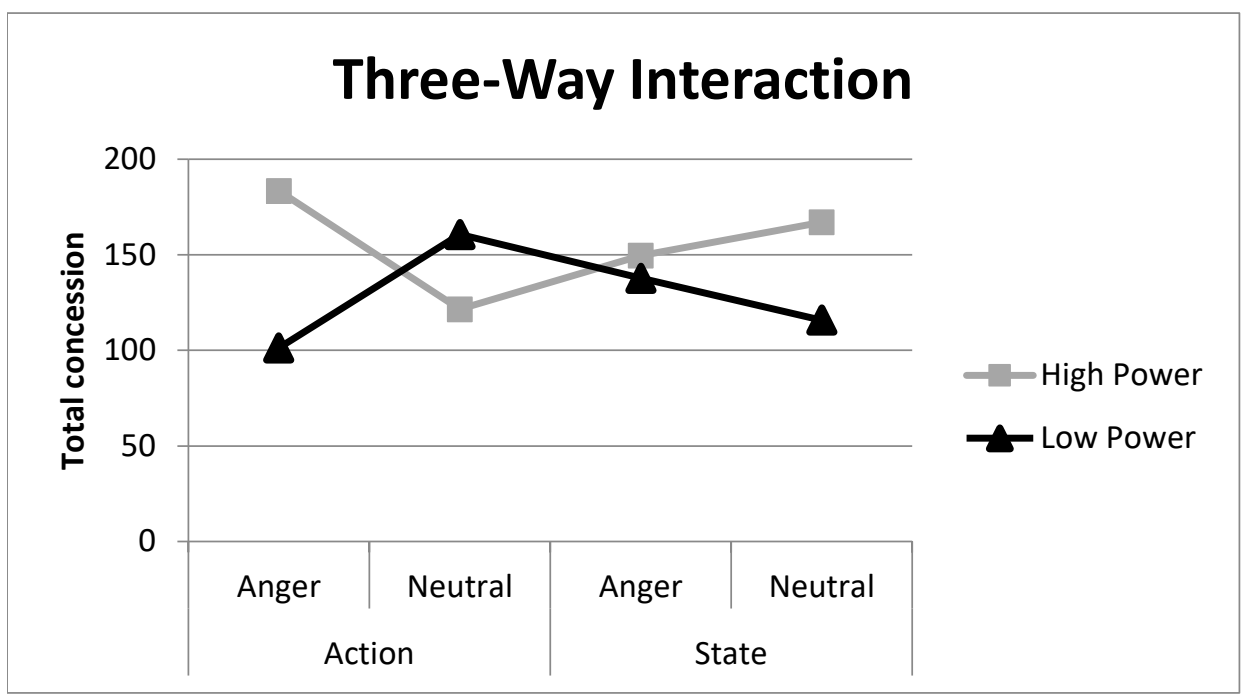

Figure 10: Concession size per power condition in anger

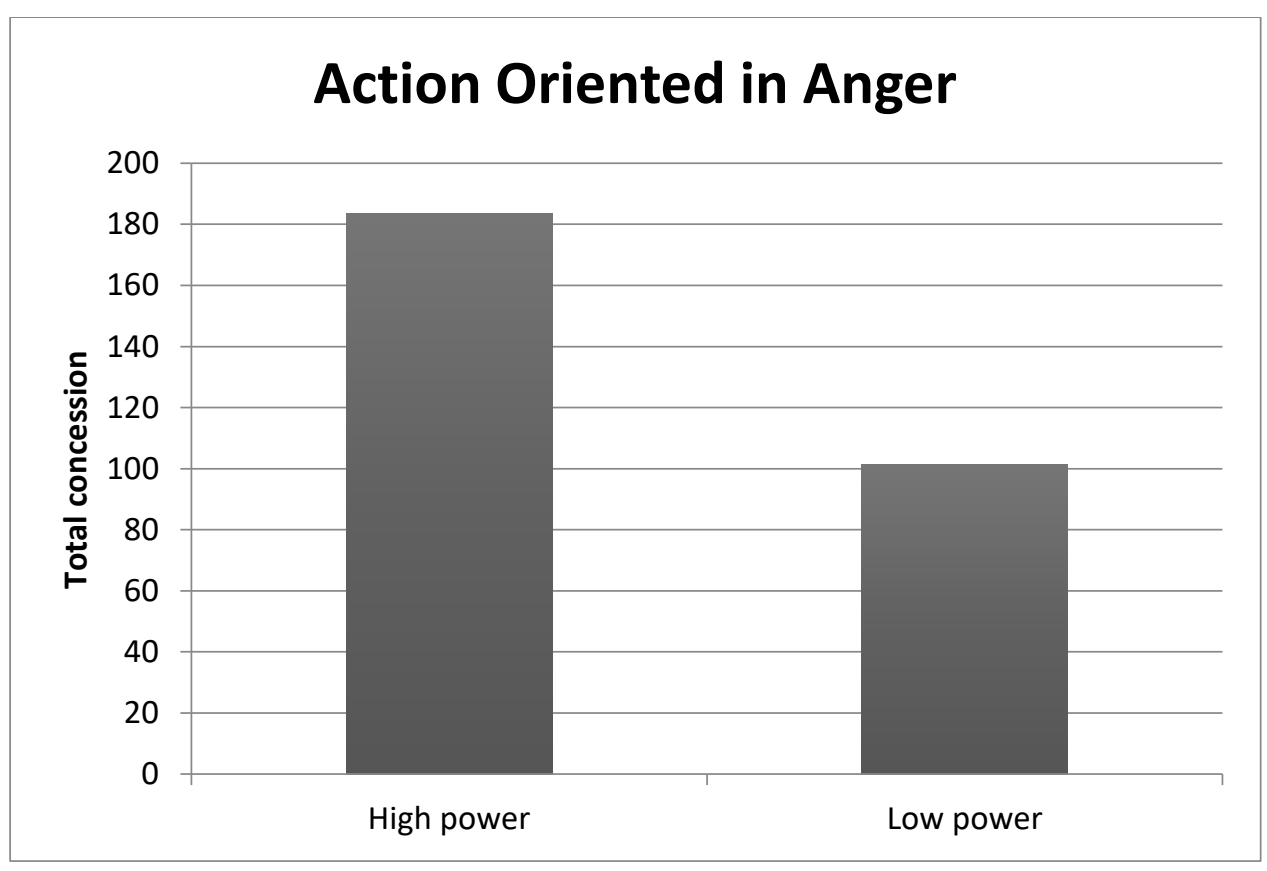


Table 12: ANCOVA results - study two

\begin{tabular}{l|cccc}
\hline \multicolumn{1}{l|}{ Points Conceded } & df & F & Sig. & Partial Eta Squared \\
\hline & 9 & 1.085 & 0.374 & .038 \\
\hline Corrected Model & 1 & 16.325 & 0.000 & .061 \\
Intercept & 1 & 0.089 & 0.766 & .000 \\
Age & 1 & 0.002 & 0.962 & .000 \\
Gender & 1 & 0.000 & 0.991 & .000 \\
PersonalityAOF & 1 & 0.007 & 0.931 & .000 \\
Anger & 1 & 2.088 & 0.150 & .008 \\
Power & 1 & 0.000 & 0.995 & .000 \\
PersonalityAOF * Anger & 1 & 0.065 & 0.798 & .000 \\
PersonalityAOF * Power & 1 & 1.224 & 0.270 & .005 \\
Anger * Power & 1 & 4.850 & 0.029 & .019 \\
PersonalityAOF * Anger * Power & 250 & & & \\
Error & 260 & & & \\
Total & 259 & & & \\
Corrected Total & & & & \\
\hline
\end{tabular}

a. $\quad \mathrm{R}^{2}=.038\left(\right.$ Adjusted $\left.\mathrm{R}^{2}=.003\right)$

Table 13: Parameter estimates - study two

\begin{tabular}{l|rrrrrr}
\hline Points Conceded & \multicolumn{1}{|c}{} & \multicolumn{1}{c}{ 95\% Confidence Interval } \\
& \multicolumn{1}{|c}{$\mathrm{B}$} & \multicolumn{1}{c}{$\mathrm{SE}$} & $\mathrm{t}$ & \multicolumn{1}{c}{ Sig } & Lower Bound & Upper Bound \\
\hline Intercept & 193.953 & 44.483 & 4.360 & .000 & 106.343 & 281.563 \\
Age & -2.163 & 7.263 & -.298 & .766 & -16.468 & 12.142 \\
Gender & -.896 & 18.552 & -.048 & .962 & -37.433 & 35.641 \\
Power & -82.594 & 31.784 & -2.599 & .010 & -145.192 & -19.996 \\
PersonalityAOF & -35.349 & 36.033 & -.981 & .328 & -106.316 & 35.619 \\
Anger & -62.118 & 33.690 & -1.844 & .066 & -128.470 & 4.233 \\
PersonalityAOF * Anger & 80.525 & 52.841 & 1.524 & .129 & -23.544 & 184.594 \\
PersonalityAOF * Power & 71.374 & 49.940 & 1.429 & .154 & -26.984 & 169.732 \\
Anger * Power & 121.317 & 47.576 & 2.550 & .011 & 27.615 & 215.018 \\
PersonalityAOF * Anger * Power & -161.527 & 73.346 & -2.202 & .029 & -305.982 & -17.072 \\
\hline
\end{tabular}


These results do not provide support for hypothesis three (U.S. negotiators who have high bargaining power dealing with a Chinese counterpart who shows anger will concede significantly less than U.S. negotiators who have low bargaining power dealing with a Chinese counterpart who shows anger).

Although hypothesis three is not supported, this result can be explained with simple effect analyses, which revealed that action-oriented negotiators' concessions had an opposite pattern than expected. When action-oriented negotiators had high power, they conceded more rather than the predicted less, compared to when they had low power (see Figure 10). When comparing this unexpected result to study one, a consistent theme is observed; actionoriented negotiators have the capability to adapt their behaviour as the external environment changes, whereas state-oriented negotiators have no differences in behaviour regardless of the condition they are in. This difference is demonstrated with the hypotheses four (a) and (b). Across conditions, state-oriented negotiators have no significant variation in negotiation outcomes; this result is portrayed in Appendix $\mathrm{J}$ (Figure B).

Overall, the intention of hypothesis four was supported, as action-oriented negotiators were able to adapt their behaviour. As portrayed in Figure 10, action-oriented participants conceded more in the high-power condition $(M=183.42)$ than in the low-power condition $(M$ = 101.30). However, statistically hypothesis four (a) is not be supported as I hypothesised the opposite direction: Action-oriented U.S. negotiators with high bargaining power dealing with a Chinese counterpart who shows anger will concede significantly less than action-oriented U.S. negotiators with low bargaining power dealing with a Chinese counterpart who shows anger.

As with the previous hypothesis, hypothesis four (b) can be supported insomuch that personality, bargaining power and emotion jointly predict demands. A significant three-way interaction was observed, however, the concession behaviour from action-oriented negotiators was in the opposite direction than expected based on past theory. Therefore, statistically hypothesis four (b) cannot be supported: Action-oriented U.S. negotiators with high bargaining power dealing with a Chinese counterpart who shows anger will concede significantly less than state-oriented U.S. negotiators with high bargaining power dealing with a Chinese counterpart who shows anger. 
Action-oriented participants were observed to have the ability and luxury to adapt their behaviour with high power (Figure 11 and Appendix J, Figure A). Although the direction is not as predicted, it is important to note that the findings do support the importance of individual differences in negotiations. It was consistently observed over two studies that action-oriented negotiators have the ability to adapt behaviour unlike state-oriented negotiators.

Figure 11: Concession size per power condition

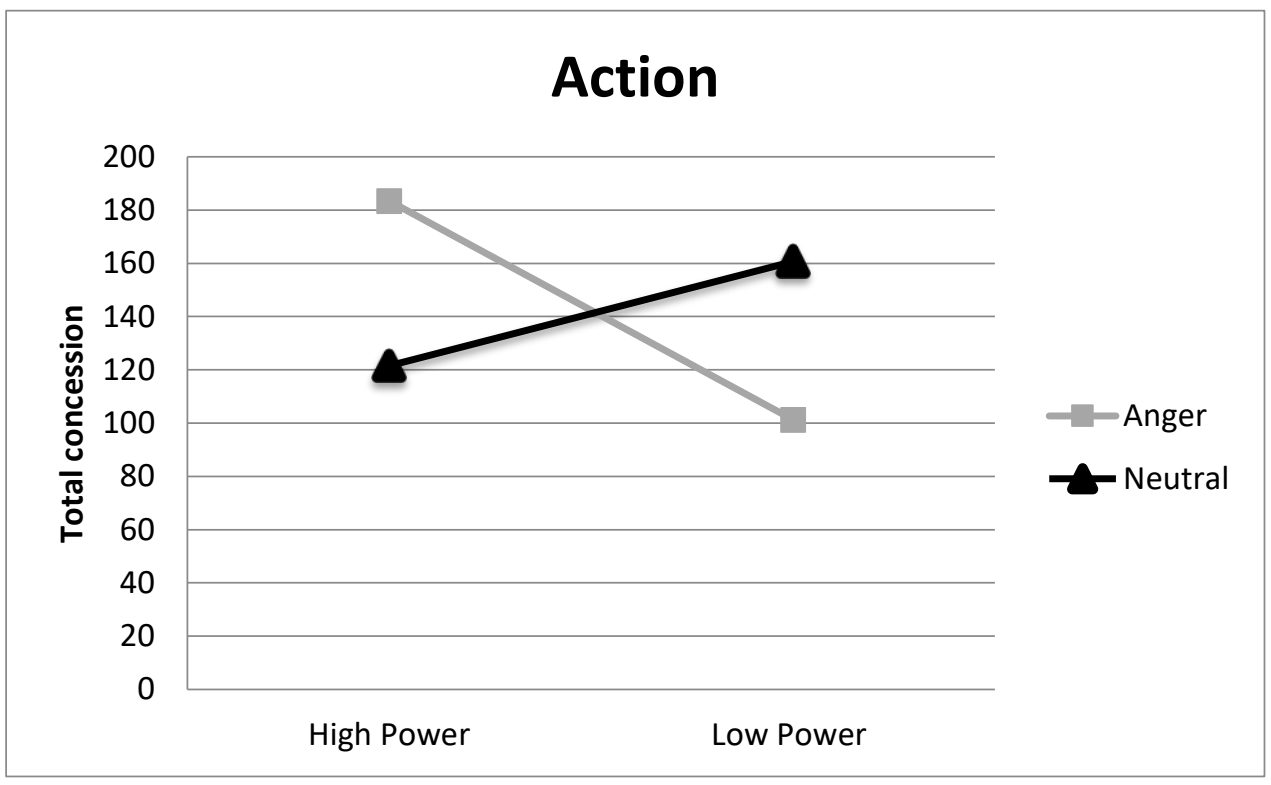

The results from both studies demonstrate that personality played a role in understanding negotiation outcomes. Further, these results demonstrate that in order to understand concessionary behaviour, one must consider the joint relationship between anger, bargaining power and the personality of the negotiator. The following section discusses these relationships in more detail.

Finally, it is normal in a thesis to report the $\mathrm{R}^{2}$ Value. The $\mathrm{R}^{2}$ value from both studies, .041 and .038 , may inherently seem low. The model in both studies predicts approximately four percent of the variation in the outcome variable. It is not unusual to get a low $\mathrm{R}^{2}$ value when predicting human behaviour, as behaviour is difficult to predict (Terborg, 1981). Studies within in this line of research do not report their $\mathrm{R}^{2}$ value (Lelieveld et al., 2012; Van Kleef et al., 2004a), because the objective of such studies is to predict the direction of the behaviour. The same can be said of this thesis. 


\subsubsection{Common Method Variance}

Finally, I discuss common method variance (CMV), which I argue was avoided in the experimental design and consequently is not analysed or reported here. Common method bias can occur when all data comes from the same source at the same time (Podsakoff et al., 2003). In particular, CMV can create a bias between self-report constructs, and this inaccurate relationship can either over- or underinflate results (MacKenzie \& Podsakoff, 2012).

In the two studies, the dependent measure (concession size) was not a self-reported scale or a perceptual measure. Participants' concessions during the negotiation were an objective measure reflecting actual behaviour between different treatment groups. Only the manipulation checks for anger and power were self-report measures. However, these checks were only used to confirm the treatment of the manipulations and consequently were not utilized to test the model. In summary, I argue that the results are robust and do not suffer from CMV.

\subsection{Discussion of results}

\subsubsection{Relationship between anger and concession size}

An interesting result of study one is that I did not find support for previous findings that anger created larger concessions (hypothesis one). This result may reflect the different context of the negotiations in this thesis.

This result of no significant difference is not altogether surprising, considering that the literature has reported contrasting results. As highlighted in earlier chapters, participants in similar studies have been found to both concede significantly more to an angry opponent (Van Kleef et al., 2004a) and concede significantly less to an angry opponent compared to a neutral opponent (Kopelman et al., 2006). There are also examples of anger not resulting in concessions, where participants conceded more to a neutral opponent than to an angry counterpart (Adam et al., 2010; study 1 and 2). These authors used a similar negotiation simulation in their second study to the one used in this thesis.

Although the negotiation scenario and anger manipulation employed in the present research have been widely used in extant studies, prior research has generally been conducted in a 
controlled laboratory environment. In comparison, both studies in this thesis were conducted online to achieve a balance of both control and external validity, as discussed in Chapter 3 .

Previous studies have suggested that in order for anger to create concessions, it has to be considered appropriate (Van Kleef \& Côté, 2007). For example, when manipulating conditions in a laboratory, European American negotiators are less likely to concede to inappropriate anger than to default anger (Adam et al., 2010) using a similar negotiation case. In an online context such as the one used here, anger may be perceived as less appropriate compared to a laboratory environment, and as such participants may be less likely to concede. This consideration may in part explain why no significant difference was found between anger and neutral expressions.

It is important to note that the hypothesis was based on EASI theory, which suggests that a negotiator will react either competitively or cooperatively to a display of anger. EASI theory is not helpful in explaining why a negotiator may be indifferent to anger during a negotiation. In the following chapter I propose a revised EASI model.

In the current study, regardless of the emotion faced, there was a difference in concessions depending on the personality orientation of the negotiator. This relationship is discussed in the following section.

\subsubsection{Influence of action versus state-orientation on concession size}

A key finding of the current research is the identification of the link between personality orientation and negotiation outcomes. These results directly answer the call from Elfenbein (2015), who suggested that scholars focus on how individual differences influenced negotiation performance. The data revealed a significant main effect of personality in the first study. That is, a difference in the level of concession size was observed depending on whether a negotiator was action-oriented or state-oriented (hypothesis two). Regardless of the emotion expressed by the opponent, action-oriented negotiators conceded less compared to state-oriented negotiators. This difference in behaviour was due to the response capability difference of these two personality types. As hypothesized in Chapter two, action-oriented negotiators have the ability to initiate a control strategy that enables flexible self-regulation of behaviour. In contrast, state-oriented individuals struggle to self-regulate during a demanding situation, which was demonstrated in this study. 
The simulated negotiation had multiple issues and involved a culturally-different opponent. As the negotiation progressed, the participants received more rejections from the opponent. This continued rejection would have made it increasingly difficult for state-oriented individuals to self-regulate, as they ruminate more about past negative events (Van Putten, 2015; Van Putten et al., 2010). Consequently, their decision-making was not strategic or optimized for the ever-changing context. In comparison, the action-oriented negotiators were able to regulate both their feelings and behaviour and in doing so, they were able to make the decision to maximize their personal gain.

These results are consistent with PSI theory and the empirical evidence from a range of fields outside of negotiation, in which state-oriented participants struggled to perform in demanding situations. In the second study, I explored the impact of high versus low bargaining power and the results are discussed in the following section.

\subsubsection{The influence of bargaining power on concession size.}

In study two, no main effect of bargaining power was found in either the anger or neutral condition (hypothesis three).

Prior studies have demonstrated that the level of power can influence the motivation or amount of attention a negotiator gives to the social environment (Van Kleef, De Dreu, Pietroni, et al., 2006). When a negotiator has high power (good alternatives), they have the luxury to be intransigent when they are facing an angry counterpart (Van Kleef \& Côté, 2007). In comparison, it is suggested that when a negotiator has low power (a weak alternative), they must be strategic and concede.

In study two, the manipulation check of high power was significant, but there were no overall differences in concessions. It is plausible to suggest that the anger was not perceived as appropriate, and this perception was the cause of no differences in concession size. Van Kleef and Côté (2007) demonstrated that when negotiators have high power, and they feel the expressed anger to be appropriate, they are likely to concede. However, if the expressed anger is perceived as inappropriate, they will retaliate and rather than concede, they will demand even more compared to when the anger is appropriate.

The presences of a three-way interaction involving anger, bargaining power and personality helps explain why no overall difference was found between high and low power. Action- 
oriented negotiators demonstrated behaviour opposite to the hypothesized behaviour when they had high power, and this relationship explains the lack of overall difference between high and low power. Considering that when they faced an angry opponent, action-oriented negotiators with high power conceded more than those with low power, there was no overall difference of low power negotiators conceding more than those with high power as hypothesised. This relationship is discussed in the following section.

\subsubsection{The joint influence of bargaining power and self-regulation ability}

The three-way interaction between personality, power and anger was an interesting finding, as it is not easily explained by existing theory (hypothesis four a \& b). EASI theory does not explain why negotiators may be indifferent to anger, nor does it explain how personality may impact concession sizes. This thesis hypothesized that action-oriented negotiators with high power will be able to maximize their individual profit and concede less compared to a stateoriented negotiator. The results show a significant difference between action and stateorientation, but not in the hypothesized direction. When action-oriented participants faced an angry opponent and had high power, they were more cooperative. Rather than using their high-power position to be intransigent, they became less competitive and conceded.

Further research is required to better understand the reasons for action-oriented individuals becoming cooperative rather than competitive, however this thesis provides two arguments as to why this behaviour may have occurred.

Firstly, past research has argued that cognitive intelligence tends to improve win-win agreements (Elfenbein, 2015). My study also found that negotiators with a greater ability to self-regulate (action-oriented) improved accommodating outcomes (Thomas \& Kilmann, 1974), but only when their own position was not sacrificed. There was little to be gained by these action-oriented negotiators with high power by remaining competitive, and they used this luxury position to form an accommodating strategy rather than to be competitive. The negotiators with high power in the current study received an attractive sum of points regardless of their agreement. However, when they had low power, action-oriented negotiators did not concede more, as such a decision would have gone against their own interests.

It is also possible that action-oriented negotiators conceding more with high power reflected the anger being perceived as appropriate. Action-oriented negotiators may have thought that 
the anger was only appropriate when they had an attractive alternative. The expressed anger may have signalled that their counterpart was in a worse position than themselves, and thus the expressed anger was appropriate. As discussed in the previous section, when negotiators have high power and they feel that the expressed anger is appropriate, they are more likely to concede than when they feel that the emotion is inappropriate (Van Kleef \& Côté, 2007). It can be argued that only action-oriented negotiators had the ability to discern whether the anger was appropriate or not and when given this luxury position, they adjusted their strategy to form an accommodating strategy.

This behaviour of these action-oriented negotiators conceding more with high power when facing an anger opponent was not replicated in the neutral condition as neutral emotion carries little information to signal the position. With anger, action-oriented negotiators were able to infer information about the counterpart's position.

In comparison, state-oriented negotiators did not change their behaviour with high power, because they did not have the capability to do so. It is possible that state-oriented individuals had the same intention, but were unable to convert this intention into action. In this thesis, state-oriented negotiators did not change their behaviour across emotion and power conditions in both studies. This finding is consistent with PSI theory, which explains that state-oriented individuals will struggle to regulate their behaviour in a demanding situation.

One further interesting finding in this study is that overall the participants were more cooperative than prior literature has suggested. In my data, most participants reached an agreement during the course of six rounds. In comparison, over $90 \%$ of students in prior studies using this negotiation case did not reach an agreement with this task (e.g., Van Kleef et al., 2004a). This finding is discussed in more depth in the following chapter, along with other contributions to theory created by these results.

\subsection{Chapter Summary}

This chapter presented the results of two experimental studies, which were conducted online. After presenting the preliminary analyses, which included sample characteristics and response rates, the model assumptions of normality and homogeneity were confirmed. Construct reliability was confirmed with each construct meeting the benchmark for the Cronbach alpha. In order to meet the benchmark for the power manipulation, two items were omitted. 
Then, a series of ANCOVAs were conducted to test the hypotheses. In study one, a significant main effect of personality was found and in study two, a three-way interaction for emotion, personality and power was identified. In summary, support was found for the second and for the final hypotheses. Importantly, these results supported the underlying tenet of this thesis that personality plays an important role in cross-cultural negotiations. The chapter closed with a discussion of these key findings. The following chapter presents the theoretical contribution of this research and it implications for practice. 


\section{Chapter 5. Conclusions and limitations}

\subsection{Overview}

This thesis set out to further understanding of how displays of anger influence negotiator behaviour in international negotiations. Specifically, it seeks to answer questions around how negotiators' self-regulation abilities moderate their concessionary behaviour in an international negotiation, and whether this moderation effect is dependent on their relative bargaining power.

I conducted two studies that measured U.S. negotiators' responses to varying displays of emotion by a Chinese counterpart. I identified the main effect of personality on concession size in study one and a three-way interaction between anger, bargaining power and personality on concessionary behaviour in study two.

My findings lead to several important theoretical, empirical and methodological contributions, which I describe in this chapter. These are:

1. The identification and integration of a personality trait that is novel in the negotiation field: negotiators' ability to regulate their response to emotion. The results of my studies have shown that the individual difference of action versus state orientation can help explain outcomes in international negotiations.

2. The present research confirmed, in an international negotiation context, that relative bargaining power is an influential moderator, with the finding that the social effect of anger is jointly moderated by both bargaining power and individual differences.

3. Further, I have extended EASI theory by incorporating negotiator capability and identifying its relationship negotiator behaviour.

4. Providing further evidence of the inefficacy of using student surrogates when exploring the social effect of emotion during negotiations.

5. Finally, this thesis extended understanding of the influence of the personality trait action orientation versus state orientation by testing it in a workplace scenario and have shown that it is linked to variations in behaviour.

In the final chapter of this thesis, I discuss each of these contributions and outline the implications for international business practice. Thereafter, I present the limitations of this thesis before I discuss avenues for future research suggested by my findings. The final section of this chapter is a summary statement. 


\subsection{Theoretical, Empirical and Methodological Contributions}

The motivation for this research was to explain the contradictory results of two seminal studies in the anger in negotiation field. Van Kleef and colleagues (2004a) reported that displays of anger were beneficial in negotiation because they led to concessions. Kopelman and her colleagues (2006) concluded that displaying anger did not lead to greater concessions than displaying happiness.

Building on economic psychology literature (Jäger et al., 2017) and incorporating negotiators' ability to self-regulate in response to displays of anger in the measurement of the individual difference of action versus state orientation, I have extended understanding of anger in negotiation. The research design answered recent calls in the negotiation literature for a renewal of efforts to explore the impact of individual differences (Elfenbein, 2015; Sharma et al., 2013).

Although there is a strengthening argument that personality differences need revisiting, the use of action orientation versus state orientation in the negotiation field was novel. In the first study, I found that regardless whether participants faced an angry counterpart or a counterpart expressing no emotion, action-oriented negotiators conceded less compared to state-oriented negotiators. Similarly, in the second study, these individual differences also influenced the negotiation outcome. When given high power, action-oriented negotiators were able to adapt their behaviour in order to achieve an accommodating strategy; whereas state-oriented negotiators were unable to regulate their behaviour. Together the results of both studies led to the first and most significant contribution of this thesis by showing that the individual difference of action versus state orientation can help explain outcomes of international negotiations.

This thesis contributes to our understanding of the relationship between anger and concessionary behaviour. Although there is a growing body of literature that has sought to explain how a negotiator will react to a display of anger, few of these studies have considered the international negotiation context and few have considered the interaction of personality traits with other moderators. This thesis explored the joint influence of individual differences and bargaining power and found that when action-oriented negotiators faced a culturally different counterpart, they adjusted their behaviour, depending on the relative power they held. In contrast, regardless of the emotion displayed or the level of bargaining power, there was no evidence that state-oriented negotiators changed their behaviour. When given the 
opportunity, only action-oriented negotiators are able to adapt their behaviour. Not all negotiators have a comparable capability to regulate their behaviour. The results of the second study extend previous findings by demonstrating that the social effect of anger is jointly moderated by both bargaining power and individual differences.

This finding that individual differences and bargaining power jointly predict the social effect of anger points to the need to extend the current negotiation model for anger. Van Kleef (2008) introduced the EASI theory as a unifying framework to help understand the diverse results of the social effect of anger, yet, it is difficult to explain the current results with EASI theory.

Within EASI theory, there is no provision to suggest that individuals may feel and respond to emotion differently. This omission is in line with the dominant paradigm in the negotiation literature that individual differences are irrelevant when researching negotiation behaviour (Sharma et al., 2013). The results of my second study demonstrate the need to incorporate and consider individual differences in self-regulation to fully understand the response to anger in a negotiation. Because negotiators don't process or react to emotion uniformly, it is important to take this attribute into account.

As explained in chapter two, EASI theory says that negotiators can react either strategically (cooperatively) or emotionally (strategically) to anger and that these two paths are moderated by two categories of variables: social relational factors and factors that influence a negotiator's motivation to process information (Van Kleef, 2010). It is difficult to accommodate action orientation versus state orientation in either of these two categories. Although Van Kleef (2010) suggests that the motivation to process information category includes the ability to process the information carried by the anger, the variables currently included in this category are bargaining power, time pressure and need for cognitive closure. All three of these can be thought of as situational variables rather than inherent individual differences in capability to react to anger. The results from my second study showed that the influence of bargaining power is dependent on the negotiator's self-regulation capability and the current variables included in the EASI model do not account for this relationship.

Accordingly, it is proposed that the individual difference of self-regulation ought to be incorporated into EASI theory under a new category: observer's capability. The term observer's capability has been chosen over self-regulation, to refer to a category of individual differences that can include other variables beyond the one identified in this thesis. 
The revised EASI theory shows a relationship between observer's capability and both existing moderating categories (see Figure 12 below). Study two found direct evidence for the relationship between observer's capability and information processing with the three-way interaction between bargaining power, personality and anger. The additional lines between social relational factors and observer's capability are untested, but there are a number of variables within this category that are also likely to depend on individual traits. For instance, the variable prevailing cultural norms could very likely depend on a negotiator's level of cultural intelligence.

Figure 12: Revised Emotion as Social Information Model Incorporating Observer's Capability

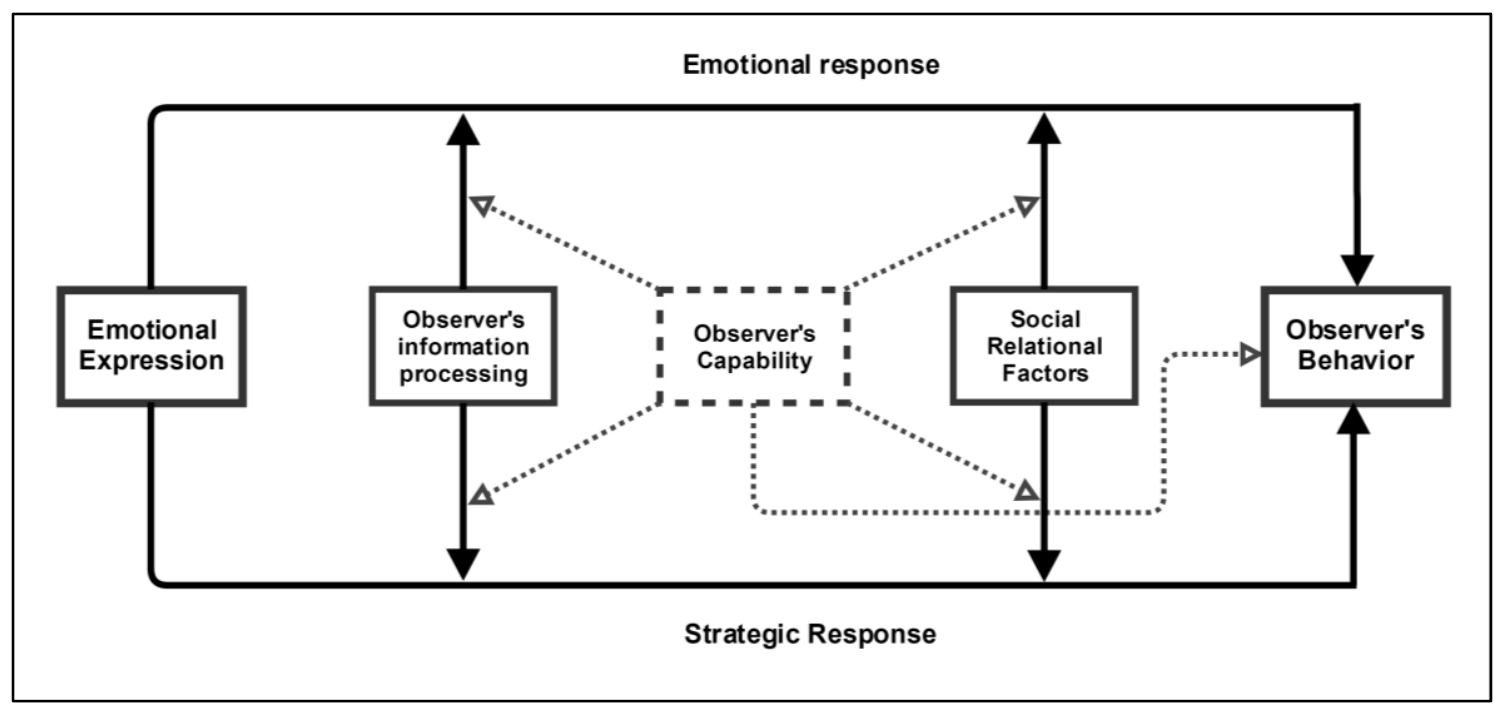

The revised EASI model incorporates a direct influence of observer's capability on observer's behaviour. This line reflects my finding that negotiators with low capability (stateoriented) do not take either path. Across both studies, state-oriented negotiators showed no evidence of being able to change their behaviour, regardless of their bargaining power level or the emotion they faced. In summary, this thesis makes a theoretical contribution extending the EASI model by including the relationship between the observer's capability and behaviour.

The findings in this research also raised an interesting methodological question regarding the use of students as surrogates for managers in negotiation research. Prior research has highlighted that students perform differently in decision making compared to older participants with more life and work experience (Hughes \& Gibson, 1991). My results 
suggest that this argument may be particularly pertinent when exploring the interpersonal effects of anger in international negotiations. In my studies, most participants came to an agreement before the final round. By comparison, studies using this case with students in a laboratory saw very few students come to an agreement. For example, in the seminal study by Van Kleef et al. (2004a) only approximately $10 \%$ of students came to an agreement across three studies. Moreover, the students who reached an agreement were excluded from the analysis, resulting in conclusions about the social effect of anger that directly contributed to EASI theory, which may well be based on negotiation impasses rather than negotiation agreements.

The results of my studies paint a picture of working professionals being less competitive than the student participants used in laboratory experiments. My findings raise a methodological flag that perhaps participants who come to an agreement (and who would have been excluded by other researchers) may be a better representation of the general population of negotiators than student negotiators.

My work joins the increasing number of papers in other areas of negotiation research that provides evidence that students are not the best surrogates for managers when exploring the social effect of emotion during negotiations.

Finally, my findings contribute to the organisational psychology literature by demonstrating the impact of action and state orientation on prevalent workplace behaviour - negotiation. Although the past decade has seen a rapid increase in the number of studies exploring action orientation and state orientation, little is known about their effect on organizational behaviour. Just one study, by Diefendorff and collegagues (2000) found that the overall reported performance of action-oriented employees was higher than that of state-oriented employees.

This study showed that action-oriented employees were rated better than state-oriented employees, but little is known about why or what behaviour created this difference in performance. My study contributes to this gap by testing and demonstrating that actionoriented negotiators have a better ability than state-oriented negotiators to adapt their behaviour during an international negotiation. I started this thesis explaining how globalisation has resulted in an increase in the number of international negotiations.

My results suggest that the personality-psychology/organisational psychology research stream has an important role to play in fully explicating conflict management and negotiation 
in multinational companies. Although I did not measure why action-oriented negotiators chose to concede more compared to state-oriented negotiators when they had high power, or concede less with no power manipulation, it is clear that action-oriented negotiators adapted their behaviour when given the opportunity. Further research in the workplace is needed to fully understand why behaviour is different between action-oriented and state-oriented individuals. In summary, this thesis adds to the broader psychology field by demonstrating a specific workplace scenario in which the personality trait action orientation versus state orientation creates variations in behaviour.

\subsection{Managerial Implications}

Most global managers would agree that understanding and dealing with emotions is an important part of any negotiation and can be particularly challenging in negotiations with a foreign counterpart. My findings raise intriguing questions regarding how individual differences influence negotiation practice. Traditionally, negotiation academics have downplayed the role of individual differences on negotiation behaviours and outcomes. This thesis is one of the first studies in the anger in negotiation field to demonstrate that individual differences play an important role, showing that two negotiators in the same position with similar skills and goals may have divergent results.

My findings suggest that recruiters should consider personality orientation during the selection process if it is likely that the manager will be involved in international negotiations. Psychometric testing plays an important role in MNC's recruitment processes (Kundu, Rattan, Sheera, \& Gahlawat, 2015; Ying Chang, Wilkinson, \& Mellahi, 2007) and adding the action orientation versus state orientation construct (ACS-90) will assist recruiters in selecting the most adaptable decision maker. It may also be worth testing current staff to understand their capabilities to self-regulate. For instance, if an organization has to select a candidate for an overseas assignment that is likely to be challenging and complex, an organization would be best served by sending an action-oriented negotiator rather than a state-oriented negotiator as their representative. My results suggest that an action-oriented manager will be better able to manage their behaviour to meet their mandated objectives. In comparison, a state-oriented representative will struggle to adapt their behaviour in such a dynamic situation.

It is worth noting that there is some evidence to suggest that it is possible to change orientation from action orientation to state orientation - in a case study with a 
psychotherapeutic intervention over 15 months, a state-oriented individual successfully became action-oriented (Blunt \& Pychyl, 2005). These findings raise a number of intriguing possibilities for professional development in MNCs. For instance, if a promising employee were state-oriented and was required to deal with displays of emotion in their work, it might be worth investing in professional development to develop their orientation toward being action-oriented. Generally, the personality trait of action orientation and state orientation is stable across time (Koole \& Fockenberg, 2011; Kuhl, 1994a) so such an intervention would be costly if it were deemed appropriate.

My results also suggest that discussing self-regulation capability would provide an interesting frame for any training on how to respond to anger in negotiations. For instance, a measurement and subsequent discussion of this capability may make negotiators more mindful of their automatic responses.

More work is needed to understand action-oriented and state-oriented negotiators before implementing these recommendations.

\subsection{Limitations of the study}

Despite every effort to design a robust study, as with all empirical studies, there are a number of important limitations that need to be considered.

Arguably, a weakness of my research design was that it did not involve face-to-face interaction. It was not possible to use a face-to-face design, or to find a trained Chinese actor who could authentically feign anger, but if it had been possible, it would have provided valuable insights into the dynamics of how negotiators react to a display of anger. The online format did provide a balance between control and naturalistic setting, strengthening generalizability.

Using participants in full-time employment strengthened external validity, however, there are some other methodological limitations. The first is the self-selection bias, because of the length of the simulation, and the specific demographic requirements of this study. To reduce self-selection bias, the study invitations did not include study-specific details, only what incentives were available and the length of time of the survey (Qualtrics, 2014). Further, the respondents did not know the demographic requirements. If they were screened out, they received a message explaining they did not qualify for this survey. 
An additional consideration for any online data collection is that the respondent's environment is outside the researcher's control. One particular concern is browser compatibility. Baker et al. (2004) argued that variations in viewing questions, and poor usability may affect data, which may also lead to premature termination. Such compatibility issues were partially reduced by using established Qualtrics panel members and hosting the study on Qualtrics software.

A further limitation on panel data is whether the respondents are honest about how they describe themselves. The veracity of the individuals' self-descriptions was managed by Qualtrics who used digital fingerprinting and/or United States Postal Service verification (Qualtrics, 2014). Finally, to strengthen the quality of the panel, Qualtrics and their partner panels keep records of invitations and survey completions to ensure that respondents maintain a consistent demographic and do not exceed weekly, monthly or even lifetime limits.

Using such a convenience sample provided the necessary control of cultural background. However, it can be argued that the panel data was only representative of Caucasian Americans active on the internet and the generalizability of the results may be limited. Replicating the influence of individual differences with the cultural background and target nationality of the negotiator showing anger will be helpful to both scholars and practice.

Another limitation, and one that was not foreseen, was two differences between study one and two, which led to an inability to compare the data across the studies. Although the data within each study is sound, inferences between study one and two must be made with caution. A programming error in study one led to a different finish point in study one and study two. Study two allowed an additional counteroffer from the participants and study two had the extra incentive for final points (their outcome) to be converted into lottery points. It is interesting to note that although the lottery was added in study two to enhance participation, the lottery did not seem to change the agreement rate. Nonetheless, the differences mean it is problematic to compare results across studies.

These studies did not include a measure for perceived appropriateness of the anger, which is a further limitation. As discussed in previous chapters, understanding whether negotiators perceived the anger as appropriate or not would have provided valuable explanatory power to the results. In my second study, action-oriented negotiators with high power conceded more compared to those with low power when facing an angry opponent. It would be particularly useful to know if the perception of appropriateness varied between action and state-oriented 
negotiators. A replication of the studies with the added measure for perceived appropriateness will provide useful information to advance the understanding of individual differences in negotiation research.

Despite these limitations, my studies have shown that action oriented negotiators have the capability to change their behaviour as the context changes. Replicating the study with an additional exploratory component to provide reasons for this behaviour would be helpful.

\subsection{Directions for future research}

This study has raised a number of interesting avenues for future research. Having shown that individual differences play an important role in understanding negotiation outcomes and that these differences were especially strong when a negotiator was facing an angry counterpart

with power imbalances, future research could examine other personality traits and individual differences that influence negotiation behaviour. For example, cultural intelligence (Thomas et al., 2015) and emotional intelligence (Côté \& Hideg, 2011) are two areas that will also likely have an impact on how a negotiator will respond to an angry counterpart.

Such studies would help validate the proposed line between the new category of the observer's capability within my extended EASI model and the social relational factors category. As previously mentioned, it is likely that the variable prevailing cultural norms depends on the individual-level difference of cultural intelligence. This thesis only explored the joint impact between the observer's capability and motivation to process information category and it would be helpful for future studies to explore the additional proposed line in EASI theory.

To develop a full picture of the role of self-regulation from an economic psychology point of view, additional studies will be needed that explore the relationship between manipulated self-regulation strategies and personality capability. Such studies would extend the work of Jäger, Loschelder and Friese (2017). For example, could those strategies help state-oriented overcome their comparative weakness in self-regulation? If so, would they apply such strategies without being prompted in subsequent negotiations? It would also be of interest whether the self-regulation strategies used in their work could be extended to other negative emotions such as guilt and sadness.

From a methodological perspective, a comparison of working professionals and students in a single study would provide a useful insight about sample selection. A large proportion of the 
anger in negotiation research has used students as surrogates for working professionals. Understanding how students and professionals differ in response to emotions in negotiations may shed further light on the contradictory findings. For example, the seminal study by Van Kleef and colleagues (2004a) used undergraduate students and concluded that the interpersonal effect of anger leads to greater concessions. In comparison, later research using MBA students found that anger generated smaller concessions in comparison to expressed happiness (Kopelman et al., 2006). A comparison between such studies is problematic and future research should test for differences.

Another interesting avenue that could help develop a more complete picture of how the social effects of emotion influence negotiations includes external mechanisms. For example, we know little about the relationship between posture and emotion. Prior research has demonstrated holding a deliberate open, expansive posture increased performance during stressful social interactions. Holding a powerful or expansive pose increases levels of testosterone (Carney, Cuddy, \& Yap, 2010; Minvaleev, Nozdrachev, Kir'yanova, \& Ivanov, 2004) and perceived level of power (Carney, Hall, \& LeBeau, 2005; Cuddy, Wilmuth, Yap, $\&$ Carney, 2015). On the contrary, holding a slumped or powerless pose is associated with higher levels of cortisol and lower perceived levels of power (Carney et al., 2010).

This finding may have important implications for anger in negotiation research, as a slumped, powerless position is connected with submissive behaviours (Tiedens \& Fragale, 2003). It can be expected that a strategic display of anger may be more successful in eliciting concessions from a counterpart with a slumped position compared to one holding an expansive pose. An expansive pose raises testosterone levels, which are associated with competitive behaviour (Eisenegger, Haushofer, \& Fehr, 2011). Therefore, an expression of anger to a person with an expansive pose may backfire. Understanding the relationship between posture and emotion may help negotiators strategically decide what emotion may be most effective to express during international negotiations.

\subsection{Final Reflections}

This study set out to explore the influence of individual differences on the social effect of anger during international negotiations. I combined literature from the anger in negotiation and the personality-psychology fields to propose that negotiators are inherently different in their capacity to self-regulate in response to displays of emotion. I hypothesised that these 
differences may explain why contradictory results have been reported from studies that explored the social effect of anger.

I have used my findings to extend Van Kleef's EASI theory, which remains the unifying model in the field of the social effect of anger in negotiation. I have extended the EASI model by adding observer's capability, which includes a negotiator's inherent ability to selfregulate. My research found that personality and the bargaining position of a negotiator jointly explain negotiation outcomes. Further, this thesis provided evidence of a direct relationship between concessionary behaviour and personality orientation. Across two studies, action-oriented negotiators were able to self-regulate and adjust their behaviour for their own gain. In comparison, across these experimental conditions, state-oriented negotiators were unable to modulate their behaviour.

In the course of this research, I have added my voice to recent dissent that individual differences are irrelevant when researching negotiation processes and outcomes (Elfenbein, 2015; Sharma et al., 2013). This study has enhanced our understanding of individual differences by demonstrating an association between personality traits and negotiator's response to displays of anger and is one of the first studies to do so.

In conclusion, this study contributes to extant knowledge by demonstrating that individual differences exert a significant influence on negotiating behaviours when the counterpart expresses anger. 


\section{Reference List}

Adam, H., \& Brett, J. M. (2015). Context matters: The social effects of anger in cooperative, balanced, and competitive negotiation situations. Journal of Experimental Social Psychology, 61, 44-58. http://doi.org/10.1016/j.jesp.2015.07.001

Adam, H., \& Shirako, A. (2013). Not all anger is created equal: the impact of the expresser's culture on the social effects of anger in negotiations. The Journal of Applied Psychology, 98(5), 785-98. http://doi.org/10.1037/a0032387

Adam, H., Shirako, A., \& Maddux, W. W. (2010). Cultural variance in the interpersonal effects of anger in negotiations. Psychological Science, 21(6), 882-9. http://doi.org/10.1177/0956797610370755

Aguinis, H., \& Lawal, S. O. (2012). Conducting field experiments using eLancing's natural environment. Journal of Business Venturing, 27(4), 493-505. http://doi.org/10.1016/j.jbusvent.2012.01.002

Aguinis, H., \& Vandenberg, R. J. (2014). An ounce of prevention is worth a pound of cure: Improving research quality before data collection. Annual Review of Organizational Psychology and Organizational Behavior, 1(1), 569-595. http://doi.org/10.1146/annurevorgpsych-031413-091231

Allemand, M., Job, V., Christen, S., \& Keller, M. (2008). Forgivingness and action orientation. Personality and Individual Differences, 45(8), 762-766. http://doi.org/10.1016/j.paid.2008.08.002

Allred, K. G. (1999). Anger and retaliation: Toward an understanding of impassioned conflict in organizations. Research in Negotiation in Organizations, 7, 27-58.

Allred, K. G., Mallozzi, J. S., Matsui, F., \& Raia, C. P. (1997). The influence of anger and compassion on negotiation performance. Organizational Behavior and Human Decision Processes, 70(3), 175-187. http://doi.org/10.1006/obhd.1997.2705

Baack, D. W., Dow, D., Parente, R., \& Bacon, D. R. (2015). Confirmation bias in individuallevel perceptions of psychic distance: An experimental investigation. Journal of International Business Studies, 46(8), 938-959. http://doi.org/10.1057/jibs.2015.19

Bagozzi, R. P., Baumgartner, H., \& Yi, Y. (1992). State versus action orientation and the theory of reasoned action: An application to coupon usage. Journal of Consumer Research, 
18(4), 505-518. http://doi.org/10.1086/209277

Baker, R. P., Crawford, S., \& Swinehart, J. (2004). Development and testing of web questionnaires. In S. Presser, J. M. Rothgeb, M. P. Couper, J. T. Lessler, E. Martin, J. Martin, \& E. Singer (Eds.), Methods for Testing and Evaluating Survey Questionnaires (pp. 361-384). Chicago, IL: John Wiley \& Sons, Inc.

Barry, B., \& Friedman, R. A. (1998). Bargainer characteristics in distributive and integrative negotiation. Journal of Personality and Social Psychology, 74(2), 345-359. http://doi.org/10.1037/0022-3514.74.2.345

Barry, B., Smithey Fulmer, I., \& van Kleef, G. (2004). I laughed, I cried, I settled. The role of emotion in negotiation. In M. J. Gelfand \& J. M. Brett (Eds.), The Handbook of Negotiation and Culture (pp. 71-94). Stanford: Stanford Business Books.

Bazerman, M. H., Curhan, J. R., Moore, D. A., \& Valley, K. L. (2000). Negotiation. Annual Review of Psychology, 51, 279-314. http://doi.org/10.1146/annurev.psych.51.1.279

Belkin, L. Y., Kurtzberg, T. R., \& Naquin, C. E. (2013). Signaling dominance in online negotiations: The role of affective tone. Negotiation and Conflict Management Research, 6(4), 285-304. http://doi.org/10.1111/ncmr.12016

Bello, D., Leung, K., Radebaugh, L., Tung, R. L., \& van Witteloostuijn, A. (2009). From the Editors: Student samples in international business research. Journal of International Business Studies, 40(3), 361-364. http://doi.org/10.1057/jibs.2008.101

Berry, J. W., Poortinga, Y. H., Breugelmans, S. M., Chasiotis, A., \& Sam, D. L. (2011). CrossCultural Psychology (3rd ed.). Cambridge, UK: Cambridge University Press.

Blunt, A., \& Pychyl, T. A. (2005). Project systems of procrastinators: a personal projectanalytic and action control perspective. Personality and Individual Differences, 38(8), 1771-1780. http://doi.org/10.1016/j.paid.2004.11.019

Borsboom, D., Mellenbergh, G. J., \& van Heerden, J. (2004). The concept of validity. Psychological Review, 111(4), 1061-1071. http://doi.org/10.1037/0033-295X.111.4.1061

Bossong, B. (1994). Scholastic stressors and achievement-related anxiety. In J. Kuhl \& J. Beckmann (Eds.), Volition and personality: Action versus state orientation (pp. 397-405). Gottingen, Germany: Hogrefe \& Huber. 
Bossong, B., \& von Saldern, M. (1984). Action-orientation, school stress and achievement anxiety. Zeitschrift für Entwicklungspsychologie und Pädagogische Psychologie, 16(3), 194-205.

Brett, J. F., Northcaft, G. B., \& Pinkley, R. L. (1999). Stairways to heaven: An interlocking self-regulation model of negotiation. Academy of Management Review, 24(3), 435-451. http://doi.org/10.5465/AMR.1999.2202130

Brooks, A. W., \& Schweitzer, M. E. (2011). Can Nervous Nelly negotiate? How anxiety causes negotiators to make low first offers, exit early, and earn less profit. Organizational Behavior and Human Decision Processes, 115(1), 43-54. http://doi.org/10.1016/j.obhdp.2011.01.008

Brunstein, J. C. (1989). The effects of action-oriented versus state-oriented styles of coping with failure on achievement related performance and cognition. Zeitschrift für Experimentelle und Angewandte Psychologie, 36(3), 349-367.

Brunstein, J. C. (1994). Dispositional action control as a predictor of how people cope with academic failure. In J. Kuhl \& J. Beckmann (Eds.), Volition and personality: Action versus state orientation (pp. 341-350). Göttingen, Germany: Hogrefe \& Huber.

Brunstein, J. C., \& Olbrich, E. (1985). Personal helplessness and action control: Analysis of achievement-related cognitions, self-assessments, and performance. Journal of Personality and Social Psychology, 48(6), 1540-1551. http://doi.org/10.1037/00223514.48.6.1540

Butt, A. N., Choi, J. N., \& Jaeger, A. M. (2005). The effects of self-emotion, counterpart emotion, and counterpart behavior on negotiator behavior: A comparison of individuallevel and dyad-level dynamics. Journal of Organizational Behavior, 26(6), 681-704. http://doi.org/10.1002/job.328

Callister, R. R., Geddes, D., \& Gibson, D. F. (2017). When is anger helpful or hurtful? Status and role impact on anger expression and outcomes. Negotiation and Conflict Management Research, 10(2), 69-87. http://doi.org/10.1111/ncmr.12090

Carney, D. R., Cuddy, A. J. C., \& Yap, A. J. (2010). Power posing: brief nonverbal displays affect neuroendocrine levels and risk tolerance. Psychological Science, 21(10), 13631368. http://doi.org/10.1177/0956797610383437 
Carney, D. R., Hall, J. A., \& LeBeau, L. S. (2005). Beliefs about the nonverbal expression of social power. Journal of Nonverbal Behavior, 29(2), 105-123. http://doi.org/10.1007/s10919-005-2743-z

Cervone, D., Shadel, W. G., Smith, R. E., \& Fiori, M. (2006). Self-regulation: Reminders and suggestions from personality science. Applied Psychology, 55(3), 333-385. http://doi.org/10.1111/j.1464-0597.2006.00261.x

Chang, S.-J., van Witteloostuijn, A., \& Eden, L. (2010). From the Editors: Common method variance in international business research. Journal of International Business Studies, 41(2), 178-184. http://doi.org/10.1057/jibs.2009.88

Chatterjee, M. B., Baumann, N., \& Osborne, D. (2013). You are not alone: relatedness reduces adverse effects of state orientation on well-being under stress. Personality \& Social Psychology Bulletin, 39(4), 432-41. http://doi.org/10.1177/0146167213476895

Chidlow, A., Ghauri, P. N., Yeniyurt, S., \& Cavusgil, S. T. (2015). Establishing rigor in mailsurvey procedures in international business research. Journal of World Business, 50(1), 26-35. http://doi.org/10.1016/j.jwb.2014.01.004

Cole, P. M., Michel, M. K., \& O’Donnell Teti, L. (1994). The development of emotion regulation and dysregulation: a clinical perspective. Monographs of the Society for Research in Child Development, 59(2-3), 73-100. http://doi.org/10.1111/j.15405834.1994.tb01278.x

Cook, T. D., Campbell, D. T., \& Peracchio, L. (1990). Quasi experimentation. In M. D. Dunnette \& L. M. Hough (Eds.), Handbook of industrial and organizational psychology (2nd ed., pp. 491-576). Palo Alto, CA: Consulting Psychologists Press.

Cornelius, R. R. (2000). Theoretical approaches to emotion. In ISCA Tutorial and Research Workshop (ITRW) on Speech and Emotion. Newcastle, Northern Ireland, UK.

Côté, S., \& Hideg, I. (2011). The ability to influence others via emotion displays: A new dimension of emotional intelligence. Organizational Psychology Review, 1(1), 53-71. http://doi.org/10.1177/2041386610379257

Côté, S., Hideg, I., \& Van Kleef, G. A. (2013). The consequences of faking anger in negotiations. Journal of Experimental Social Psychology, 49(3), 453-463. http://doi.org/10.1016/j.jesp.2012.12.015 
Cox, D. R., \& McCullagh, P. (1982). A biometrics invited paper with discussion. Some aspects of analysis of coveriance. Biometrics, 38(3, Special Issue: Analysis of Covariance), 541561.

Cozby, P. C., \& Bates, S. C. (2011). Methods in Behavioral Research (11th ed.). New York, NY: McGraw Hill.

Cronbach, L. J. (1951). Coefficient alpha and the internal structure of tests. Psychometrika, 16(3), 297-334. http://doi.org/10.1007/BF02310555

Cronbach, L. J., \& Meehl, P. E. (1955). Construct validity in psychological tests. Psychological Bulletin, 52(4), 281-302. http://doi.org/10.1037/h0040957

Cuddy, A. J. C., Wilmuth, C. A., Yap, A. J., \& Carney, D. R. (2015). Preparatory power posing affects nonverbal presence and job interview performance. Journal of Applied Psychology, 100(4), 1286-1295. http://doi.org/10.1037/a0038543

Darwin, C. (1872). The expression of the emotions in man and animals. London, England: John Murray. http://doi.org/10.1037/10001-000

De Dreu, C. K. W., \& Van Lange, P. A. M. (1995). The impact of social value orientations on negotiator cognition and behavior. Personality and Social Psychology Bulletin, 21(11), 1178-1188. http://doi.org/10.1177/01461672952111006

Dehghani, M., Carnevale, P. J., \& Gratch, J. (2014). Interpersonal effects of expressed anger and sorrow in morally charged negotiation. Judgment and Decision Making, 9(2), 104113. Retrieved from http://journal.sjdm.org/13/13910b/jdm13910b.html

Dholakia, U., Tam, L., Yoon, S., \& Wong, N. (2016). The ant and the grasshopper: Understanding personal saving orientation of consumers. Journal of Consumer Research, 43(1), 134-155. http://doi.org/10.1093/jcr/ucw004

Diefendorff, J. M., Hall, R. J., Lord, R. G., \& Strean, M. L. (2000). Action-state orientation: construct validity of a revised measure and its relationship to work-related variables. The Journal of Applied Psychology, 85(2), 250-263. http://doi.org/10.1037/00219010.85 .2 .250

Dillman, D. A., \& Redline, C. D. (2004). Testing paper self-administered questionnaires: Cognitive interview and field test comparisons. In S. Presser, J. M. Rothgeb, M. P. Couper, J. T. Lessler, E. Martin, J. Martin, \& E. Singer (Eds.), Methods for Testing and 
Evaluating Survey Questionnaires (pp. 299-317). Chicago, IL: John Wiley \& Sons, Inc.

Dinkevych, E., Wilken, R., Aykac, T., Jacob, F., \& Prime, N. (2017). Can outnumbered negotiators succeed? The case of intercultural business negotiations. International Business Review, 26(3), 592-603. http://doi.org/10.1016/j.ibusrev.2016.12.001

Edmondson, A. M. Y. C., \& McManus, S. E. (2007). Methodological fit in management. Academy of Management Review, 32(4), 1155-1179.

Eisenegger, C., Haushofer, J., \& Fehr, E. (2011). The role of testosterone in social interaction. Trends in Cognitive Sciences, 15(6), 263-271. http://doi.org/10.1016/j.tics.2011.04.008

Ekman, P. (1992a). An argument for basic emotions. Cognition \& Emotion, 6(3/4), 169-200.

Ekman, P. (1992b). Are there basic emotions? Psychological Review, 99(3), 550-553. http://doi.org/10.1037//0033-295X.99.3.550

Ekman, P., \& Friesen, W. V. (1971). Constants across cultures in the face and emotion. Journal of Personality and Social Psychology, 17, 124-129.

Ekman, P., Roper, G., \& Hager, J. C. (1980). Deliberate facial movement. Child Development, $51,886-891$.

Elfenbein, H. A. (2013). Individual differences in negotiation. In M. Olekalns \& W. L. Adair (Eds.), Handbook of Research on Negotiation (pp. 25-45). Northampton, MA, USA: Edward Elgar.

Elfenbein, H. A. (2015). Individual differences in negotiation: A nearly abandoned pursuit revived. Current Directions in Psychological Science, 24(2), 131-136. http://doi.org/10.1177/0963721414558114

Ellis, P. D. (2010). Effect sizes and the interpretation of research results in international business. Journal of International Business Studies, 41(9), 1581-1588. http://doi.org/10.1057/jibs.2010.39

Fabiansson, E. C., \& Denson, T. F. (2012). The Effects of Intrapersonal Anger and Its Regulation in Economic Bargaining. PLoS ONE, 7(12), e51595. http://doi.org/10.1371/journal.pone.0051595

Field, A. (2013). Discovering statistics using IBM SPSS statistics (4th ed.). Thousand Oaks, CA: SAGE Publications Ltd. 
Filipowicz, A., Barsade, S., \& Melwani, S. (2011). Understanding emotional transitions: The interpersonal consequences of changing emotions in negotiations. Journal of Personality and Social Psychology, 101(3), 541-556. http://doi.org/10.1037/a0023545

Fischer, R., Plessow, F., Dreisbach, G., \& Goschke, T. (2015). Individual differences in the context-dependent recruitment of cognitive control: Evidence from action versus state orientation. Journal of Personality, 83(5), 575-583. http://doi.org/10.1111/jopy.12140

Forgas, J. (2002). Feeling and doing: Affective influences on interpersonal behavior. Psychological Inquiry, 13(1), 1-28. Retrieved from http://www.tandfonline.com/doi/pdf/10.1207/S15327965PLI1301_01

French, J. R. P., \& Raven, B. (1959). The bases of social power. In D. Cartwright (Ed.), Studies in social power (pp. 150-167). Ann Arbor, MI: Institute for Social Research.

Friedman, R., Anderson, C., Brett, J., Olekalns, M., Goates, N., \& Lisco, C. C. (2004). The positive and negative effects of anger on dispute resolution: evidence from electronically mediated disputes. The Journal of Applied Psychology, 89(2), 369-76. http://doi.org/10.1037/0021-9010.89.2.369

Friedman, R., Chi, S.-C., \& Liu, L. A. (2006). An expectancy model of Chinese-American differences in conflict-avoiding. Journal of International Business Studies, 37(4), 572573. http://doi.org/10.1057/palgrave.jibs. 8400212

Fuhrer, U. (1994). The search for information in an unfamiliar field setting as a function of action versus state orientation. In J. Kuhl \& J. Beckmann (Eds.), Volition and personality: Action versus state orientation (pp. 407-415). Göttingen, Germany: Hogrefe \& Huber.

George, J. M., Jones, G. R., \& Gonzalez, J. A. (1998). The Role of Affect in Cross-Cultural Negotiations. Journal of International Business Studies, 29(4), 749-772. http://doi.org/10.1057/palgrave.jibs.8490051

Gibson, D. E., \& Callister, R. R. (2010). Anger in organizations: Review and integration. Journal of Management, 36(1), 66-93. http://doi.org/10.1177/0149206309348060

Glass, G. V. (1966). Testing homogeneity of variances. American Educational Research Journal, 3(3), 187-190.

Greer, L., \& Bendersky, C. (2013). Power and status in conflict and negotiation research: Introduction to the special issue. Negotiation and Conflict Management Research, 6(4), 
239-252. http://doi.org/10.1111/ncmr.12021

Gromet, D. M., Hartson, K. A., \& Sherman, D. K. (2015). The politics of luck: Political ideology and the perceived relationship between luck and success. Journal of Experimental Social Psychology, 59, 40-46. http://doi.org/10.1016/j.jesp.2015.03.002

Gross, J. J. (2008). Emotion regulation. In M. Lewis, J. M. Haviland-Jones, \& L. Feldman Barrett (Eds.), Handbook of Emotion (3rd ed., pp. 497-512). New York, NY: Guilford Press.

Gross, J. J., \& Thompson, R. A. (2007). Emotion regulation: Conceptual foundations. In J. J. Gross (Ed.), Handbook of emotion regulation (3rd ed., pp. 3-26). Guilford Press.

Hagtvedt, H. (2011). The impact of incomplete typeface logos on perceptions of the firm. Journal of Marketing, 75(4), 86-93. http://doi.org/10.1509/jmkg.75.4.86

Hair, J. F. J., Black, W. C., Babin, B. J., \& Anderson, R. E. (2010). Multivariate data analysis (7th ed.). Upper Saddle River, NJ: Pearson Prentice Hall. http://doi.org/10.1016/j.ijpharm.2011.02.019

Hansen, S. E., \& Couper, M. P. (2004). Usability testing to evaluate computer-assisted instruments. In S. Presser, J. M. Rothgeb, M. P. Couper, J. T. Lessler, E. Martin, J. Martin, \& E. Singer (Eds.), Methods for Testing and Evaluating Survey Questionnaires (pp. 337360). Chicago, IL: John Wiley \& Sons, Inc.

Hareli, S., David, S., Akron, S., \& Hess, U. (2013). The effect of the negotiator's social power as a function of the counterpart's emotional reactions in a computer mediated negotiation. Europe's Journal of Psychology, 9(4), 820-831. http://doi.org/10.5964/ejop.v9i4.639

Harinck, F., \& Van Kleef, G. A. (2012). Be hard on the interests and soft on the values: Conflict issue moderates the effects of anger in negotiations. British Journal of Social Psychology, 51(4), 741-752. http://doi.org/10.1111/j.2044-8309.2011.02089.x

Heckhausen, H., \& Strang, H. (1988). Efficiency under record performance demands: Exertion control — an individual difference variable? Journal of Personality and Social Psychology, $55,489-498$.

Hine, M. J., Murphy, S. A., Weber, M., \& Kersten, G. (2009). The Role of Emotion and Language in Dyadic E-negotiations. Group Decision and Negotiation, 18(3), 193-211. http://doi.org/10.1007/s10726-008-9151-9 
Hughes, C. T., \& Gibson, M. L. (1991). Students as surrogates for managers in a decisionmaking environment: An experimental study. Journal of Management Information Systems, 8(2), 153-166. http://doi.org/10.1080/07421222.1991.11517925

Hunsaker, D. A. (2017). Anger in negotiations : A review of causes, effects, and unanswered questions, 10(3), 220-241. http://doi.org/10.1111/ncmr.12096

IJzerman, H., \& Van Prooijen, J. W. (2008). Just world and the emotional defense of self. Social Psychology, 39(2), 117-120. http://doi.org/10.1027/1864-9335.39.2.117

Jäger, A., Loschelder, D. D., \& Friese, M. (2017). Using self-regulation to overcome the detrimental effects of anger in negotiations. Journal of Economic Psychology, 58, 31-43. http://doi.org/10.1016/j.joep.2016.09.003

James, W. (1884). What is an emotion? Mind, 9(34), 188-205. http://doi.org/10.1093/mind/osIX.34.188

Johnson, J. A. (2005). Ascertaining the validity of individual protocols from Web-based personality inventories. Journal of Research in Personality, 39(1), 103-129. http://doi.org/10.1016/j.jrp.2004.09.009

Jostmann, N. B., \& Koole, S. L. (2006). On the waxing and waning of working memory: Action orientation moderates the impact of demanding relationship primes on working memory capacity. Personality and Social Psychology Bulletin, 32(12), 1716-1728. http://doi.org/10.1017/CBO9781107415324.004

Jostmann, N. B., Koole, S. L., van der Wulp, N. Y., \& Fockenberg, D. a. (2005). Subliminal affect regulation: The moderating role of action vs state orientation. European Psychologist, 10(3), 209-217. http://doi.org/10.1027/1016-9040.10.3.209

Kazén, M., Baumann, N., \& Kuhl, J. (2003). Self-infiltration vs. self-compatibility checking in dealing with unattractive tasks: The moderating influence of state vs. action orientation. Motivation and Emotion, 27(3), 157-197. http://doi.org/10.1023/A:1025043530799

Kilmann, R. H., \& Thomas, K. W. (1977). Developing a Forced-Choice Measure of ConflictHandling Behavior: The "MODE" Instrument. Educational and Psychological Measurement, 37(2), 309-325.

Kim, P. H., Pinkley, R. L., \& Fragale, A. R. (2005). Power dynamics in negotiation. Academy of Management Review, 30(4), 799-822. http://doi.org/10.5465/AMR.2005.18378879 
Kline, P. (1999). The handbook of psychological testing (2nd ed.). London: Routledge.

Koole, S. L., \& Fockenberg, D. A. (2011). Implicit emotion regulation under demanding conditions: the moderating role of action versus state orientation. Cognition \& Emotion, 25(3), 440-52. http://doi.org/10.1080/02699931.2010.544891

Koole, S. L., \& Jostmann, N. B. (2004). Getting a grip on your feelings: Effects of action orientation and external demands on intuitive affect regulation. Journal of Personality and Social Psychology, 87(6), 974-990. http://doi.org/10.1037/0022-3514.87.6.974

Koole, S. L., Jostmann, N. B., \& Baumann, N. (2012). Do demanding conditions help or hurt self- regulation? Social and Personality Psychology Compass, 6(4), 328-346. Retrieved from http://onlinelibrary.wiley.com/doi/10.1111/j.1751-9004.2012.00425.x/full

Koole, S. L., Kuhl, J., Jostmann, N. B., \& Vohs, K. D. (2005). On the hidden benefits of state orientation: Can people prosper without efficient affect regulation skills? In A. Tesser, J. V. Wood, \& D. A. Stapel (Eds.), On building, defending and regulating the self: $A$ psychological perspective (pp. 217-244). New York, NY: Psychology Press.

Kopelman, S., \& Rosette, A. S. (2008). Cultural variation in response to strategic emotions in negotiations. Group Decision and Negotiation, 17(1), 65-77. http://doi.org/10.1007/s10726-007-9087-5

Kopelman, S., Rosette, A., \& Thompson, L. (2006). The three faces of Eve: Organizational Behavior and Human Decision Processes, 99, 81-101.

Kraiger, K., Billings, R. S., \& Isen, A. M. (1989). The influence of positive affective states on task perceptions and satisfaction. Organizational Behavior and Human Decision Processes, 44, 12-25.

Kuhl, J. (1994a). A theory of action and state orientation. In J. Kuhl \& J. Beckmann (Eds.), Volition and personality: Action versus state orientation (pp. 9-46). Göttingen, Germany: Hogrefe \& Huber.

Kuhl, J. (1994b). Action versus state orientation: Psychometric properties of the Action Control Scale (ACS-90). In J. Kuhl \& J. Beckmann (Eds.), Volition and personality: Action versus state orientation (pp. 47-59). Göttingen, Germany: Hogrefe \& Huber.

Kuhl, J. (2000). The volitional basis of personality systems interaction theory: Applications in learning and treatment contexts. International Journal of Educational Research, 33(7-8), 
665-703. http://doi.org/10.1016/S0883-0355(00)00045-8

Kuhl, J., \& Goschke, T. (1994). A theory of action control: Mental subsystems, models of control, and volitional conflict-resolution strategies. In J. Kuhl \& J. Beckmann (Eds.), Volition and personality: Action versus state orientation (pp. 91-124). Göttingen, Germany: Hogrefe \& Huber.

Kuhl, J., Kazén, M., \& Koole, S. (2006). Putting self- regulation theory into practice: A user's manual. Applied Psychology, 55(3), 408-418. Retrieved from http://onlinelibrary.wiley.com/doi/10.1111/j.1464-0597.2006.00260.x/full

Kuhl, J., \& Weiß, M. (1994). Performance deficits following uncontrollable failure: Impaired action control or global attributions and generalized expectancy deficits? In J. Kuhl \& J. Beckmann (Eds.), Volition and personality: Action versus state orientation (pp. 317-328). Göttingen, Germany: Hogrefe \& Huber.

Kundu, S. C., Rattan, D., Sheera, V. P., \& Gahlawat, N. (2015). Recruitment and selection techniques used in corporate sector: A comparative study of Indian and multinational companies recruitment and selection techniques used in corporate sector. Journal of Organisation and Human Behaviour, 4(4), 40-50.

Landers, R. N., \& Behrend, T. S. (2015). An inconvenient truth: Arbitrary distinctions between organizational, mechanical turk, and other convenience samples. Industrial and Organizational Psychology, 8(2), 142-164. http://doi.org/10.1017/iop.2015.13

Ledoux, J. (1996). The emotional brain. New York, NY: Simon \& Shuster.

Lelieveld, G.-J., Van Dijk, E., Van Beest, I., Steinel, W., \& Van Kleef, G. A. (2011). Disappointed in you, angry about your offer: Distinct negative emotions induce concessions via different mechanisms. Journal of Experimental Social Psychology, 47(3), 635-641. http://doi.org/10.1016/j.jesp.2010.12.015

Lelieveld, G.-J., Van Dijk, E., Van Beest, I., \& Van Kleef, G. A. (2012). Why anger and disappointment affect other's bargaining behavior differently. Personality and Social Psychology Bulletin, 38(9), 1209-1221. http://doi.org/10.1177/0146167212446938

Lewicki, R. J., Barry, B., \& Saunders, D. M. (2010). Negotiation (Sixth Edit). McGraw-Hill Irwinneog.

Lewicki, R. J., Litterer, J. A., Minton, J. W., \& Saunders, D. M. (1994). Negotiation (2nd ed.). 
Burr Ridge, IL: Irwin.

Lewicki, R. J., Saunders, D. M., \& Barry, B. (2015). Negotiation (7th ed.). New York, NY: McGraw-Hill Education.

Lincoln, Y. S., \& Guba, E. G. (2000). Paradigmatic controversies, contradictions, and emerging confluences. In N. K. Denzin \& Y. S. Lincoln (Eds.), The handbook of qualitative research (2nd ed., pp. 163-188). London: Sage.

Liu, M. (2009). The intrapersonal and interpersonal effects of anger on negotiation strategies:

A cross-cultural investigation. Human Communication Research, 35(1), 148-169. http://doi.org/10.1111/j.1468-2958.2008.01342.x

Long, C. P., Bendersky, C., \& Morrill, C. (2011). Fairness monitoring: Linking managerial controls and fairness judgments in organizations. Academy of Management Journal, 54(5), 1045-1068. http://doi.org/10.5465/amj.2011.0008

MacKenzie, S. B., \& Podsakoff, P. M. (2012). Common method bias in marketing: Causes, mechanisms, and procedural remedies. Journal of Retailing, 88(4), 542-555. http://doi.org/10.1016/j.jretai.2012.08.001

Mason, C. H., \& Perreault, W. D. (1991). Collinearity, power, and interpretation of multiple regression analysis. Journal of Marketing Research, 28(3), 268-280. http://doi.org/10.2307/3172863

Meade, A. W., \& Craig, S. B. (2011). Identifying careless responses in survey data. Psychological Methods, 17(3), 437-455. http://doi.org/10.1037/a0028085

Mertens, D. M. (2014). Research and evaluation in education and psychology: Integrating diversity with quantitative, qualitative, and mixed methods. Thousand Oaks, CA: Sage Publications.

Messick, S. (1989). Validity. In R. L. Linn (Ed.), Educational measurement (pp. 13-103). New York, NY: Macmillan.

Metcalf, L. E., Bird, A., Shankarmahesh, M., Aycan, Z., Larimo, J., \& Valdelamar, D. D. (2006). Cultural tendencies in negotiation: A comparison of Finland, India, Mexico, Turkey, and the United States. Journal of World Business, 41(4), 382-394. http://doi.org/10.1016/j.jwb.2006.08.004 
Miller, G. M., \& Chapman, J. P. (2001). Misunderstanding analysis of covariance. Journal of Abnormal Psychology, 110(1), 40-48. http://doi.org/10.1037//0021-843X.110.1.40

Minvaleev, R. S., Nozdrachev, A. D., Kir'yanova, V. V., \& Ivanov, A. I. (2004). Postural influences on the hormone level in healthy subjects: I. The cobra posture and steroid hormones. Human Physiology, 30(4), 452-456. http://doi.org/10.1023/B:HUMP.0000036341.80214.28

Muraven, M., \& Baumeister, R. F. (2000). Self-regulation and depletion of limited resources: Does self-control resemble a muscle? Psychological Bulletin, 126(2), 247-259. http://doi.org/10.1037//0033-2909.126.2.247

Niven, K., Totterdell, P., \& Holman, D. (2009). A classification of controlled interpersonal affect regulation strategies. Emotion, 9(4), 498-509. http://doi.org/10.1037/a0015962

Oetzel, J., Garcia, A. J., \& Ting-Toomey, S. (2008). An analysis of the relationships among face concerns and facework behaviors in perceived conflict situations: A four-culture investigation. International Journal of Conflict Management, 19(4), 382-403. http://doi.org/10.1108/10444060810909310

Olejnik, S., \& Algina, J. (2003). Generalized eta and omega squared statistics: Measures of effect size for some common research designs. Psychological Methods, 8(4), 434-447. http://doi.org/10.1037/1082-989X.8.4.434

Palfai, T. P. (2002). Action-state orientation and the self-regulation of eating behavior. Eating Behaviors, 3(3), 249-259. http://doi.org/10.1016/S1471-0153(02)00068-5

Paolacci, G., \& Chandler, J. (2014). Inside the turk: Understanding mechanical turk as a participant pool. Current Directions in Psychological Science, 23(3), 184-188. http://doi.org/10.1177/0963721414531598

Peter, J. P. (1981). Construct validity: A review of basic issues and marketing practices. Journal of Marketing Research, 18(2), 133-145. http://doi.org/10.2307/3150948

Pietroni, D., Van Kleef, G. A., Rubaltelli, E., \& Rumiati, R. (2008). When happiness pays in negotiation. Mind \& Society, 8(1), 77-92. http://doi.org/10.1007/s11299-008-0047-9

Pillutla, M., \& Murnighan, J. (1996). Unfairness, anger, and spite: Emotional rejections of ultimatum offers. Organizational Behavior and Human Decision ..., 68(3), 208-224. Retrieved from http://www.sciencedirect.com/science/article/pii/S0749597896901004 
Podsakoff, P. M., MacKenzie, S. B., Lee, J.-Y., \& Podsakoff, N. P. (2003). Common method biases in behavioral research: a critical review of the literature and recommended remedies. The Journal of Applied Psychology, 88(5), 879-903. http://doi.org/10.1037/0021-9010.88.5.879

Presser, S., Couper, M. P., Lessler, J. T., Martin, E., Martin, J., Rothgeb, J. M., \& Singer, E. (2004). Methods for testing and evaluating survey questions. Public Opinion Quarterly, 68(1), 109-130. http://doi.org/10.1093/poq/nfh008

Qualtrics. (2014). ESOMAR 28: 28 Questions to help research buyers of online samples. Retrieved from http://success.qualtrics.com/rs/qualtrics/images/ESOMAR 28 2014.pdf

Reichardt, C. S., \& Rallis, S. F. (1994). Qualitative and quantitative inquiries are not incompatible: A call for a new partnership. New Directions for Program Evaluation, (61), 85-91. http://doi.org/10.1002/ev.1670

Rivers, C., \& Lytle, A. (2007). Lying, cheating foreigners!! Negotiation ethics across cultures. $\begin{array}{llll}\text { International Negotiation, } & \text { Retrieved } & \text { from }\end{array}$ http://www.ingentaconnect.com/content/mnp/iner/2007/00000012/00000001/art00001

Rosette, A. S., Kopelman, S., \& Abbott, J. L. (2013). Good grief! Anxiety sours the economic benefits of first offers. Group Decision and Negotiation, 23(3), 629-647. http://doi.org/doi:10.1007/s10726-013-9348-410

Roth, K. (1993). Entscheidungsverhalten im Sportspiel in Abhängigkeit von situations-und personenbezogenen Konzentrationsmerkmalen. In J. Beckmann, H. Strang, \& E. Hahn (Eds.), Aufmerksamkeit und Energetisierung. Facetten von Konzentration und Leistung (pp. 155-175). Göttingen, Germany: Hogrefe \& Huber.

Rousseeuw, P. J., \& Hubert, M. (2011). Robust statistics for outlier detection. Wiley Interdisciplinary Reviews: Data Mining and Knowledge Discovery, 1(1), 73-79. http://doi.org/10.1002/widm.2

Rutherford, A. (2001). Introduction ANOVA and ANCOVA: A GLM Approach. London: Sage publications.

Salacuse, J. W. (1999). Intercultural negotiation in international business. Group Decision and Negotiation, 8(3), 217-236. http://doi.org/10.1023/A:1008660330550

Schoenewolf, G. (1990). Emotional contagion: Behavioral induction in individuals and groups. 
Modern Psychoanalysis.

Schultz, B. B. (1985). Levene's test for relative variation. Systematic Biology, 34(4), 449-456.

Sharma, S., Bottom, W. P., \& Elfenbein, H. A. (2013). On the role of personality, cognitive ability, and emotional intelligence in predicting negotiation outcomes: A meta-analysis. Organizational Psychology Review, 3(4), 293-336. http://doi.org/10.1177/2041386613505857

Shell, G. R. (2001). Bargaining styles and negotiation: The Thomas-Kilmann conflict mode instrument in negotiation training. Negotiation Journal. http://doi.org/10.1023/A:1013280109471

Shenkar, O., \& Ronen, S. (1987). The cultural context of negotiations: The implications of Chinese interpersonal norms. The Journal of Applied Behavioral Science, 23(2), 263-275. http://doi.org/10.1177/0021886387232009

Simmons, J. P., Nelson, L. D., \& Simonsohn, U. (2011). False-positive psychology: Undisclosed flexibility in data collection and analysis allows presenting anything as significant. Psychological Science, 22(11), 1359-1366. http://doi.org/10.1177/0956797611417632

Sinaceur, M., Kopelman, S., Vasiljevic, D., \& Haag, C. (2015). Weep and get more: When and why sadness expression is effective in negotiations. Journal of Applied Psychology, 100(6), 1847-1871. http://doi.org/10.1037/a0038783

Sinaceur, M., \& Tiedens, L. Z. (2006). Get mad and get more than even: When and why anger expression is effective in negotiations. Journal of Experimental Social Psychology, 42(3), 314-322. http://doi.org/10.1016/j.jesp.2005.05.002

Sinaceur, M., Van Kleef, G. A., Neale, M. A., Adam, H., \& Haag, C. (2011). Hot or cold: is communicating anger or threats more effective in negotiation? The Journal of Applied Psychology, 96(5), 1018-32. http://doi.org/10.1037/a0023896

Song, Z., Wanberg, C., Niu, X., \& Xie, Y. (2006). Action-state orientation and the theory of planned behavior: A study of job search in China. Journal of Vocational Behavior, 68(3), 490-503. http://doi.org/10.1016/j.jvb.2005.11.001

Steinel, W., Van Kleef, G. A., \& Harinck, F. (2008). Are you talking to me?! Separating the people from the problem when expressing emotions in negotiation. Journal of 
Experimental Social Psychology, $\quad$ 44(2), 362-369. http://doi.org/10.1016/j.jesp.2006.12.002

Stiensmeier-Pelster, J. (1994). Choice of decision-making strategies and action versus state orientation. In J. Kuhl \& J. Beckmann (Eds.), Volition and personality: Action versus state orientation (pp. 167-176). Göttingen, Germany: Hogrefe \& Huber.

Stiensmeier-Pelster, J., John, M., \& Stulik, A. (1989). Die Wahl von Entscheidungsstrategien: Der Einfluss von Handlungs- und Lageorientierung und die Bedeutung psychologischer Kosten. Zeitschrift für Experimentelle und Angewandte Psychologie, 36(2), 292-310. Retrieved from http://pub.uni-bielefeld.de/download/1778713/2312499

Strang, H. (1986). Handlungskontrolle und sportliche Leistung: Leistungstheorien und experimentelle Untersuchungen über die Auswirkungen von Misserfolg auf die konzentrierte Handlungsausführung. University of Kiel.

Strang, H. (1994). Performance-inducing influence of action and state orientation: Applying control theories to processes in sport. In J. Kuhl \& J. Beckmann (Eds.), Volition and personality: Action versus state orientation (pp. 453-465). Göttingen, Germany: Hogrefe $\&$ Huber.

Strang, H., Wegener, M., \& Schwarze, S. (1987). Die Bewältigung von Miserfolgserfahrungen. Sportpsychologie, 1, 22-25.

Terborg, J. R. (1981). Interactional psychology and research on human behavior in organizations. Academy of Management Review, 6(4), 569-576. http://doi.org/10.5465/AMR.1981.4285691

Thomas, D. C., Liao, Y., Aycan, Z., Cerdin, J.-L., Pekerti, A. A., Ravlin, E. C., ... van de Vijver, F. (2015). Cultural intelligence: A theory-based, short form measure. Journal of International Business Studies, 46(9), 1099-1118. http://doi.org/10.1057/jibs.2014.67

Thomas, K. W., \& Kilmann, R. H. (1974). Thomas-Kilmann conflict mode instrument. Tuxedo, NY: Xicom Inc.

Thompson, L. (1990). Negotiation behavior and outcomes: Empirical evidence and theoretical issues. Psychological Bulletin, 108(3), 515-532. http://doi.org/10.1037/00332909.108.3.515

Tiedens, L. Z., \& Fragale, a R. (2003). Power moves: complementarity in dominant and 
submissive nonverbal behavior. Journal of Personality and Social Psychology, 84(3), 558-568. http://doi.org/10.1037/0022-3514.84.3.558

Tng, H., \& Au, A. K. C. (2014). Strategic display of anger and happiness in negotiation: The moderating role of perceived authenticity. Negotiation Journal, 30(3), 301-327. http://doi.org/10.1111/nejo.12062

Triandis, H. C., Carnevale, P. J., Gelfand, M., Robert, C., Wasti, S. a., Probst, T., ... Schmitz, P. (2001). Culture and deception in business negotiations: A multilevel analysis. International Journal of Cross Cultural Management, 1(1), 73-90. http://doi.org/10.1177/147059580111008

Trompenaars, F., \& Hampden-Turner, C. (1998). Riding the waves of culture. Understanding cultural diversity in business (2nd ed.). New York, NY: McGraw Hill. Retrieved from http://scholar.google.com/scholar?hl=en\&btnG=Search\&q=intitle:Riding+the+Waves+o $\mathrm{f}+$ Culture.+Understanding+Cultural+Diversity+in+Business\#1

Trompenaars, F., \& Hampden-Turner, C. (2012). Riding the waves of culture: Understanding diversity in global business (3rd ed.). New York, NY: McGraw-Hill Professional Publishing.

Ulijn, J., Rutkowski, A. F., Kumar, R., \& Zhu, Y. (2005). Patterns of feelings in face-to-face negotiation: a Sino-Dutch pilot study. Cross Cultural Management: An International Journal, 12(3), 103-118. http://doi.org/10.1108/13527600510798097

Van Dijk, E., Van Kleef, G. A., Steinel, W., \& Van Beest, I. (2008). A social functional approach to emotions in bargaining: when communicating anger pays and when it backfires. Journal of Personality and Social Psychology, 94(4), 600-14. http://doi.org/10.1037/0022-3514.94.4.600

Van Kleef, G. A. (2008). Emotion in Conflict and Negotiation: Introducing the Emotions as Social Information (EASI) Model. In N. M. Ashkanasy \& C. L. Cooper (Eds.), Research companion to emotion in organizations (pp. 392-404). London: Edward Elgar. http://doi.org/10.4337/9781848443778.00034

Van Kleef, G. A. (2009). How emotions regulate social life: The Emotions as Social Information (EASI) model. Current Directions in Psychological Science, 18(3), 184-188. http://doi.org/10.1111/j.1467-8721.2009.01633.x 
Van Kleef, G. A. (2010). The emerging view of emotion as social information. Social and Personality Psychology Compass, 4(5), 331-343. http://doi.org/10.1111/j.17519004.2010.00262.x

Van Kleef, G. A., \& Côté, S. (2007). Expressing anger in conflict: when it helps and when it hurts. The Journal of Applied Psychology, 92(6), 1557-69. http://doi.org/10.1037/00219010.92.6.1557

Van Kleef, G. A., \& De Dreu, C. K. W. (2010). Longer-term consequences of anger expression in negotiation: Retaliation or spillover? Journal of Experimental Social Psychology, 46(5), 753-760. http://doi.org/10.1016/j.jesp.2010.03.013

Van Kleef, G. A., De Dreu, C. K. W., \& Manstead, A. S. R. (2004a). The interpersonal effects of anger and happiness in negotiations. Journal of Personality and Social Psychology, 86(1), 57-76. http://doi.org/10.1037/0022-3514.86.1.57

Van Kleef, G. A., De Dreu, C. K. W., \& Manstead, A. S. R. (2004b). The interpersonal effects of emotions in negotiations: a motivated information processing approach. Journal of Personality and Social Psychology, 87(4), 510-28. http://doi.org/10.1037/00223514.87.4.510

Van Kleef, G. A., De Dreu, C. K. W., \& Manstead, A. S. R. (2006). Supplication and appeasement in conflict and negotiation: The interpersonal effects of disappointment, worry, guilt, and regret. Journal of Personality and Social Psychology, 91(1), 124-42. http://doi.org/10.1037/0022-3514.91.1.124

Van Kleef, G. A., De Dreu, C. K. W., Pietroni, D., \& Manstead, A. S. R. (2006). Power and emotion in negotiation: power moderates the interpersonal effects of anger and happiness on concession making. European Journal of Social Psychology, 36(4), 557-581. http://doi.org/10.1002/ejsp.320

Van Kleef, G. A., Homan, A. C., Beersma, B., Van Knippenberg, D., Van Knippenberg, B., \& Damen, F. (2009). Searing sentiment or cold calculation? The effects of leader emotional displays on team performance depend on follower epistemic motivation. Academy of Management Journal, 52(3), 562-580. Retrieved from http://amj.aom.org/content/52/3/562.short

Van Kleef, G. A., \& Sinaceur, M. (2013). The demise of the "rational" negotiator: emotional 
forces in conflict and negotiation. In M. Olekalns \& W. L. Adair (Eds.), Handbook of Research on Negotiation. (pp. 103-130). Cheltenham, UK: Edward Elgar.

Van Kleef, G. A., Van Dijk, E., Steinel, W., Harinck, F., \& Van Beest, I. (2008). Anger in social conflict: Cross-situational comparisons and suggestions for the future. Group Decision and Negotiation, 17(1), 13-30. http://doi.org/10.1007/s10726-007-9092-8

Van Putten, M. (2015). The bright side of brooding: State orientation increases positive emotions about positive outcomes. Cognition and Emotion, 29(8), 1368-1381. http://doi.org/10.1080/02699931.2014.981250

Van Putten, M., Zeelenberg, M., \& Van Dijk, E. (2010). Who throws good money after bad? Action vs . state orientation moderates the sunk cost fallacy. Judgment and Decision Making, 5(1), 33-36. Retrieved from http://journal.sjdm.org/10/91028/jdm91028.html

Vignovic, J. a, \& Thompson, L. F. (2010). Computer-mediated cross-cultural collaboration: attributing communication errors to the person versus the situation. The Journal of Applied Psychology, 95(2), 265-76. http://doi.org/10.1037/a0018628

Wang, L., Northcraft, G. B., \& Van Kleef, G. A. (2012). Beyond negotiated outcomes: The hidden costs of anger expression in dyadic negotiation. Organizational Behavior and Human Decision Processes, 119(1), 54-63. http://doi.org/10.1016/j.obhdp.2012.05.002

Wiedemann, A., Busjahn, A., Heinrich, B., Listing, J., Mueller, W., \& Richter-Heinrich, E. (1994). State versus action orientation after failure: Prevalence of coping strategies and related personality factors in two groups of hypertensives (with and without antihypertensive medication). In J. Kuhl \& J. Beckmann (Eds.), Volition and personality: Action versus state orientation (pp. 267-280). Göttingen, Germany: Hogrefe \& Huber.

Wilson, K. S., DeRue, D. S., Matta, F. K., Howe, M., \& Conlon, D. E. (2016). Personality similarity in negotiations: Testing the dyadic effects of similarity in interpersonal traits and the use of emotional displays on negotiation outcomes. Journal of Applied Psychology, 101(10), 1405-1421. http://doi.org/10.1037/ap10000132

Yifeng, N. C., Tjosvold, D., \& Peiguan, W. (2007). Effects of warm-heartedness and reward distribution on negotiation. Group Decision and Negotiation, 17(1), 79-96. http://doi.org/10.1007/s10726-007-9088-4

Ying Chang, Y., Wilkinson, A. J., \& Mellahi, K. (2007). HRM strategies and MNCs from 
emerging economies in the UK. European Business Review, 19(5), 404-419. http://doi.org/10.1108/09555340710818987

Zajonc, R. B. (1980). Feeling and thinking: Preferences need no inferences. American Psychologist, 35(2), 151-175. http://doi.org/10.1037/0003-066X.35.2.151

Zhang, Q., Ting-Toomey, S., \& Oetzel, J. G. (2014). Linking Emotion to the Conflict FaceNegotiation Theory: A U.S.-China Investigation of the Mediating Effects of Anger, Compassion, and Guilt in Interpersonal Conflict. Human Communication Research, 40(3), 373-395. http://doi.org/10.1111/hcre.12029 


\section{Appendices:}

\section{Appendix A: Theoretical approaches of viewing emotions}

\begin{tabular}{|c|c|c|}
\hline Study & Emotion Perspective & Summary \\
\hline \multirow[t]{2}{*}{ Matsumoto, 2001} & Universal & $\begin{array}{l}\text { Despite cultural and language differences, there is a "small set" of universal emotions (which the } \\
\text { author does not list). Cultures generally differ in the states they feel and the words used to describe } \\
\text { these states. }\end{array}$ \\
\hline & Culture-specific & $\begin{array}{l}\text { This perspective includes the majority of emotions, and focuses on specific differences in intensity of } \\
\text { expression and social norms in the use of emotions. }\end{array}$ \\
\hline \multirow[t]{4}{*}{ Cornelius, 2000} & Darwinian (universal) & $\begin{array}{l}\text { Emotions have evolved as a survival function, and therefore emotions are expressed and recognised } \\
\text { across cultures. }\end{array}$ \\
\hline & Jamesian (universal) & $\begin{array}{l}\text { This perspective focuses on the emotional experience. That is one experiences emotions due to their } \\
\text { automatic bodily response. For example, "we feel sorry because we cry, angry because we strike, } \\
\text { afraid because we tremble" (James, } 1884, \text { p. 190). }\end{array}$ \\
\hline & Cognitive & $\begin{array}{l}\text { This perspective says there are appraisals or thought processes that precede emotions. The main } \\
\text { criticism of this perspective is that emotional responses occur faster than deliberate thoughts can } \\
\text { achieve, and thus it is possible to have subconscious emotional reactions (Ledoux, 1996; Zajonc, } \\
\text { 1980). }\end{array}$ \\
\hline & Social constructivist & Emotions are culturally dependent as they are learnt through social values and norms. \\
\hline \multirow[t]{2}{*}{ (Berry et al., 2011) } & Universalism & $\begin{array}{l}\text { This perspective highlights the similarities in human behaviour across cultures. The authors agree with } \\
\text { the six universal emotions (happiness, surprise, anger, disgust, sadness and fear), and acknowledge } \\
\text { that there is an argument to add pride as a seventh universal emotion. }\end{array}$ \\
\hline & Relativism & $\begin{array}{l}\text { This perspective examines the culturally specific elements of an emotion, such as the fact that } \\
\text { information carried by an emotion varies across cultures. Further, emotions are categorised across } \\
\text { cultures differently. Many cultures have emotion terms with unique meanings. }\end{array}$ \\
\hline
\end{tabular}




\section{Appendix B: Negotiation case and instructions}

Please read all instructions slowly and carefully, remember this task is $100 \%$ confidential.

In this negotiation task, you will negotiate 3 issues regarding a cell-phone consignment (a shipment of cell phones).

1. Price of the Phones

2. Warranty Period

\section{Service Contract}

You will either be assigned the role of "Buyer" or "Seller" of this consignment, once you have been assigned your role you will receive a "payoff chart" with your payoff or points you will receive if you agree on that level.

Your objective is to get as many points as possible. - Every point is a ticket into the Amazon gift card lottery draw.

If you do not reach an agreement, your points will not go into the lottery draw.

Please act like you normally would, there is no right or wrong way to act.

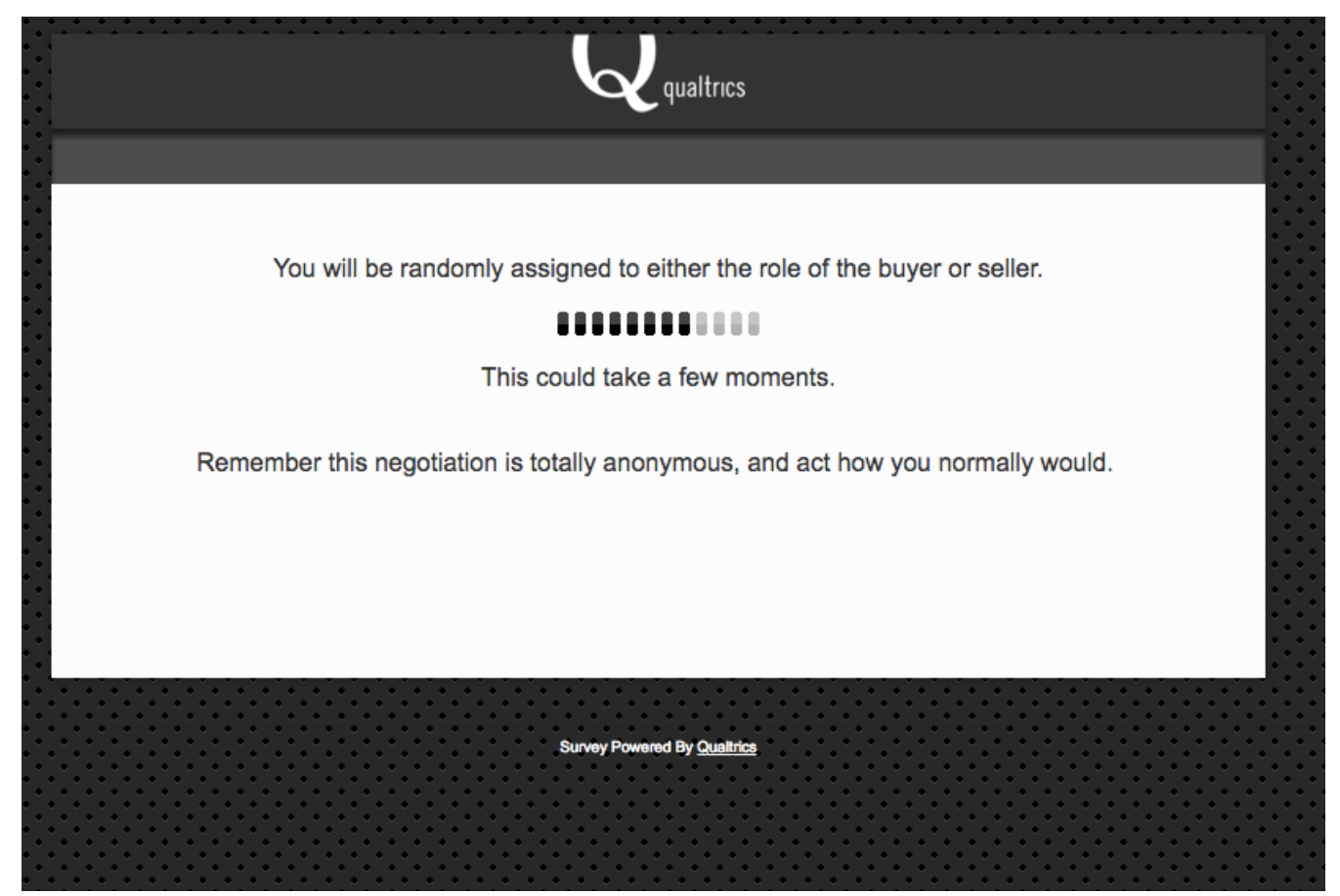

(Screenshot example of instructions)

You have been assigned the role of the [SELLER]. You have been paired with [Wang Wei] from [China] 
The next screen will show your payoff chart. Remember to maximize your points.

What is your counter offer? (Enter the level for Each of the three issues)

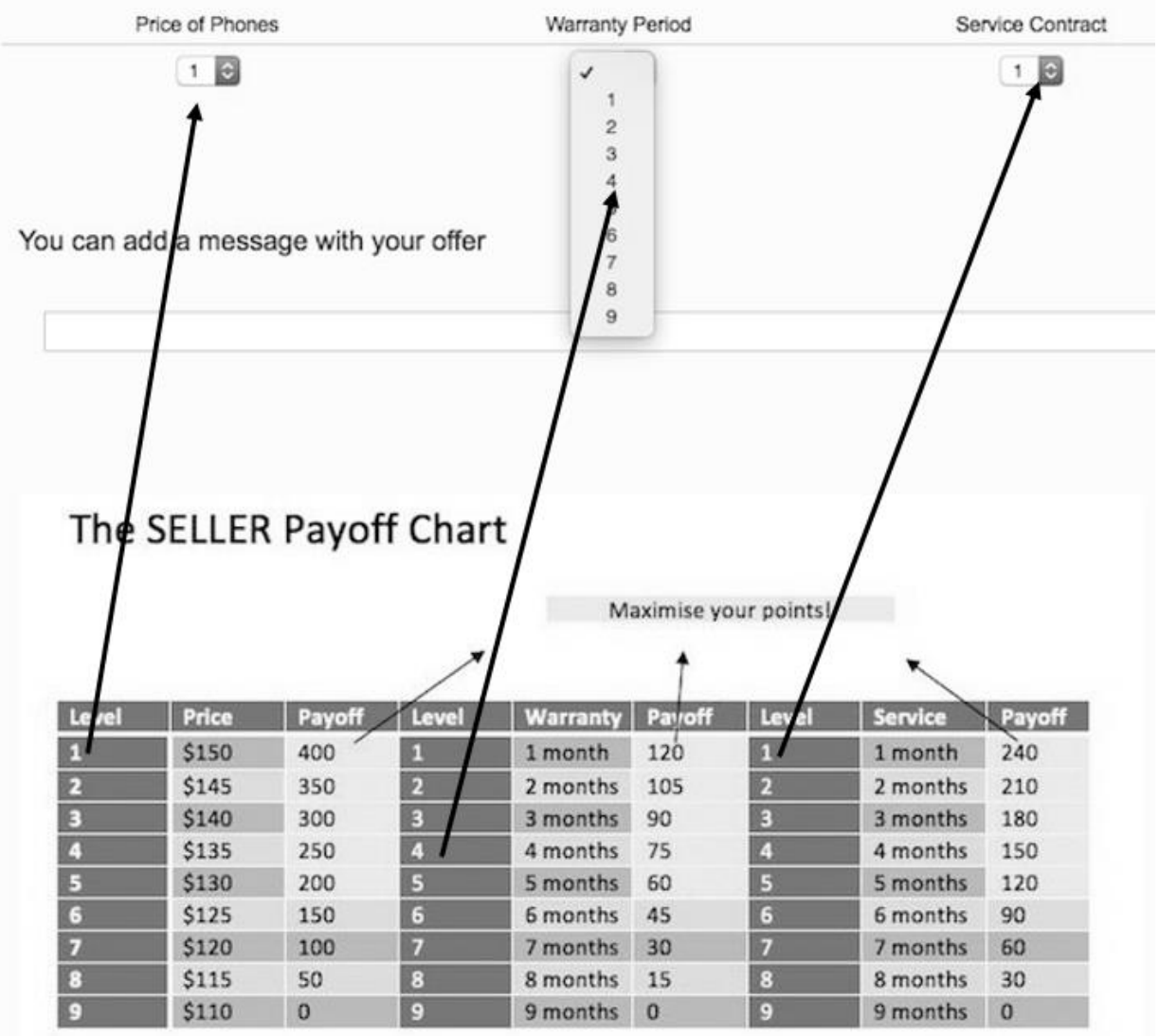

\section{Instructions:}

Your total points will be turned into lottery tickets for the $\$ 50$ amazon gift card draw, however, you must reach an agreement to be eligible!

The more points you earn, the higher the chance you will receive the \$50 Amazon gift card. $1+1+1$ or 760 points $=760$ tickets into the draw

Source: Van Kleef et al. (2004b) 


\section{Appendix C: Simulation pre-programmed offer strategy}

The pre-programmed offer strategy.

\begin{tabular}{|c|c|c|c|c|c|}
\hline Round 1 & Round 2 & Round 3 & Round 4 & Round 5 & Round 6 \\
\hline $8-7-8^{*}$ & $8-7-7$ & $8-6-7$ & $7-6-7$ & $7-6-6$ & $6-6-6$ \\
\hline
\end{tabular}

* Level for price-warranty-service contract

The above numbers correspond to the Payoff chart.

Source: Adapted from Van Kleef et al. (2004b) 


\section{Appendix D: Action Control Scale (ACS-90)}

This scale is used to measure action versus state orientation and is retrieved from Kuhl (1994b).

The ACS-90 has three subscales:

\section{i. Action orientation subsequent to failure versus preoccupation (AOF)*}

Questions: 1, 4, 7, 10, 13, 16, 19, 22, 25, 28, 31, 34

\section{ii. Prospective and decision-related action orientation versus hesitation (AOD)}

Questions: 2, 5, 8, 11, 14, 17, 20, 23, 26, 29, 32, 35

iii. Action orientation during (successful) performance of activities (intrinsic orientation) versus volatility (AOP)

Questions: 3, 6, 9, 12, 15, 18, 21, 24, 27, 30, 33, 36

*Subscale used in analysis

\section{Scale as shown to participants}

1. When I have lost something that is very valuable to me and I can't find it anywhere:

A. I have a hard time concentrating on something else

B. I put it out of my mind after a little while

2. When I know I must finish something soon:

A. I have to push myself to get started

B. I find it easy to get it done and over with

3. When I have learned a new and interesting game:

A. I quickly get tired of it and do something else

B. I can really get into it for a long time

4. When I have to solve a difficult problem:

A. It takes me a long time to adjust myself to it

B. It bothers me for a while, but then I don't think about it anymore

5. When I don't have anything in particular to do and I am getting bored:

A. I have trouble getting up enough energy to do anything at all

B. I quickly find something to do

6. When I'm working on something that's important to me:

A. I still like to do other things in between working on it

B. I get into it so much that I can work on it for a long time

7. When I'm in a competition and have lost every time:

A. I can soon put losing out of my mind

B. The thought that I lost keeps running through my mind

8. When I am getting ready to tackle a difficult problem:

A. It feels like I am facing a big mountain that I don't think I can climb

B. I look for a way that the problem can be approached in a suitable manner

9. When I'm watching a really good movie: 
A. I get so involved in the film that I don't even think of doing anything else

B. I often want to get something else to do while I'm watching the movie

10. If I had just bought a new piece of equipment (for example, a tape deck) and it accidentally fell on the floor and was damaged beyond repair:

A. I would manage to get over it quickly

B. It would take me a long time to get over it

11. When I have to solve a difficult problem:

A. I usually don't have a problem getting started on it

B. I have trouble sorting out things in my head so that I can get down to working on the problem

12. When I have been busy for a long time doing something interesting (for example, reading a book or working on a project):

A. I sometimes think about whether what I'm doing is really worthwhile

B. I usually get so involved in what I'm doing that I never think to ask about whether it's worthwhile

13. If I have to talk to someone about something important and, repeatedly, can't find her/him at home:

A. I can't stop thinking about it, even while I'm doing something else

B. I easily forget about it until I can see the person again

14. When I have to make up my mind about what I am going to do when I get some unexpected free time:

A. It takes me a long time to decide what I should do during this free time

B. I can usually decide on something to do without having to think it over very much

15. When I read an article in the newspaper that interests me:

A. I usually remain so interested in the article that I read the entire article

B. I still often skip to another article before I've finished the first one

16. When I've bought stuff at a store and realize when I get home that I paid too much -but I can't get my money back:

A. I can't concentrate on anything else

B. I easily forget about it

17. When I have work to do at home:

A. It is often hard for me to get the work done

B. I usually get it done right away

18. When I'm on vacation and I'm having a good time:

A. After a while, I really feel like doing something completely different

B. I don't even think about doing anything else until the end of my vacation

19. When I am told that my work has been completely unsatisfactory:

A. I don't let it bother me for too long

B. I feel paralysed

20. When I have a lot of important things to do and they must all be done soon:

A. I often don't know where to begin

B. I find it easy to make a plan and stick with it

21. When one of my co-workers brings up an interesting topic for discussion: 
A. It can easily develop into a long conversation

B. I soon lose interest and want to go do something else

22. If I'm stuck in traffic and miss an important appointment:

A. At first, it's difficult for me to start doing anything else at all

B. I quickly forget about it and do something else

23. When there are two things that I really want to do, but I can't do both of them:

A. I quickly begin one thing and forget about the other thing I couldn't do.

B. It's not easy for me to put the thing that I couldn't do out of my mind

24. When I am busy working on an interesting project:

A. I need to take frequent breaks and work on other projects

B. I can keep working on the same project for a long time

25. When something is very important to me, but I can't seem to get it right:

A. I gradually lose heart

B. I just forget about it and go do something else

26. When I have to take care of something important but which is also unpleasant

A. I do it and get it over with

B. It can take a while before I can bring myself to do it

27. When I am having an interesting conversation with someone at a party:

A. I can talk to him or her the entire evening

B. I prefer to go do something else after a while

28. When something really gets me down:

A. I have trouble doing anything at all

B. I find it easy to distract myself by doing other things

29. When I am facing a big project that has to be done:

A. I often spend too long thinking about where I should begin

B. I don't have any problems getting started

30. When it turns out that I am much better at a game than the other players:

A. I usually feel like doing something else

B. I really like to keep playing

31. When several things go wrong on the same day:

A. I usually don't know how to deal with it

B. I just keep on going as though nothing had happened

32. When I have a boring assignment:

A. I usually don't have any problem getting through it

B. I sometimes just can't get moving on it

33. When I read something I find interesting:

A. I sometimes still want to put the article down and do something else

B. I will sit and read the article for a long time

34. When I have put all my effort into doing a really good job on something and the whole thing doesn't work out:

A. I don't have too much difficulty starting something else

B. I have trouble doing anything else at all

35. When I have an obligation to do something that is boring and uninteresting:

A. I do it quickly and get it over with

B. It usually takes a while before I get around to doing it 
36. When I am trying to learn something new that I want to learn:

A. I'll keep at it for a long time

B. I often feel like I need to take a break and go do something else for a while

Example of screen view for participants

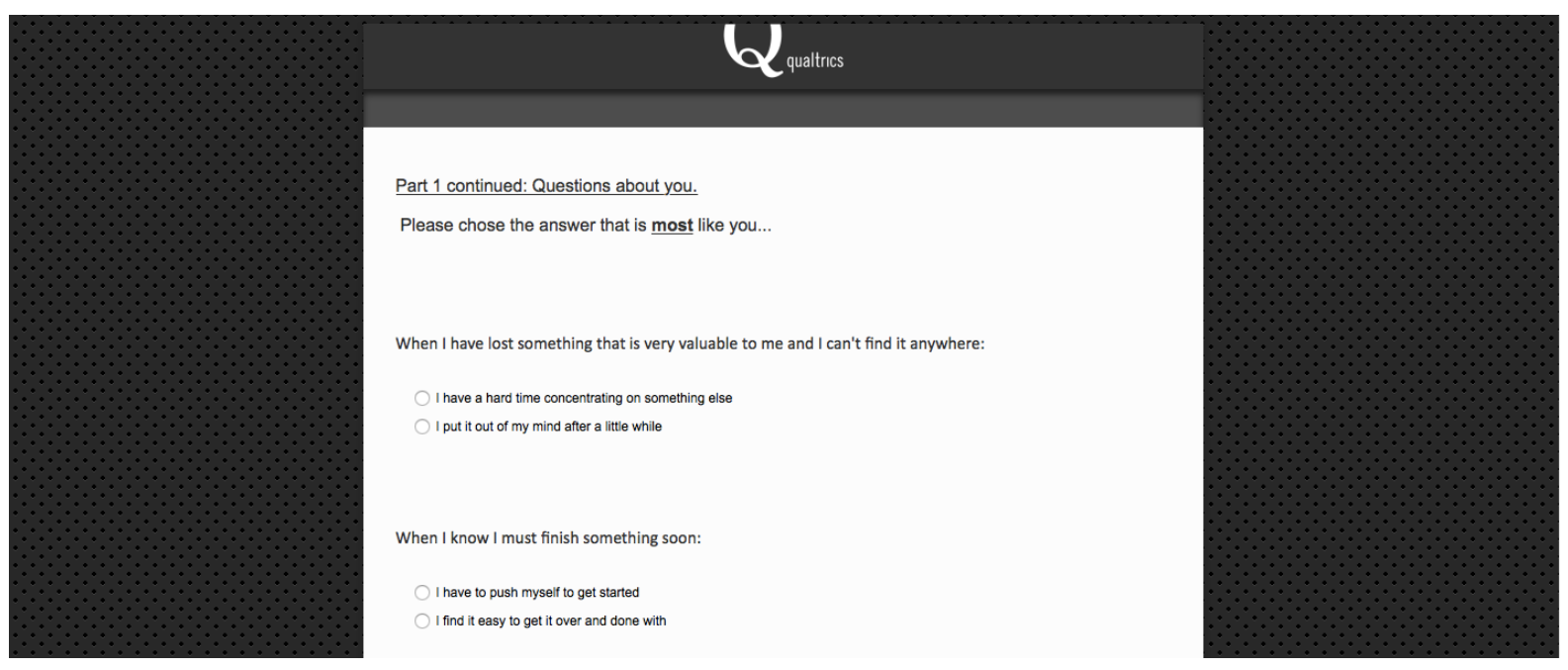




\section{Appendix E: Manipulations and checks}

\section{Emotion manipulation}

\section{First Response (Round 2)}

Angry: This offer makes me really angry, I think I will offer 8-7-7

Neutral: I think I will offer 8-7-7

\section{Second Response (Round 4)}

Anger: This is really getting on my nerves. I am going to offer 7-6-7

Neutral: I am going to offer 7-6-7

Third Reponses: (Round 6)

Anger: I am going to offer 6-6-6, because this negotiation pisses me off.

Neutral: I am going to offer 6-6-6

Source: Van Kleef et al., 2004b

\section{Emotion manipulation check}

5-point Likert scale ranging from Strongly Agree to Strongly Disagree

- The opponent appeared angry during the negotiation

- The opponent appeared irritated during the negotiation

- The opponent appeared aggravated during the negotiation

- The opponent appeared happy during the negotiation

- The opponent appeared satisfied during the negotiation

- The opponent appeared joyful during the negotiation

Sources: Van Kleef et al. (2004a) and Van Kleef, De Dreu, Pietroni, et al. (2006) Example of screen view for participants

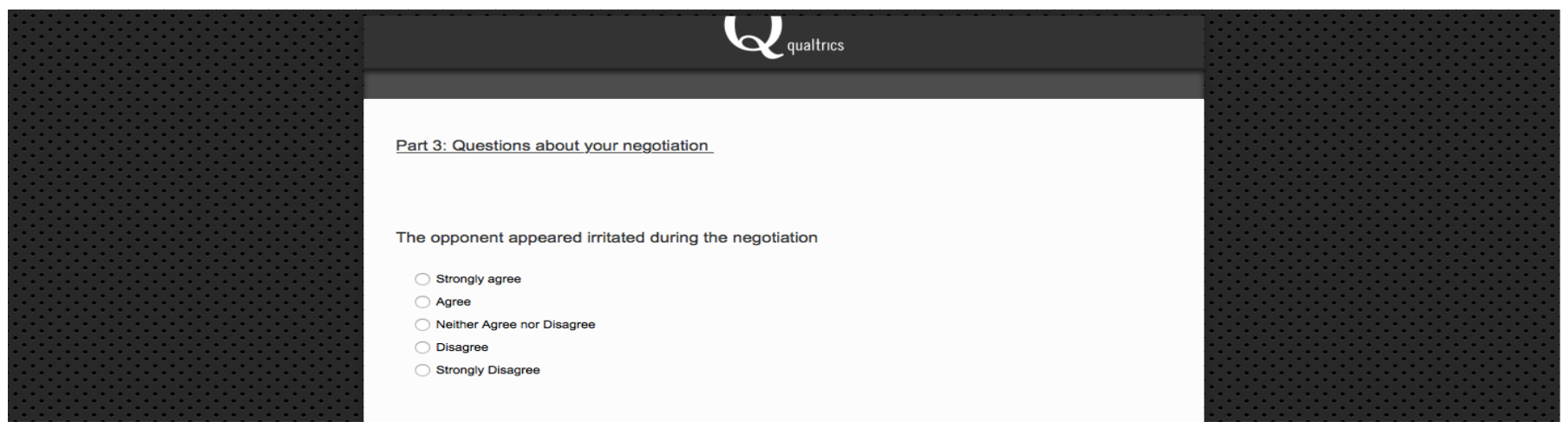




\section{Bargaining power manipulation}

\section{Low power manipulation}

If you do not reach a deal with your opponent, you will receive 190 points for the lottery draw (which is the same as $7+7+7$ ).

You have low bargaining power!

\section{High power manipulation}

If you do not reach a deal with your opponent, you will receive 570 points for the lottery draw (which is the same as $3+3+3$ ).

You have high bargaining power!

Source: Adapted from Sinaceur and Tiedens (2006) and Van Kleef, De Dreu, Pietroni, et al. (2006)

\section{Bargaining power manipulation check}

\section{5-point Likert scale ranging from Strongly Agree to Strongly Disagree}

- I felt that I was dependent on my opponent (Reversed scored)

- I think that I had a better negotiation position than my opponent

- I felt that I needed my opponent to finish the negotiation successfully (Reversed scored)

- I felt that I had a powerful negotiation position

Source: Adapted from Van Kleef et al. (2004b)

Example of screen view for participants
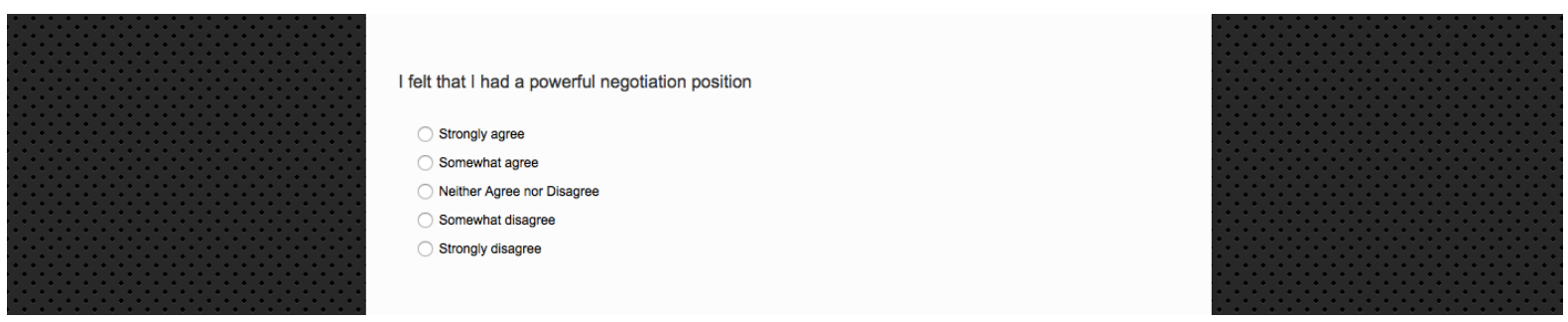


\section{Appendix F: Welcome message}

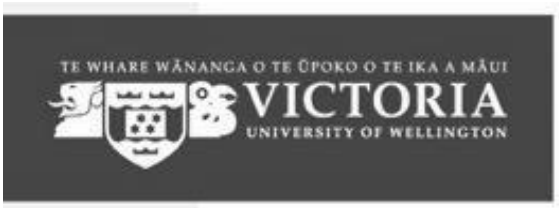

SCHOOL OF MARKETING AND INTERNATIONAL BUSINESS

TE KURA HOKOHOKO, PAKIHI KI TE AO

LEVEL. 11, RUTHERFORD HOUSE, PIPITEA CAMPUS, 23 LAMBTON QUAY, WELLINGTON

PO Box 600 , Wellington 6140 , New Zealand

Phone +64-4-4635330 Fax +64-4-4635231 Email: marketing@vuw.ac.nz Website: www.victoria.ac.nz/smib

Welcome,

Thank you for choosing to take part in this research.

My name is Steffen Bertram and I am an International Business PhD student at Victoria University of Wellington (VUW) New Zealand. This study is being undertaken to better understand negotiations.

This survey is voluntary and the information is confidential. Ethics approval has been granted for this research from the VUW Human Ethics Committee, reference: 0000022630

This website is secure and all responses are confidential. All of the material related to survey responses will be viewed only by the researcher and the research supervisor. All printed information will be kept in a locked file with access restricted to the researcher and research supervisor. All electronic data will be kept in a password protected file accessible only by the researcher. Data collected in this survey will be deleted after 10 years. It is possible that summary results from this survey may appear in academic or professional journals and may also be presented at academic or professional conferences.

The survey should take around 25 minutes to complete.

If you have any concerns, questions, or require any further information, please feel free to contact

\section{Steffen Bertram}

PhD Candidate

steffen.bertram@vuw.ac.nz

This survey is in three parts and will take 25 Minutes

1) Questions about you

2) A global negotiation simulation

3) Questions about your negotiation 


\section{Appendix G: Pilot study; instruction modifications}

\begin{tabular}{|c|c|c|c|c|c|c|c|c|}
\hline \multicolumn{6}{|c|}{ Original Payoff chart } & \multirow{2}{*}{\multicolumn{3}{|c|}{$\begin{array}{l}\text { Service } \\
\text { Contract }\end{array}$}} \\
\hline \multicolumn{4}{|c|}{ Price of Phones } & Period & & & & \\
\hline Level & Price & Payoff & Level & Warranty & Payoff & Level & Service & Payoff \\
\hline 1 & $\$ 150$ & 400 & 1 & 1 month & 120 & 1 & 1 month & 240 \\
\hline 2 & $\$ 145$ & 350 & 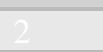 & 2 months & 105 & 2 & 2 months & 210 \\
\hline 3 & $\$ 140$ & 300 & 3 & 3 months & 90 & 3 & 3 months & 180 \\
\hline 4 & $\$ 135$ & 250 & 4 & 4 months & 75 & 4 & 4 months & 150 \\
\hline 5 & $\$ 130$ & 200 & 5 & 5 months & 60 & 5 & 5 months & 120 \\
\hline 6 & $\$ 125$ & 150 & 6 & 6 months & 45 & 6 & 6 months & 90 \\
\hline 7 & $\$ 120$ & 100 & 7 & 7 months & 30 & 7 & 7 months & 60 \\
\hline 8 & $\$ 115$ & 50 & 8 & 8 months & 15 & 8 & 8 months & 30 \\
\hline 9 & $\$ 110$ & 0 & 9 & 9 months & 0 & 9 & 9 months & 0 \\
\hline
\end{tabular}

Updated payoff chart

Maximise your points!

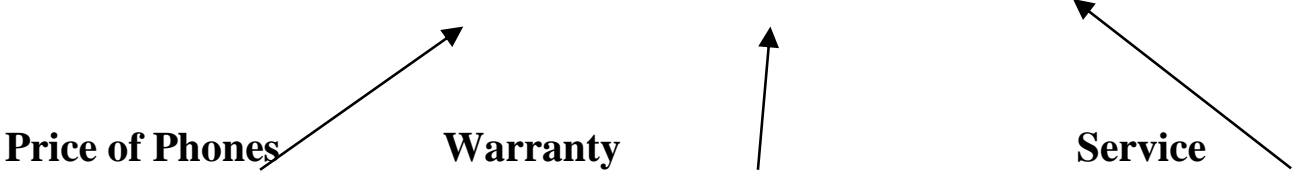

Period

\begin{tabular}{|l|l|l|l|l|l|l|l|l|}
\hline Level & Price & Payoff & Level & Warranty & Payoff & Level & Service & Payoff \\
\hline $\mathbf{1}$ & $\$ 150$ & 400 & 1 & 1 month & 120 & 1 & 1 month & 240 \\
\hline $\mathbf{2}$ & $\$ 145$ & 350 & & 2 months & 105 & & 2 months & 210 \\
\hline $\mathbf{3}$ & $\$ 140$ & 300 & 3 & 3 months & 90 & 3 & 3 months & 180 \\
\hline $\mathbf{4}$ & $\$ 135$ & 250 & 4 & 4 months & 75 & 4 & 4 months & 150 \\
\hline $\mathbf{5}$ & $\$ 130$ & 200 & 5 & 5 months & 60 & 5 & 5 months & 120 \\
\hline $\mathbf{6}$ & $\$ 125$ & 150 & & 6 months & 45 & 6 & 6 months & 90 \\
\hline $\mathbf{7}$ & $\$ 120$ & 100 & 7 & 7 months & 30 & 7 & 7 months & 60 \\
\hline $\mathbf{8}$ & $\$ 115$ & 50 & 8 & 8 months & 15 & 8 months & 30 \\
\hline $\mathbf{9}$ & $\$ 110$ & 0 & 9 & 9 months & 0 & 9 & 9 months & 0 \\
\hline
\end{tabular}

Adapted from Van Kleef et al. (2004b). 
Appendix H: Sample-industry break down

\begin{tabular}{|c|c|c|c|c|}
\hline Industry & Study $1(\mathrm{~N}=)$ & $\%$ & Study $2(\mathrm{~N}=)$ & $\%$ \\
\hline Forestry, fishing, or agriculture support & 2 & 1.3 & 1 & .4 \\
\hline Mining & 1 & .6 & 1 & .4 \\
\hline Utilities & 4 & 2.5 & 4 & 1.5 \\
\hline Construction & 9 & 5.7 & 22 & 8.5 \\
\hline Manufacturing & 15 & 9.4 & 27 & 10.4 \\
\hline Wholesale trade & 5 & 3.1 & 4 & 1.5 \\
\hline Retail trade & 11 & 6.9 & 24 & 9.2 \\
\hline Transportation or warehousing & 6 & 3.8 & 10 & 3.8 \\
\hline Information & 4 & 2.5 & 9 & 3.5 \\
\hline Finance or insurance & 13 & 8.2 & 14 & 5.4 \\
\hline Real estate or rental and leasing & 0 & 0 & 5 & 1.9 \\
\hline $\begin{array}{l}\text { Professional, scientific or technical } \\
\text { services }\end{array}$ & 17 & 10.7 & 21 & 8.1 \\
\hline Management of companies & 3 & 1.9 & 5 & 1.9 \\
\hline $\begin{array}{l}\text { Admin, support, waste management or } \\
\text { remediation services }\end{array}$ & 3 & 1.9 & 5 & 1.9 \\
\hline Educational services & 15 & 9.4 & 21 & 8.1 \\
\hline Health care or social assistance & 15 & 9.4 & 25 & 9.6 \\
\hline Arts, entertainment or recreation & 2 & 1.3 & 5 & 1.9 \\
\hline Accommodation or food services & 3 & 1.9 & 3 & 1.2 \\
\hline $\begin{array}{l}\text { Other services (except public } \\
\text { administration) }\end{array}$ & 26 & 16.4 & 50 & 19.2 \\
\hline Unclassified establishments & 5 & 3.1 & 4 & 1.5 \\
\hline
\end{tabular}




\section{Appendix I: Normality}

\begin{tabular}{|c|c|c|c|c|c|}
\hline \multirow{4}{*}{ Study 1} & Groups & Concessions & Anger & Personality & Power \\
\hline & Action/Anger & $-0.044,1.412^{\mathrm{a}}$ & $0.787,0.429$ & $0.518,-0.827$ & --- \\
\hline & Action/Neutral & $0.539,-0.038$ & $0.011,-0.246$ & $0.068,-1.151$ & --- \\
\hline & State/Anger & $0.478,-0.512$ & $0.884,-0.092$ & $-0.644,-0.975$ & -- \\
\hline \multirow{17}{*}{ Study 2} & State/Neutral & $0.562,-0.025$ & $0.042,-0.661$ & $-0.819,-0.370$ & --- \\
\hline & Action/Anger/High & $0.151,-0.454$ & $0.492,-0.882$ & $0.712,-0.816$ & $0.641,0.691$ \\
\hline & Power & & & & \\
\hline & Action/Anger/Low & $-0.602,2.471$ & $0.283,-0.600$ & $0.248,-1.087$ & $0.264,-0.404$ \\
\hline & Power & & & & \\
\hline & Action/Neutral/High & $-0.408,-0.067$ & $-0.310,-0.493$ & $0.565,-0.905$ & $0.461,-0.897$ \\
\hline & Power & & & & \\
\hline & Action/Neutral/Low & $-0.267,0.336$ & $0.216,-0.676$ & $0.140,-1.230$ & $0.679,0.120$ \\
\hline & Power & & & & \\
\hline & State/Anger/High & $-0.644,0.237$ & $0.952,0.806$ & $-0.679,-0.836$ & $0.020,-1.157$ \\
\hline & Power & & & & \\
\hline & State/Anger/Low & $0.308,-0.727$ & $0.994,0.454$ & $-0.530,-0.541$ & $-0.195,-1.258$ \\
\hline & Power & & & & \\
\hline & State/Neutral/High & $1.066,0.760$ & $-0.183,0.440$ & $-0.742,-0.437$ & $-0.008,-0.247$ \\
\hline & Power & & & & \\
\hline & State/Neutral/Low & $0.580,0.440$ & $-0.315,0.867$ & $-0.133,-0.976$ & $0.107,-0.658$ \\
\hline & Power & & & & \\
\hline
\end{tabular}

${ }^{\text {a }}$ Skewness, Kurtosis 
Appendix J: Study 2 concession size per power condition for personality

Figure A. Concession size per power condition for actionoriented participants

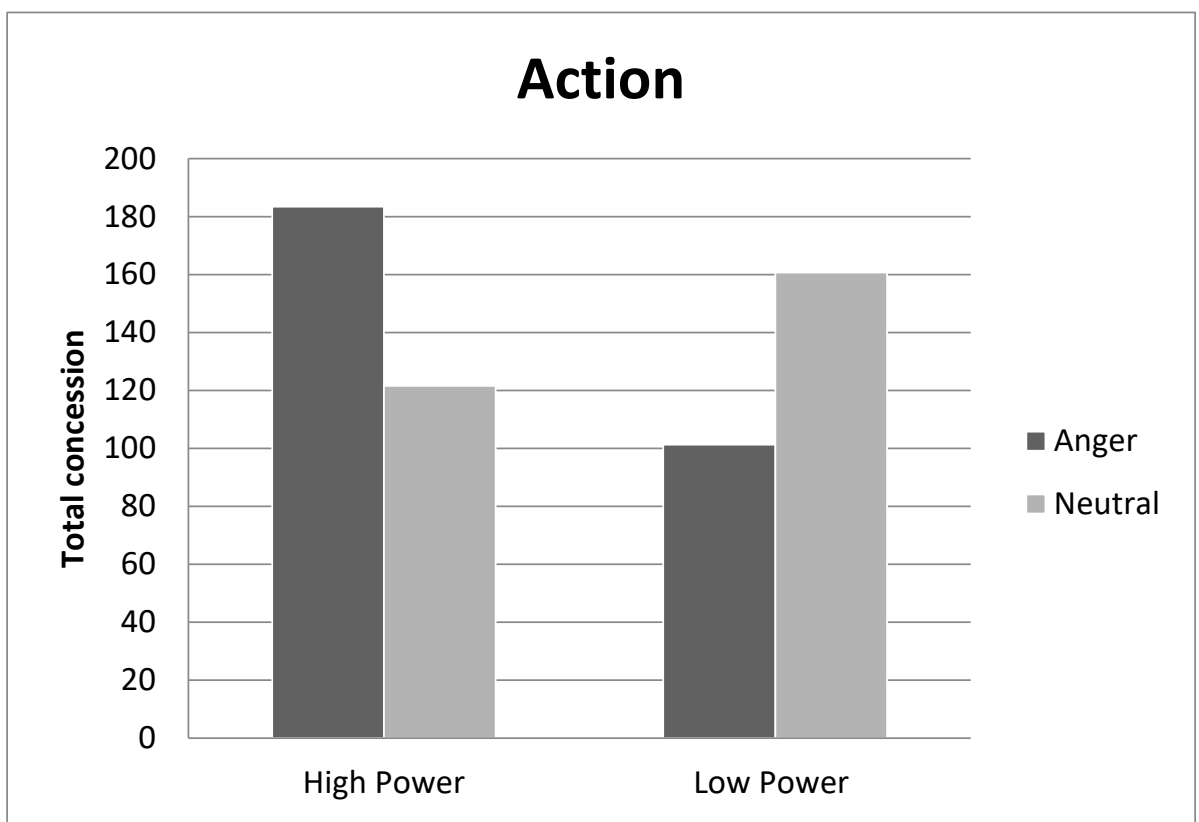

Figure B. Concession size per power condition for state-oriented participants

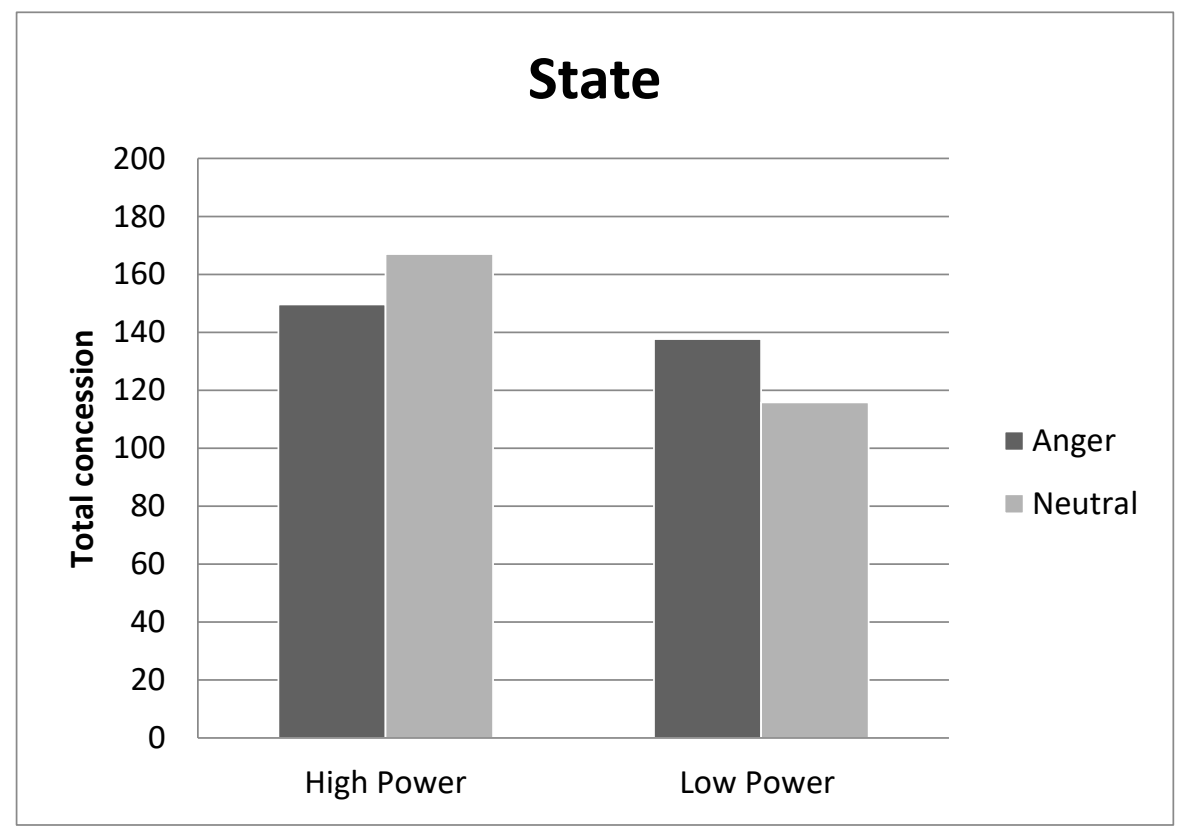

